\title{
Structural Requirements of Alkylglyceryl-L-Ascorbic Acid Derivatives for Melanogenesis Inhibitory Activity
}

\author{
Norihisa Taira ${ }^{1,2, *}$, Yushi Katsuyama ${ }^{1}$, Masato Yoshioka ${ }^{1}$, Osamu Muraoka ${ }^{2,3}$ and \\ Toshio Morikawa 2,3 (iD \\ 1 SEIWA KASEI CO, LTD., 1-2-14, Nunoichicho, Higashi-osaka, Osaka 579-8004, Japan; \\ katsuyama_yushi@seiwakasei.co.jp (Y.K.); yoshioka_masato@seiwakasei.co.jp (M.Y.) \\ 2 Pharmaceutical Research and Technology Institute, Kindai University, 3-4-1 Kowakae, Higashi-osaka, \\ Osaka 577-8502, Japan; muraoka@phar.kindai.ac.jp (O.M.); morikawa@kindai.ac.jp (T.M.) \\ 3 Antiaging Center, Kindai University, 3-4-1 Kowakae, Higashi-osaka, Osaka 577-8502, Japan \\ * Correspondence: Taira_Norihisa@seiwakasei.co.jp; Tel.: +81-72-987-2626; Fax: +81-72-987-2072
}

Received: 23 January 2018; Accepted: 6 April 2018; Published: 10 April 2018

\begin{abstract}
L-Ascorbic acid has multifunctional benefits on skin aesthetics, including inhibition of melanin production, and is widely used in cosmetics. It, however, has low stability and poor skin penetration. We hypothesize that alkylglyceryl-L-ascorbic acid derivatives, highly stable vitamin C-alkylglycerol conjugates, would have similar anti-melanogenic activity with better stability and penetration. We test 28 alkylglyceryl-L-ascorbic acid derivatives (1-28) on theophylline-stimulated B16 melanoma 4A5 cells to determine if they inhibit melanogenesis and establish any structure-function relationships. Although not the most potent inhibitors, 3-O-(2,3-dihydroxypropyl)-2-O-hexyl-L-ascorbic acid $\left(6, \mathrm{IC}_{50}=81.4 \mu \mathrm{M}\right)$ and 2-O-(2,3-dihydroxypropyl)-3-O-hexyl-L-ascorbic acid $\left(20, \mathrm{IC}_{50}=117 \mu \mathrm{M}\right)$ are deemed the best candidate derivatives based on their inhibitory activities and low toxicities. These derivatives are also found to be more stable than L-ascorbic acid and to have favorable characteristics for skin penetration. The following structural requirements for inhibitory activity of alkylglyceryl-L-ascorbic acid derivatives are also determined: (i) alkylation of glyceryl-L-ascorbic acid is essential for inhibitory activity; (ii) the 3-O-alkyl-derivatives (2-14) exhibit stronger inhibitory activity than the corresponding 2-O-alkyl-derivatives (16-28); and (iii) derivatives with longer alkyl chains have stronger inhibitory activities. Mechanistically, our studies suggest that L-ascorbic acid derivatives exert their effects by suppressing the mRNA expression of tyrosinase and tyrosine-related protein-1.
\end{abstract}

Keywords: alkylglyceryl-L-ascorbic acid; melanogenesis inhibitor; 3-O-(2,3-dihydroxypropyl)-2-O -hexyl-L-ascorbic acid; 2-O-(2,3-dihydroxypropyl)-3-O-hexyl-L-ascorbic acid; structural requirement; mechanism of action

\section{Introduction}

Melanin is a broad term for a group of natural pigments found in bacteria, fungi, plants, and animals. It is a heterogeneous, polyphenol-like biopolymer with a complex structure, and its color varies from yellow to black [1-5]. The color of mammalian skin and hair is determined by several factors, the most important one being the degree and distribution of melanin pigmentation [3-6]. Melanin is produced in the skin and hair [7,8]. Its role is to protect the skin from UV damage by absorbing UV light and removing reactive oxygen species $[9,10]$. However, excess production of melanin due to prolonged exposure to sunlight causes dermatologic disorders such as melasma, freckles, post-inflammatory melanoderma, and solar lentigines [9,11-13]. Melanin is secreted 
from melanocytes distributed in the basal layer of the dermis. Melanocytes are known to be stimulated by various factors including UV radiation [14], POMC-derived $\alpha$-melanocyte-stimulating hormone $(\alpha-\mathrm{MSH})$, and other neuropeptides [7,15-17], and phosphodiesterase inhibitors, such as theophylline [18]. Stimulation by these factors increases melanin production using L-tyrosine and L-3,4-dihydroxyphenylalanine (L-DOPA) as substrates through various mechanisms of action $[7,19]$. In addition to being substrates, L-tyrosine and L-DOPA act as bioregulatory agents [19].

In our previous investigation of compounds from several natural resources possessing melanogenesis inhibitory activity, we reported that dimeric pyrrolidinoindoline- [20], aporphine- [21,22], benzylisoquinoline- [22], and phenanthridine-type [23] alkaloids, as well as phenylethanoid glycosides [23], methoxyflavones [24], phenylpropanoids [25], neolignans [25], and diterpenes [26,27] exhibited significant positive effects against theophylline-stimulated melanogenesis in B16 melanoma 4A5 cells. As a continuing study on melanogenesis inhibitors from naturally occurring compounds and their related analogs, we focus on L-ascorbic acid (AsA), one of the most recognized sugar acids, and its highly stable derivatives. AsA has multifunctional benefits on parameters affecting skin aesthetics, such as the reduction in oxidative stress and increase in collagen production. Among them, the prevention and improvement in skin pigmentation by AsA and its derivatives are, collectively, one of the most important benefits for people [28-36]. However, it is well known that AsA is unstable in formulations, and has a low ability to penetrate the skin due to its hydrophilicity. In addition, existing water-soluble AsA derivatives, which were developed to improve its stability [30,32], have low skin penetration. To limit these disadvantages, we recently synthesized several alkylglyceryl-AsA derivatives (1-28) by introducing a glycerol group and an alkyl group to the 2,3-enediol positions in AsA [37]. In the present study, we examine the inhibitory effects of these amphiphilic AsA derivatives (1-28) on melanogenesis in theophylline-stimulated murine B16 melanoma 4A5 cells.

\section{Results and Discussion}

\subsection{Syntheses of Alkylglyceryl AsA Derivatives (1-28)}

As shown in Figure 1, a variety of alkylglyceryl-AsA derivatives were synthesized as described previously [37]: 3-O-(2,3-dihydroxypropyl)-AsA (1), 3-O-(2,3-dihydroxypropyl)-2-O-ethyl-AsA (2), 3-O-(2,3-dihydroxypropyl)-2-O-propyl-AsA (3), 2-O-butyl-3-O-(2,3-dihydroxypropyl)-AsA (4), 3-O-(2,3-dihydroxypropyl)-2-O-pentyl-AsA (5), 3-O-(2,3-dihydroxypropyl)-2-O-hexyl-AsA (6), 3-O-(2,3-dihydroxypropyl)-2-O-heptyl-AsA (7), 3-O-(2,3-dihydroxypropyl)-2-O-octyl-AsA (8), 3-O-(2,3-dihydroxypropyl)-2-O-nonyl-AsA (9), 2-O-decyl-3-O-(2,3-dihydroxypropyl)-AsA (10), 3-O-(2,3-dihydroxypropyl)-2-O-undecyl-AsA (11), 3-O-(2,3-dihydroxypropyl)-2-O-dodecyl-AsA (12), 3-O-(2,3-dihydroxypropyl)-2-O-tridecyl-AsA (13), 3-O-(2,3-dihydroxypropyl)-2-O-tetradecyl-AsA (14), 2-O-(2,3-dihydroxypropyl)-AsA (15), 2-O-(2,3-dihydroxypropyl)-3-O-ethyl-AsA (16), 2-O-(2,3-dihydroxypropyl)-3-O-propyl-AsA (17), 3-O-butyl-2-O-(2,3-dihydroxypropyl)-AsA (18),

2-O-(2,3-dihydroxypropyl)-3-O-pentyl-AsA (19), 2-O-(2,3-dihydroxypropyl)-3-O-hexyl-AsA (20), 2-O-(2,3-dihydroxypropyl)-3-O-heptyl-AsA (21), 2-O-(2,3-dihydroxypropyl)-3-O-octyl-AsA (22), 2-O-(2,3-dihydroxypropyl)-3-O-nonyl-AsA (23), 3-O-decyl-2-O-(2,3-dihydroxypropyl)-AsA (24), 2-O-(2,3-dihydroxypropyl)-3-O-undecyl-AsA (25), 2-O-(2,3-dihydroxypropyl)-3-O-dodecyl-AsA (26), 2-O-(2,3-dihydroxypropyl)-3-O-tridecyl-AsA (27), and 2-O-(2,3-dihydroxypropyl)-3-O-tetradecyl-AsA (28).

Considering general applications for cosmetics, these AsA derivatives (2-14 and 16-28) were designed to have both a hydrophilic glyceryl moiety and lipophilic alkyl chain to obtain high skin permeation and high stability in aqueous solution. Bos and Meinardi suggested that the development of new innovative compounds should be restricted to a molecular weight of less than 500 Dalton when topical dermatological therapy, percutaneous systemic therapy, or vaccination is the objective for pharmaceutical development purposes [38]. Therefore, we designed the AsA derivatives with molecular weights from 278 ( 2 and 16$)$ to 446 (14 and 28) in accordance with their proposed " 500 Dalton 
rule". As plotted in Figure S1, excellent correlation was observed between clog P values and the length of the alkyl chains in these AsA derivatives $(\mathbf{2}-\mathbf{1 4}$ and 16-28) $(R=0.9998)$.

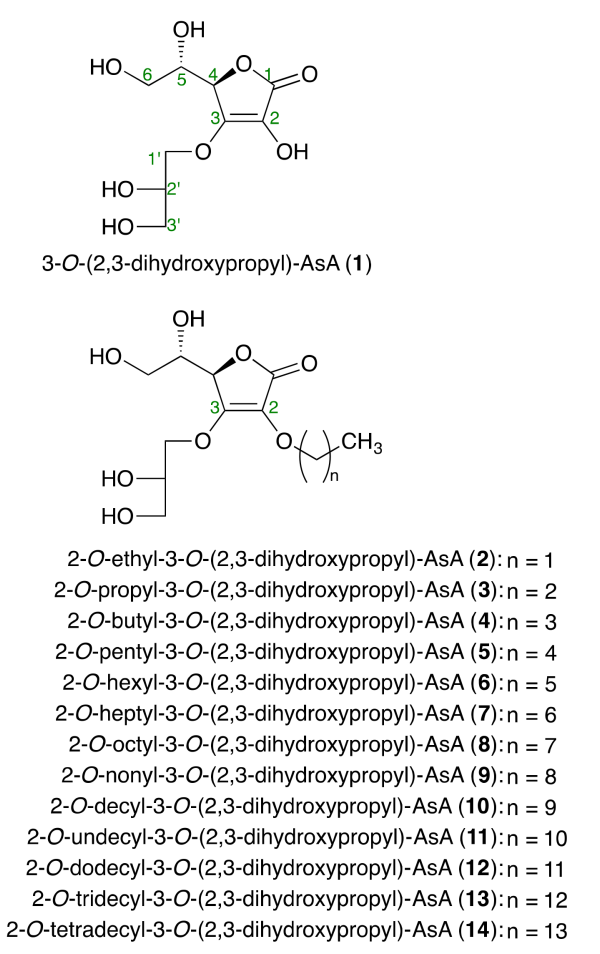

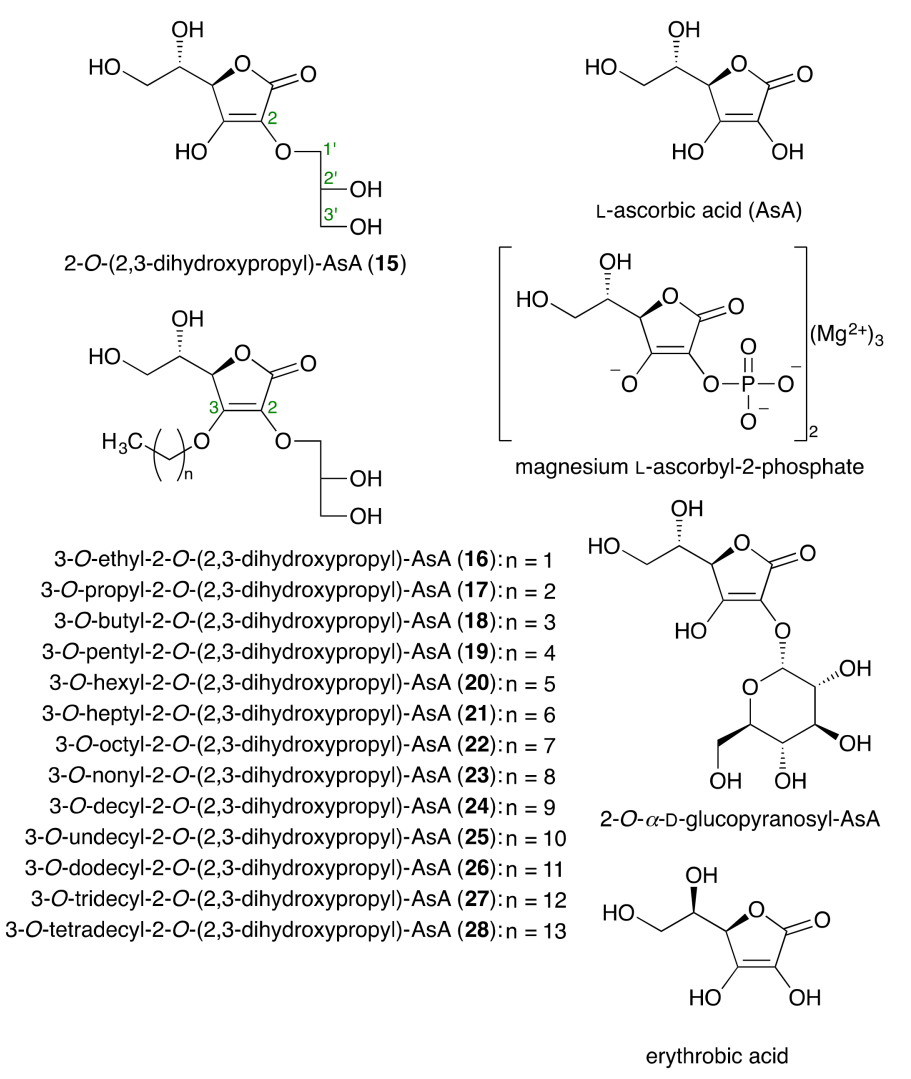

Figure 1. Structures of AsA derivatives (1-28). AsA: L-ascorbic acid.

\subsection{Effects of the Alkylglyceryl AsA Derivatives (1-28) and Commercially Available AsA Derivatives on Theophylline-Stimulated Melanogenesis Inhibitory Activity}

Since AsA and existing AsA derivatives are used in cosmetic materials as skin whitening and/or brightening agents $[39,40]$, we compared their effects with those of the alkylglyceryl-AsA derivatives (1-28) on theophylline-stimulated melanogenesis in B16 melanoma 4A5 cells. As shown in Table 1, the commercially available derivatives, magnesium L-ascorbyl-2-phosphate and 2-O- $\alpha$-D-glucopyranosyl-AsA, were found to significantly inhibit melanogenesis at a concentration of $3000 \mu \mathrm{M}$. However, these derivatives were weaker than a commercially used tyrosinase inhibitor, arbutin $\left(\mathrm{IC}_{50}=830 \mu \mathrm{M}\right)$ [40,41]. Among a series of 2-O-alkyl-3-O-glyceryl-AsA compounds (1-14), the derivatives having 6- to 14-carbon alkyl chains (6-14) exhibited the strongest inhibitory activities $\left(\mathrm{IC}_{50}=11.1-89.1 \mu \mathrm{M}\right)$. Likewise, for the 3-O-alkyl-2-O-glyceryl-AsA compounds (15-28), inhibitory activities were observed for derivatives with 4- to 14-carbon alkyl chains $\left(\mathbf{1 8}-\mathbf{2 8}, \mathrm{IC}_{50}=5.0-473 \mu \mathrm{M}\right)$. The derivative 2-O-(2,3-dihydroxypropyl)-3-O-tetradecyl-AsA $\left(28, \mathrm{IC}_{50}=5.0 \mu \mathrm{M}\right)$ exhibited the most potent inhibitory effect without notable cytotoxicity at effective concentrations. This melanogenesis inhibitory activity was found to be equivalent to that of the active metabolite of arbutin ( $\left.\mathrm{IC}_{50}=830 \mu \mathrm{M}\right)$, hydroquinone [40] $\left(\mathrm{IC}_{50}=8.7 \mu \mathrm{M}\right)$, and compound 28 was more than 166-fold more potent than arbutin (Figure 2). Plotting the alkyl chain length vs. the $\mathrm{IC}_{50}$ further revealed that the alkyl chain length is directly proportional to the inhibitory activity of the derivatives (Figure 3). Specifically, the potency of the derivative increased with increasing alkyl chain length. Compounds with longer alkyl chains (compounds 9-14 and 24-28), however, were also found to be cytotoxic at concentration ranges similar to those required for their melanogenesis inhibitory activities. Considering the need for both safety and effectiveness for cosmetic use, the derivatives having a hexyl chain, such as 
3-O-(2,3-dihydroxypropyl)-2-O-hexyl-AsA (6) and 2-O-(2,3-dihydroxypropyl)-3-O-hexyl-AsA (20), were considered to be the most valuable candidates for study due to their low toxicity and relatively high potency. Compound $\mathbf{6}$ at $100 \mu \mathrm{M}$ significantly suppressed the inhibition of melanin production as compared with the control in normal melanocytes (Figure 4). Accordingly, for other compounds, it is necessary to determine whether the same trend is observed even in normal melanocytes.

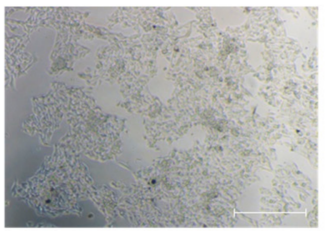

nomal

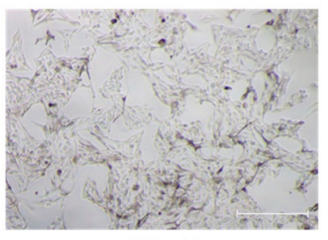

$100 \mu \mathrm{M}$

3-O-(2,3-dihydroxypropyl)-2-O-hexyl-AsA (6)

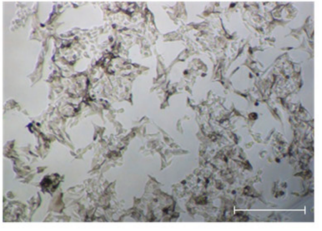

$3 \mu \mathrm{M}$

$10 \mu \mathrm{M}$

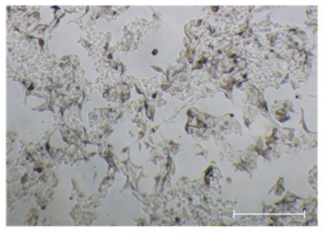

yl)-2-O-tetradecyl-AsA (14)

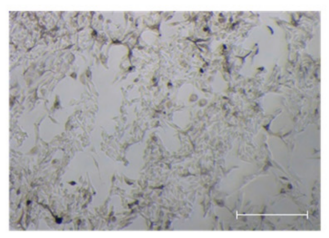

$300 \mu \mathrm{M}$

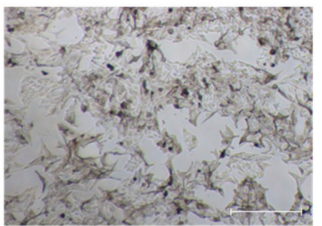

$100 \mu \mathrm{M}$

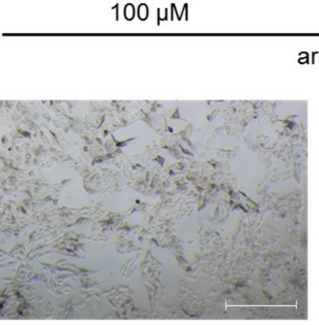

$100 \mu \mathrm{M}$

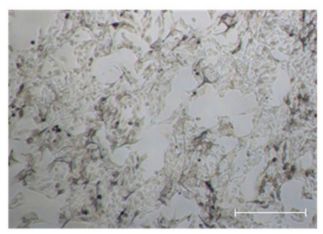

$300 \mu \mathrm{M}$

arbutin

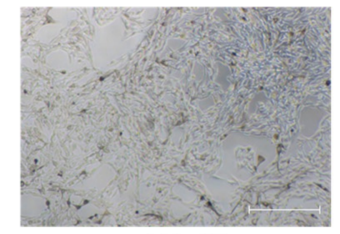

$300 \mu \mathrm{M}$

2-O-(2,3-dihydroxypropyl)-3-O-hexyl-AsA (20)

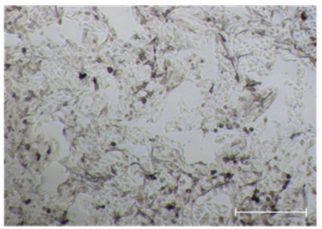

$3 \mu \mathrm{M}$

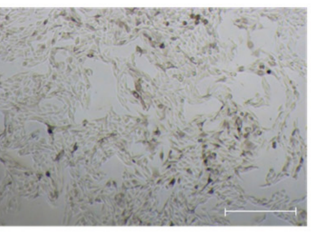

$10 \mu \mathrm{M}$

2-O-(2,3-dihydroxypropyl)-3-O-tetradecyl-AsA (28)

Figure 2. Theophylline-stimulated B16 melanoma $4 \mathrm{~A} 5$ cells $72 \mathrm{~h}$ after treatment with $6(100 \mu \mathrm{M}$, $300 \mu \mathrm{M}), 20(100 \mu \mathrm{M}, 300 \mu \mathrm{M}), \mathbf{1 4}(3 \mu \mathrm{M}, 10 \mu \mathrm{M}))$, or $\mathbf{2 8}(3 \mu \mathrm{M}, 10 \mu \mathrm{M})$. The images are representative of several experiments. normal: theophylline $(-)$; control: theophylline $(+)$.
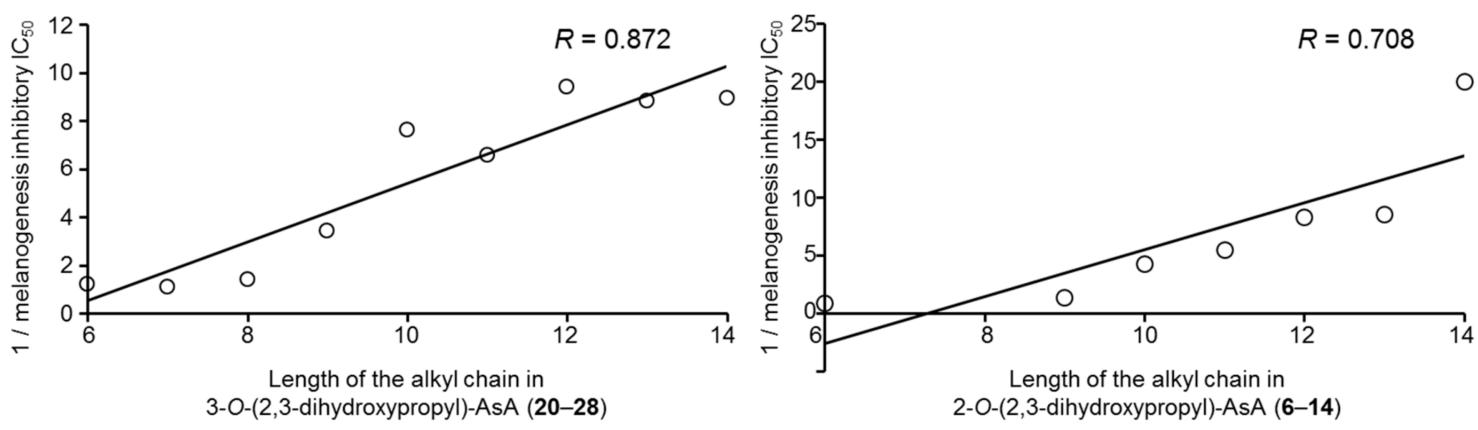

Figure 3. Correlation between melanogenesis inhibitory activity $\left[1 / \mathrm{IC}_{50}\right.$ values $\left.(\mu \mathrm{M})\right]$ and length of the alkyl chain in 2-O-alkyl-3-O-(2,3-dihydroxypropyl)-AsA compounds (6-14) and 3-O-alkyl-2-O-(2,3-dihydroxypropyl)-AsA compounds (20-28). AsA: L-ascorbic acid. 
Table 1. Inhibitory effects of alkylglyceryl AsA (1-28) and commercially available AsA derivatives on theophylline-stimulated melanogenesis and viability of B16 4 A5 cells.

\begin{tabular}{|c|c|c|c|c|c|c|}
\hline \multirow{2}{*}{ Treatment } & \multicolumn{5}{|c|}{ Inhibition (\%) } & \multirow{2}{*}{$\begin{array}{l}\mathrm{IC}_{50} \\
(\mu \mathrm{M})\end{array}$} \\
\hline & $0 \mu \mathrm{M}$ & $100 \mu \mathrm{M}$ & $300 \mu \mathrm{M}$ & $1000 \mu \mathrm{M}$ & $3000 \mu \mathrm{M}$ & \\
\hline 3-O-(2,3-Dihydroxypropyl)-AsA (1) & $\begin{array}{c}0.0 \pm 4.1 \\
(100.0 \pm 6.4)\end{array}$ & $\begin{array}{c}-11.8 \pm 1.9 \\
(100.0 \pm 1.0)\end{array}$ & $\begin{array}{l}-10.7 \pm 1.1 \\
(96.8 \pm 2.3) \\
\end{array}$ & $\begin{array}{c}-5.0 \pm 2.9 \\
(100.4 \pm 0.4)\end{array}$ & $\begin{array}{c}0.5 \pm 2.5 \\
(107.9 \pm 1.0)\end{array}$ & $>3000$ \\
\hline 3-O-(2,3-Dihydroxypropyl)-2-O-ethyl-AsA (2) & $\begin{array}{c}0.0 \pm 5.9 \\
(100.0 \pm 3.3)\end{array}$ & $\begin{array}{c}-28.1 \pm 3.2 \\
(101.3 \pm 3.3)\end{array}$ & $\begin{array}{c}-2.8 \pm 3.6 \\
(99.7 \pm 1.8)\end{array}$ & $\begin{array}{c}-8.9 \pm 2.0 \\
(101.3 \pm 1.5)\end{array}$ & $\begin{array}{c}40.4 \pm 8.6^{* *} \\
(103.8 \pm 4.1)\end{array}$ & $>3000$ \\
\hline 3-O-(2,3-Dihydroxypropyl)-2-O-propyl-AsA (3) & $\begin{array}{c}0.0 \pm 9.2 \\
(100.0 \pm 1.3)\end{array}$ & $\begin{array}{c}-2.1 \pm 5.3 \\
(101.6 \pm 1.9)\end{array}$ & $\begin{array}{c}8.2 \pm 3.2 \\
(98.2 \pm 1.7)\end{array}$ & $\begin{array}{c}2.5 \pm 7.9 \\
(94.5 \pm 2.0)\end{array}$ & $\begin{array}{l}35.9 \pm 3.4^{*} \\
(95.0 \pm 1.5)\end{array}$ & $>3000$ \\
\hline 2-O-Butyl-3-O-(2,3-dihydroxy-propyl)-AsA (4) & $\begin{array}{c}0.0 \pm 6.0 \\
(100.0 \pm 2.1)\end{array}$ & $\begin{array}{c}-1.2 \pm 0.8 \\
(94.5 \pm 2.3)\end{array}$ & $\begin{array}{l}20.8 \pm 10.6 \\
(97.4 \pm 0.8)\end{array}$ & $\begin{array}{c}30.2 \pm 5.1^{* *} \\
(93.9 \pm 0.8)\end{array}$ & $\begin{array}{c}58.9 \pm 2.7^{* *} \\
(88.7 \pm 1.1)\end{array}$ & 2220 \\
\hline 3-O-(2,3-Dihydroxypropyl)-2-O-pentyl-AsA (5) & $\begin{array}{c}0.0 \pm 11.4 \\
(100.0 \pm 2.1)\end{array}$ & $\begin{array}{c}-14.0 \pm 9.7 \\
(118.1 \pm 2.9)\end{array}$ & $\begin{array}{c}29.8 \pm 8.1 \\
(107.3 \pm 2.3)\end{array}$ & $\begin{array}{l}45.9 \pm 1.2 * * \\
(105.1 \pm 1.2)\end{array}$ & $\begin{array}{l}81.9 \pm 3.3^{* *} \\
\left(78.7 \pm 1.1^{\#}\right)\end{array}$ & 931 \\
\hline 2-O-(2,3-Dihydroxypropyl)-AsA (15) & $\begin{array}{c}0.0 \pm 4.4 \\
(100.0 \pm 8.5)\end{array}$ & $\begin{array}{c}-9.7 \pm 1.2 \\
(101.2 \pm 2.2)\end{array}$ & $\begin{array}{c}-4.8 \pm 1.0 \\
(102.0 \pm 3.6)\end{array}$ & $\begin{array}{c}-2.3 \pm 1.7 \\
(101.6 \pm 3.2) \\
\end{array}$ & $\begin{array}{c}-6.1 \pm 2.7 \\
(106.7 \pm 1.8)\end{array}$ & $>3000$ \\
\hline 2-O-(2,3-Dihydroxypropyl)-3-O-ethyl-AsA (16) & $\begin{array}{c}0.0 \pm 3.0 \\
(100.0 \pm 6.2)\end{array}$ & $\begin{array}{c}-4.2 \pm 2.3 \\
(104.9 \pm 1.4)\end{array}$ & $\begin{array}{c}-5.4 \pm 1.5 \\
(95.9 \pm 1.2)\end{array}$ & $\begin{array}{c}12.1 \pm 2.2 * * \\
(95.9 \pm 3.1)\end{array}$ & $\begin{array}{c}42.0 \pm 1.4^{* *} \\
(84.0 \pm 1.1)\end{array}$ & $>3000$ \\
\hline 2-O-(2,3-Dihydroxypropyl)-3-O-propyl-AsA (17) & $\begin{array}{c}0.0 \pm 7.4 \\
(100.0 \pm 4.3) \\
\end{array}$ & $\begin{array}{c}-5.9 \pm 3.3 \\
(98.4 \pm 4.7) \\
\end{array}$ & $\begin{array}{c}-3.9 \pm 4.1 \\
(95.6 \pm 3.5) \\
\end{array}$ & $\begin{array}{c}1.3 \pm 4.2 \\
(92.0 \pm 2.3) \\
\end{array}$ & $\begin{array}{c}23.2 \pm 5.6^{* *} \\
(82.9 \pm 2.3) \\
\end{array}$ & $>3000$ \\
\hline 3-O-Butyl-2-O-(2,3-dihydroxy-propyl)-AsA (18) & $\begin{array}{c}0.0 \pm 2.7 \\
(100.0 \pm 1.0)\end{array}$ & $\begin{array}{c}0.2 \pm 4.4 \\
(99.8 \pm 1.1)\end{array}$ & $\begin{array}{c}36.3 \pm 2.8^{* *} \\
(89.1 \pm 1.6)\end{array}$ & $\begin{array}{l}68.0 \pm 2.1^{* *} \\
\left(78.1 \pm 0.5^{\#}\right)\end{array}$ & $\begin{array}{l}84.1 \pm 1.4^{* *} \\
\left(70.6 \pm 1.0^{\#}\right)\end{array}$ & 473 \\
\hline 2-O-(2,3-Dihydroxypropyl)-3-O-pentyl-AsA (19) & $\begin{array}{c}0.0 \pm 5.2 \\
(100.0 \pm 0.4)\end{array}$ & $\begin{array}{l}14.0 \pm 4.4^{*} \\
(86.7 \pm 1.5)\end{array}$ & $\begin{array}{l}53.0 \pm 1.1^{\text {** }} \\
\left(73.4 \pm 0.7^{\#}\right)\end{array}$ & $\begin{array}{l}83.1 \pm 1.4^{* *} \\
\left(54.7 \pm 0.8^{\#}\right)\end{array}$ & $\begin{array}{l}97.1 \pm 0.9^{* *} \\
\left(22.5 \pm 0.5^{\#}\right)\end{array}$ & 283 \\
\hline 2-O-(2,3-Dihydroxypropyl)-3-O-hexyl-AsA (20) & $\begin{array}{c}0.0 \pm 2.9 \\
(100.0 \pm 1.0)\end{array}$ & $\begin{array}{c}43.5 \pm 2.6^{* *} \\
(95.3 \pm 0.6)\end{array}$ & $\begin{array}{c}77.0 \pm 2.1^{* *} \\
(83.9 \pm 0.4)\end{array}$ & $\begin{array}{l}94.9 \pm 1.5^{* *} \\
\left(60.8 \pm 0.6^{\#}\right)\end{array}$ & $\begin{array}{c}80.9 \pm 4.1^{* *} \\
\left(44.7 \pm 1.9^{\#}\right)\end{array}$ & 117 \\
\hline AsA & $\begin{array}{c}0.0 \pm 1.7 \\
(100.0 \pm 2.2)\end{array}$ & - & - & $\begin{array}{c}-17.4 \pm 4.0 \\
(103.8 \pm 0.8)\end{array}$ & $\begin{array}{c}3.8 \pm 4.7 \\
(89.2 \pm 0.8)\end{array}$ & $>3000$ \\
\hline Magnesium L-ascorbyl-2-phosphate & $\begin{array}{c}0.0 \pm 5.5 \\
(100.0 \pm 0.5)\end{array}$ & - & - & $\begin{array}{c}2.1 \pm 4.1 \\
(125.6 \pm 3.6)\end{array}$ & $\begin{array}{l}14.5 \pm 1.3^{*} \\
(92.8 \pm 3.0)\end{array}$ & $>3000$ \\
\hline 2-O- $\alpha$-D-Glucopyranosyl-AsA & $\begin{array}{c}0.0 \pm 3.0 \\
(100.0 \pm 4.3)\end{array}$ & - & - & $\begin{array}{c}-8.9 \pm 2.7 \\
(106.8 \pm 2.2)\end{array}$ & $\begin{array}{c}15.0 \pm 3.5^{*} \\
(108.4 \pm 5.4)\end{array}$ & $>3000$ \\
\hline Erythrobic acid & $\begin{array}{c}0.0 \pm 6.7 \\
(100.0 \pm 5.7)\end{array}$ & $\begin{array}{l}-22.9 \pm 6.5 \\
(98.7 \pm 4.3)\end{array}$ & $\begin{array}{c}-10.6 \pm 4.8 \\
(94.8 \pm 3.6)\end{array}$ & $\begin{array}{l}75.8 \pm 4.2^{* *} \\
\left(44.5 \pm 2.0^{\#}\right)\end{array}$ & $\begin{array}{l}92.6 \pm 15.3^{* *} \\
\left(29.8 \pm 2.2^{*}\right)\end{array}$ & - \\
\hline Arbutin & $\begin{array}{c}0.0 \pm 10.0 \\
(100.0 \pm 3.7)\end{array}$ & $\begin{array}{c}32.2 \pm 3.4^{* *} \\
(92.2 \pm 0.6)\end{array}$ & $\begin{array}{c}22.3 \pm 4.3^{* *} \\
(96.0 \pm 2.0)\end{array}$ & $\begin{array}{c}63.0 \pm 2.3^{* *} \\
(96.2 \pm 2.7)\end{array}$ & $\begin{array}{c}94.0 \pm 2.8^{* *} \\
(105.8 \pm 2.9)\end{array}$ & 830 \\
\hline
\end{tabular}


Table 1. Cont.

\begin{tabular}{|c|c|c|c|c|c|c|}
\hline \multirow{2}{*}{ Treatment } & \multicolumn{5}{|c|}{ Inhibition (\%) } & \multirow{2}{*}{$\begin{array}{l}\mathrm{IC}_{50} \\
(\mu \mathrm{M})\end{array}$} \\
\hline & $0 \mu \mathrm{M}$ & $3 \mu \mathrm{M}$ & $10 \mu \mathrm{M}$ & $30 \mu \mathrm{M}$ & $100 \mu \mathrm{M}$ & \\
\hline 3-O-(2,3-Dihydroxypropyl)-2-O-hexyl-AsA (6) & $\begin{array}{c}0.0 \pm 5.7 \\
(100.0 \pm 6.0)\end{array}$ & $\begin{array}{c}-1.8 \pm 4.9 \\
\left(102.1 \pm 4.9^{\#}\right)\end{array}$ & $\begin{array}{c}5.6 \pm 2.0 \\
(96.1 \pm 4.9)\end{array}$ & $\begin{array}{c}26.2 \pm 6.0^{* *} \\
(88.4 \pm 6.6)\end{array}$ & $\begin{array}{l}53.1 \pm 3.1^{* *} \\
\left(77.1 \pm 5.8^{\#}\right)\end{array}$ & 81.4 \\
\hline 3-O-(2,3-Dihydroxypropyl)-2-O-heptyl-AsA (7) & $\begin{array}{c}0.0 \pm 9.5 \\
(100.0 \pm 0.7)\end{array}$ & $\begin{array}{c}-4.2 \pm 6.3 \\
(100.6 \pm 3.0)\end{array}$ & $\begin{array}{c}3.4 \pm 5.2 \\
(95.4 \pm 3.6)\end{array}$ & $\begin{array}{l}20.0 \pm 6.4^{*} \\
(91.9 \pm 4.7)\end{array}$ & $\begin{array}{l}52.2 \pm 5.0^{* *} \\
\left(79.7 \pm 2.9^{\#}\right)\end{array}$ & 89.1 \\
\hline 3-O-(2,3-Dihydroxypropyl)-2-O-octyl-AsA (8) & $\begin{array}{c}0.0 \pm 8.3 \\
(100.0 \pm 5.1)\end{array}$ & $\begin{array}{c}5.7 \pm 6.9 \\
(108.4 \pm 6.2)\end{array}$ & $\begin{array}{c}10.6 \pm 4.6^{*} \\
(102.8 \pm 4.8)\end{array}$ & $\begin{array}{c}22.4 \pm 4.4^{* *} \\
(92.5 \pm 4.6)\end{array}$ & $\begin{array}{c}64.1 \pm 8.2 * * \\
(80.0 \pm 4.4)\end{array}$ & 68.8 \\
\hline 3-O-(2,3-Dihydroxypropyl)-2-O-nonyl-AsA (9) & $\begin{array}{c}0.0 \pm 5.9 \\
(100.0 \pm 2.3)\end{array}$ & $\begin{array}{c}0.2 \pm 4.4 \\
(99.2 \pm 0.5)\end{array}$ & $\begin{array}{l}19.1 \pm 1.3^{* *} \\
(88.9 \pm 4.2)\end{array}$ & $\begin{array}{l}51.9 \pm 4.6^{* *} \\
\left(77.6 \pm 3.6^{\#}\right)\end{array}$ & $\begin{array}{l}91.6 \pm 1.2^{* *} \\
\left(58.4 \pm 2.3^{\#}\right)\end{array}$ & 28.8 \\
\hline 2-O-Decyl-3-O-(2,3-dihydroxy-propyl)-AsA (10) & $\begin{array}{c}0.0 \pm 6.7 \\
(100.0 \pm 4.3)\end{array}$ & $\begin{array}{c}3.7 \pm 7.8 \\
(98.6 \pm 4.3)\end{array}$ & $\begin{array}{c}39.2 \pm 4.1^{* *} \\
(85.9 \pm 2.3)\end{array}$ & $\begin{array}{c}78.1 \pm 4.8^{* *} \\
\left(73.5 \pm 5.8^{\#}\right)\end{array}$ & $\begin{array}{l}98.0 \pm 3.7^{* *} \\
\left(27.9 \pm 2.8^{\#}\right)\end{array}$ & 13.0 \\
\hline 3-O-(2,3-Dihydroxypropyl)-2-O-undecyl-AsA (11) & $\begin{array}{c}0.0 \pm 2.9 \\
(100.0 \pm 4.8)\end{array}$ & $\begin{array}{l}12.4 \pm 3.0^{* *} \\
(106.2 \pm 2.5)\end{array}$ & $\begin{array}{c}35.4 \pm 2.8^{* *} \\
(90.8 \pm 7.1)\end{array}$ & $\begin{array}{l}89.3 \pm 1.5^{* *} \\
\left(69.0 \pm 1.9^{\#}\right)\end{array}$ & $\begin{array}{l}100.3 \pm 4.7^{\text {** }} \\
\left(25.8 \pm 1.9^{\#}\right)\end{array}$ & 15.1 \\
\hline 3-O-(2,3-Dihydroxypropyl)-2-O-dodecyl-AsA (12) & $\begin{array}{c}0.0 \pm 5.3 \\
(100.0 \pm 7.3)\end{array}$ & $\begin{array}{l}20.4 \pm 10.2^{*} \\
(112.1 \pm 5.8)\end{array}$ & $\begin{array}{l}50.0 \pm 5.7^{* *} \\
(103.8 \pm 1.2)\end{array}$ & $\begin{array}{l}96.0 \pm 2.9^{* *} \\
\left(73.3 \pm 2.1^{\#}\right)\end{array}$ & $\begin{array}{l}97.9 \pm 4.2^{* *} \\
\left(24.6 \pm 3.4^{\#}\right)\end{array}$ & 10.6 \\
\hline 3-O-(2,3-Dihydroxypropyl)-2-O-tridecyl-AsA (13) & $\begin{array}{c}0.0 \pm 5.2 \\
(100.0 \pm 2.7)\end{array}$ & $\begin{array}{c}0.1 \pm 8.6 \\
(96.3 \pm 3.5)\end{array}$ & $\begin{array}{c}46.0 \pm 7.9^{* *} \\
(87.2 \pm 1.8)\end{array}$ & $\begin{array}{l}97.1 \pm 2.3^{* *} \\
\left(63.7 \pm 1.1^{\#}\right)\end{array}$ & $\begin{array}{l}107.8 \pm 9.1^{* *} \\
\left(23.5 \pm 2.1^{\#}\right)\end{array}$ & 11.3 \\
\hline 3-O-(2,3-Dihydroxypropyl)-2-O-tetradecyl-AsA (14) & $\begin{array}{c}0.0 \pm 7.1 \\
(100.0 \pm 2.3)\end{array}$ & $\begin{array}{c}6.3 \pm 2.6 \\
(101.2 \pm 1.8) \\
\end{array}$ & $\begin{array}{c}48.4 \pm 2.2^{* *} \\
(89.1 \pm 4.5)\end{array}$ & $\begin{array}{l}97.6 \pm 1.8^{* *} \\
\left(56.3 \pm 3.2^{\#}\right)\end{array}$ & $\begin{array}{c}100.0 \pm 18.2^{* *} \\
\left(21.0 \pm 2.4^{*}\right)\end{array}$ & 11.1 \\
\hline 2-O-(2,3-Dihydroxypropyl)-3-O-heptyl-AsA (21) & $\begin{array}{c}0.0 \pm 2.8 \\
(100.0 \pm 7.1)\end{array}$ & $\begin{array}{l}-6.3 \pm 2.7^{*} \\
(97.9 \pm 0.9)\end{array}$ & $\begin{array}{c}0.9 \pm 8.2 \\
(92.7 \pm 3.7)\end{array}$ & $\begin{array}{c}21.0 \pm 5.0^{* *} \\
(92.7 \pm 4.2)\end{array}$ & $\begin{array}{l}44.6 \pm 6.2^{* *} \\
(86.3 \pm 2.7)\end{array}$ & $>100$ \\
\hline 2-O-(2,3-Dihydroxypropyl)-3-O-octyl-AsA (22) & $\begin{array}{c}0.0 \pm 8.8 \\
(100.0 \pm 2.0)\end{array}$ & $\begin{array}{l}-10.4 \pm 6.0 \\
(98.8 \pm 3.4)\end{array}$ & $\begin{array}{c}1.0 \pm 7.0 \\
(99.3 \pm 5.2)\end{array}$ & $\begin{array}{c}2.3 \pm 5.9 \\
(91.6 \pm 4.0)\end{array}$ & $\begin{array}{c}34.8 \pm 8.2^{* *} \\
(83.0 \pm 4.9)\end{array}$ & $>100$ \\
\hline 2-O-(2,3-Dihydroxypropyl)-3-O-nonyl-AsA (23) & $\begin{array}{c}0.0 \pm 14.8 \\
(100.0 \pm 2.4)\end{array}$ & $\begin{array}{c}-1.3 \pm 9.4 \\
(96.6 \pm 5.5)\end{array}$ & $\begin{array}{c}-2.6 \pm 8.0 \\
(90.6 \pm 2.2)\end{array}$ & $\begin{array}{c}14.9 \pm 5.6 \\
(81.2 \pm 4.7)\end{array}$ & $\begin{array}{l}77.1 \pm 2.4^{* *} \\
\left(60.7 \pm 3.2^{\#}\right)\end{array}$ & 72.9 \\
\hline 3-O-Decyl-2-O-(2,3-dihydroxy-propyl)-AsA (24) & $\begin{array}{c}0.0 \pm 5.0 \\
(100.0 \pm 3.2)\end{array}$ & $\begin{array}{c}-5.8 \pm 6.0 \\
(92.5 \pm 5.7)\end{array}$ & $\begin{array}{c}20.9 \pm 5.4^{* *} \\
(87.1 \pm 1.6)\end{array}$ & $\begin{array}{l}64.3 \pm 3.8^{* *} \\
\left(68.5 \pm 2.6^{\#}\right)\end{array}$ & $\begin{array}{l}102.7 \pm 2.4^{* *} \\
\left(34.3 \pm 1.5^{\#}\right)\end{array}$ & 23.5 \\
\hline 2-O-(2,3-Dihydroxypropyl)-3-O-undecyl-AsA (25) & $\begin{array}{c}0.0 \pm 2.0 \\
(100.0 \pm 4.8)\end{array}$ & $\begin{array}{c}-5.1 \pm 2.3^{*} \\
(101.0 \pm 2.9)\end{array}$ & $\begin{array}{c}26.6 \pm 3.0^{* *} \\
(85.8 \pm 3.5)\end{array}$ & $\begin{array}{l}85.0 \pm 3.8^{* *} \\
\left(53.6 \pm 2.7^{*}\right)\end{array}$ & $\begin{array}{c}100.8 \pm 10.1^{* *} \\
\left(24.0 \pm 0.5^{*}\right)\end{array}$ & 18.1 \\
\hline 2-O-(2,3-Dihydroxypropyl)-3-O-dodecyl-AsA (26) & $\begin{array}{c}0.0 \pm 7.9 \\
(100.0 \pm 7.2)\end{array}$ & $\begin{array}{l}14.1 \pm 8.5^{*} \\
(99.8 \pm 4.2)\end{array}$ & $\begin{array}{c}46.0 \pm 3.0 * * \\
(87.3 \pm 2.8)\end{array}$ & $\begin{array}{l}96.2 \pm 2.8^{* *} \\
\left(45.5 \pm 1.1^{\#}\right)\end{array}$ & $\begin{array}{l}89.6 \pm 24.4^{* *} \\
\left(24.3 \pm 12.7^{\#}\right)\end{array}$ & 12.1 \\
\hline 2-O-(2,3-Dihydroxypropyl)-3-O-tridecyl-AsA (27) & $\begin{array}{c}0.0 \pm 8.4 \\
(100.0 \pm .5 .5)\end{array}$ & $\begin{array}{c}20.1 \pm 5.7^{* *} \\
(104.9 \pm 4.1)\end{array}$ & $\begin{array}{c}44.2 \pm 3.9^{* *} \\
(84.3 \pm 2.8)\end{array}$ & $\begin{array}{l}96.6 \pm 3.0^{* *} \\
\left(40.2 \pm 2.5^{\#}\right)\end{array}$ & $\begin{array}{c}112.9 \pm 10.1^{* *} \\
\left(21.0 \pm 1.5^{\#}\right)\end{array}$ & 11.7 \\
\hline 2-O-(2,3-Dihydroxypropyl)-3-O-tetradecyl-AsA (28) & $\begin{array}{c}0.0 \pm 7.6 \\
(100.0 \pm 1.3)\end{array}$ & $\begin{array}{c}32.8 \pm 7.2^{* *} \\
(85.1 \pm 4.6)\end{array}$ & $\begin{array}{l}75.7 \pm 3.9^{* *} \\
\left(62.6 \pm 1.6^{\#}\right)\end{array}$ & $\begin{array}{l}95.9 \pm 8.4^{\text {** }} \\
\left(23.0 \pm 2.1^{\#}\right)\end{array}$ & $\begin{array}{c}95.2 \pm 20.7^{* *} \\
\left(18.1 \pm 1.9^{\#}\right)\end{array}$ & 5.0 \\
\hline Hydroquinone & $\begin{array}{c}0.0 \pm 4.4 \\
(100.0 \pm 1.6)\end{array}$ & $\begin{array}{c}37.4 \pm 3.7^{* *} \\
\left(94.1 \pm 1.7^{*}\right.\end{array}$ & $\begin{array}{c}59.5 \pm 3.7^{* *} \\
(85.2 \pm 1.4)\end{array}$ & $\begin{array}{l}76.3 \pm 2.1^{* *} \\
\left(64.3 \pm 0.8^{\#}\right)\end{array}$ & - & 8.7 \\
\hline
\end{tabular}

Each value represents the mean \pm S.D. $(n=4)$; asterisks denote significant differences from the control group, ${ }^{*} p<0.05,{ }^{* *} p<0.01$; ${ }^{*}$ cytotoxic effects were observed, and values in parentheses indicate cell viability (\%). —: not measured; AsA: L-ascorbic acid. 


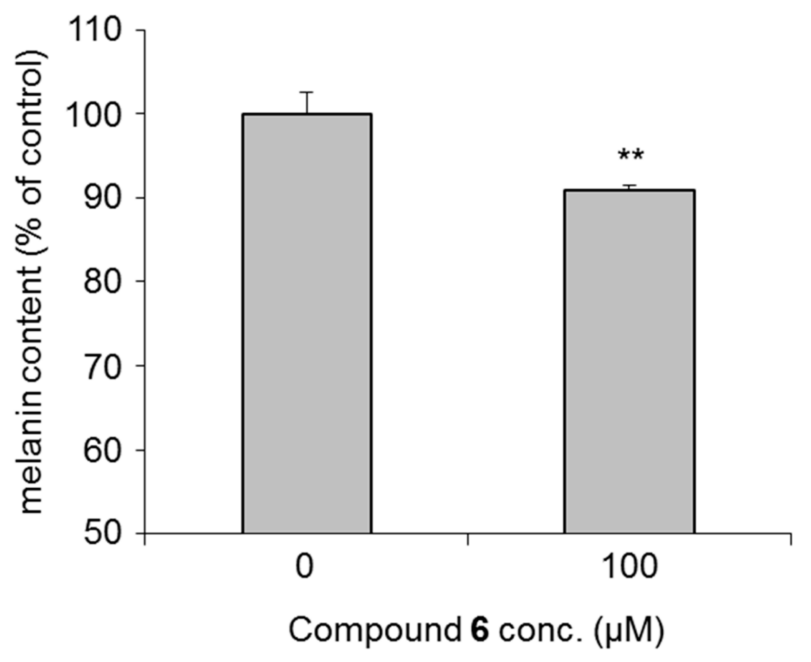

Figure 4. Inhibitory effect of 3-O-(2,3-dihydroxypropyl)-2-O-hexyl-AsA (6) on melanogenesis by normal melanocytes. Each value represents the mean \pm S.D. $(n=3)$; asterisks denote significant differences from the control group, ${ }^{* *} p<0.01$.

\subsection{Stability in Aqueous Solution}

We examined the stability of 3-O-(2,3-dihydroxypropyl)-2-O-hexyl-AsA (6) and 2-O-(2,3-dihydroxypropyl)-3-O-hexyl-AsA (20) in aqueous solution at elevated temperature. As presented in Figure 5, residual AsA was found to decrease rapidly with only $9 \%$ remaining after $3 \mathrm{~h}$. However, more than $80 \%$ of $6(85 \%)$ and $20(82 \%)$ remained after $3 \mathrm{~h}$ of treatment.

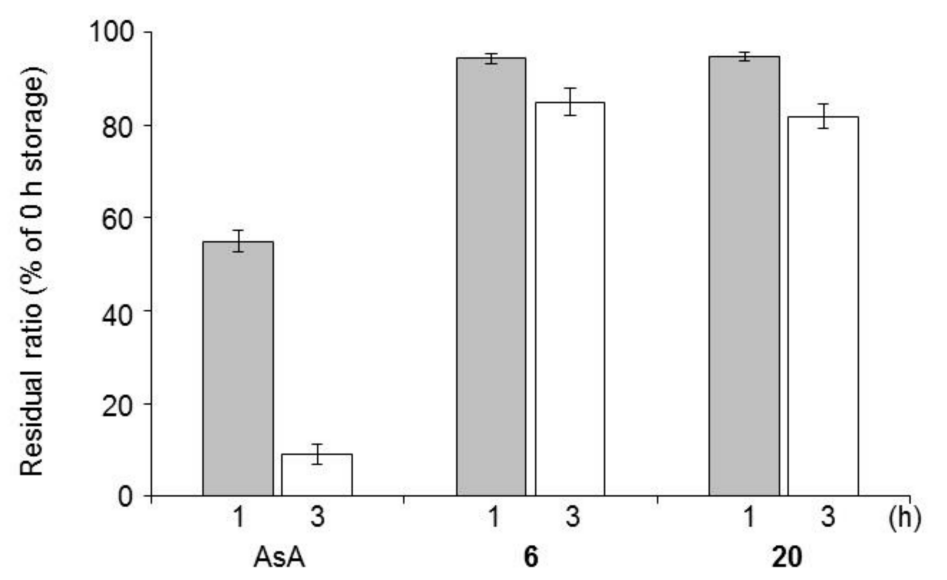

Figure 5. Residual ratio of 6, 20, and AsA in aqueous solution $\left(20 \mathrm{mg} / \mathrm{mL}\right.$ at $125^{\circ} \mathrm{C}$ in the dark) after $1 \mathrm{~h}$ (gray bars) and $3 \mathrm{~h}$ (white bars). Each value represents the mean \pm S.D. $(n=3)$; AsA: L-ascorbic acid.

\subsection{Effects on Tyrosinase}

Tyrosinase, a copper-containing enzyme, plays a key role in melanin biosynthesis, which is involved in determining the color of skin and hair [42]. It catalyzes the oxidation of both L-tyrosine to L-DOPA, and L-DOPA to dopaquinone. Dopaquinone then undergoes a chain of oxidative polymerizations to yield melanin. Tyrosinase inhibitors are clinically used for the treatment of several dermatological disorders associated with melanin hyperpigmentation [43,44]. The tyrosinase inhibitor kojic acid is commonly used as an additive in cosmetics for skin whitening and/or depigmentation [10,45]. AsA reduces o-quinones to o-diphenols. Thus, AsA inhibits melanin production by reducing back quinone structures, such as L-DOPAquinone, to L-DOPA [45-48]. 
Therefore, to characterize the mode of action of melanogenesis inhibitory activity of the derivatives (6-14 and 20-28), their effects on mushroom tyrosinase enzymatic activity were examined. As shown in Table 2, none of the AsA derivatives showed inhibitory activity when using either L-tyrosine or L-DOPA as substrates. In addition, in mammalian tyrosinase testing, compound $\mathbf{6}$ did not show activity when using L-DOPA as substrates [49], and this result was similar to that observed in the mushroom tyrosinase test (Figure 6). This suggests that tyrosinase inhibition is not involved in the mechanisms of action of these melanogenesis inhibitors.

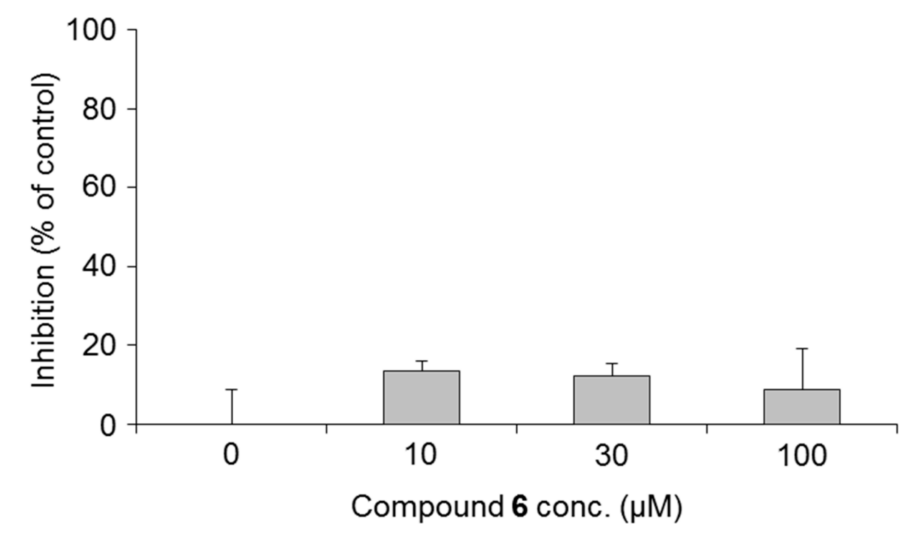

Figure 6. Effects of 3-O-(2,3-dihydroxypropyl)-2-O-hexyl-AsA (6) on the activity of mammalian tyrosinase. Each value represents the mean \pm S.D. $(n=3)$. 
Table 2. Effects on activity of tyrosinase from mushroom.

\begin{tabular}{|c|c|c|c|c|c|c|}
\hline \multirow{3}{*}{ Treatment } & \multicolumn{6}{|c|}{ Inhibition (\%) } \\
\hline & \multicolumn{3}{|c|}{ Substrate: L-Tyrosine } & \multicolumn{3}{|c|}{ Substrate: L-DOPA } \\
\hline & $0 \mu \mathrm{M}$ & $30 \mu \mathrm{M}$ & $100 \mu \mathrm{M}$ & $0 \mu \mathrm{M}$ & $30 \mu \mathrm{M}$ & $100 \mu \mathrm{M}$ \\
\hline 3-O-(2,3-Dihydroxypropyl)-2-O-hexyl-AsA (6) & $0.0 \pm 0.4$ & $-1.5 \pm 6.7$ & $0.9 \pm 1.4$ & $0.0 \pm 6.3$ & $-1.5 \pm 1.5$ & $-1.0 \pm 0.7$ \\
\hline 3-O-(2,3-Dihydroxypropyl)-2-O-heptyl-AsA (7) & $0.0 \pm 0.4$ & $-1.7 \pm 4.0$ & $1.0 \pm 2.4$ & $0.0 \pm 6.3$ & $-0.7 \pm 3.1$ & $1.1 \pm 4.8$ \\
\hline 3-O-(2,3-Dihydroxypropyl)-2-O-octyl-AsA (8) & $0.0 \pm 0.4$ & $-0.3 \pm 2.3$ & $-0.6 \pm 4.3$ & $0.0 \pm 2.4$ & $2.4 \pm 1.1$ & $2.3 \pm 2.7$ \\
\hline 3-O-(2,3-Dihydroxypropyl)-2-O-nonyl-AsA (9) & $0.0 \pm 0.4$ & $4.0 \pm 6.1$ & $-1.2 \pm 4.5$ & $0.0 \pm 2.4$ & $4.8 \pm 6.6$ & $0.9 \pm 6.0$ \\
\hline 2-O-(2,3-Dihydroxypropyl)-3-O-hexyl-AsA (20) & $0.0 \pm 10.7$ & $1.4 \pm 4.7$ & $-6.1 \pm 0.6$ & $0.0 \pm 8.7$ & $-5.7 \pm 5.1$ & $-2.4 \pm 4.2$ \\
\hline 2-O-(2,3-Dihydroxypropyl)-3-O-heptyl-AsA (21) & $0.0 \pm 10.7$ & $-9.2 \pm 2.1$ & $-9.8 \pm 3.9$ & $0.0 \pm 8.7$ & $-10.0 \pm 1.7$ & $-11.3 \pm 2.4$ \\
\hline 2-O-(2,3-Dihydroxypropyl)-3-O-octyl-AsA (22) & $0.0 \pm 10.7$ & $-11.5 \pm 1.6$ & $-14.4 \pm 1.8$ & $0.0 \pm 11.2$ & $-13.1 \pm 3.3$ & $-4.5 \pm 2.0$ \\
\hline \multirow[t]{2}{*}{ 2-O-(2,3-Dihydroxypropyl)-3-O-nonyl-AsA (23) } & $0.0 \pm 7.0$ & $-5.0 \pm 3.1$ & $-2.6 \pm 2.4$ & $0.0 \pm 2.2$ & $-4.1 \pm 2.2$ & $-1.5 \pm 2.2$ \\
\hline & $\mathbf{0 \mu M}$ & $10 \mu \mathrm{M}$ & $30 \mu \mathrm{M}$ & $0 \mu \mathrm{M}$ & $10 \mu \mathrm{M}$ & $30 \mu \mathrm{M}$ \\
\hline 2-O-Decyl-3-O-(2,3-dihydroxy-propyl)-AsA (10) & $0.0 \pm 0.4$ & $1.3 \pm 3.1$ & $0.4 \pm 1.7$ & $0.0 \pm 2.4$ & $0.4 \pm 1.1$ & $2.4 \pm 2.9$ \\
\hline 3-O-(2,3-Dihydroxypropyl)-2-O-undecyl-AsA (11) & $0.0 \pm 0.4$ & $2.9 \pm 3.9$ & $1.0 \pm 2.5$ & $0.0 \pm 3.2$ & $-4.6 \pm 1.4$ & $-5.1 \pm 2.2$ \\
\hline 3-O-(2,3-Dihydroxypropyl)-2-O-dodecyl-AsA (12) & $0.0 \pm 6.7$ & $-0.7 \pm 4.5$ & $-7.1 \pm 1.4$ & $0.0 \pm 3.2$ & $-3.1 \pm 3.3$ & $-4.6 \pm 2.2$ \\
\hline 3-O-(2,3-Dihydroxypropyl)-2-O-tridecyl-AsA (13) & $0.0 \pm 6.7$ & $-4.7 \pm 2.9$ & $-7.1 \pm 1.7$ & $0.0 \pm 3.2$ & $-4.7 \pm 5.0$ & $-4.4 \pm 1.8$ \\
\hline 3-O-(2,3-Dihydroxypropyl)-2-O-tetradecyl-AsA (14) & $0.0 \pm 6.7$ & $-7.0 \pm 6.7$ & $-9.7 \pm 2.7$ & $0.0 \pm 13.8$ & $-8.9 \pm 3.5$ & $-8.2 \pm 4.3$ \\
\hline 3-O-Decyl-2-O-(2,3-dihydroxy-propyl)-AsA (24) & $0.0 \pm 7.0$ & $-4.1 \pm 5.3$ & $-3.1 \pm 4.1$ & $0.0 \pm 4.2$ & $0.7 \pm 3.8$ & $-5.3 \pm 4.2$ \\
\hline 2-O-(2,3-Dihydroxypropyl)-3-O-undecyl-AsA (25) & $0.0 \pm 7.0$ & $-8.0 \pm 0.6$ & $-8.7 \pm 1.5$ & $0.0 \pm 4.2$ & $-10.2 \pm 2.3$ & $-10.7 \pm 3.8$ \\
\hline 2-O-(2,3-Dihydroxypropyl)-3-O-dodecyl-AsA (26) & $0.0 \pm 7.0$ & $-2.2 \pm 6.4$ & $-0.5 \pm 4.3$ & $0.0 \pm 3.0$ & $-6.4 \pm 3.1$ & $-6.6 \pm 8.7$ \\
\hline 2-O-(2,3-Dihydroxypropyl)-3-O-tridecyl-AsA (27) & $0.0 \pm 7.0$ & $-3.3 \pm 8.1$ & $-5.4 \pm 1.9$ & $0.0 \pm 3.0$ & $-2.0 \pm 3.3$ & $-3.2 \pm 2.7$ \\
\hline 2-O-(2,3-Dihydroxypropyl)-3-O-tetradecyl-AsA (28) & $0.0 \pm 7.0$ & $-4.4 \pm 4.6$ & $-8.4 \pm 1.0$ & $0.0 \pm 3.0$ & $-5.7 \pm 9.5$ & $-8.1 \pm 5.2$ \\
\hline Substrate: L-Tyrosine & \multicolumn{6}{|c|}{ Inhibition (\%) } \\
\hline Treatment & $\mathbf{0 \mu M}$ & $10 \mu \mathrm{M}$ & $30 \mu \mathrm{M}$ & $100 \mu \mathrm{M}$ & $300 \mu \mathrm{M}$ & $\mathrm{IC}_{50}(\mu \mathrm{M})$ \\
\hline Kojic acid [20,22-27] & $0.0 \pm 2.4$ & $12.2 \pm 3.3$ & $46.4 \pm 2.6^{* *}$ & $66.5 \pm 2.1^{* *}$ & $96.8 \pm 0.9^{* *}$ & 43.6 \\
\hline Substrate: L-DOPA & \multicolumn{6}{|c|}{ Inhibition (\%) } \\
\hline Treatment & $0 \mu \mathrm{M}$ & $10 \mu \mathrm{M}$ & $30 \mu \mathrm{M}$ & $100 \mu \mathrm{M}$ & $300 \mu \mathrm{M}$ & $\mathrm{IC}_{50}(\mu \mathrm{M})$ \\
\hline Kojic acid $[20,22-27]$ & $0.0 \pm 0.9$ & $22.3 \pm 2.1^{* *}$ & $50.6 \pm 0.6 * *$ & $78.2 \pm 0.7^{* *}$ & $89.3 \pm 0.3^{* *}$ & 29.6 \\
\hline
\end{tabular}

Each value represents the mean \pm S.D. $(n=4)$; asterisks denote significant differences from the control group, ${ }^{* *} p<0.01$. AsA: L-ascorbic acid. 


\subsection{Effects on Expression of Tyrosinase, TRP-1, and TRP-2 $m R N A$}

The TRP enzyme family (tyrosinase, TRP-1, and TRP-2) catalyzes the major steps in melanin synthesis [50]. To clarify the mechanisms of action of the derivatives, we examined the effects of 6 and 20 on the expression of tyrosinase, TRP-1, and TRP- 2 mRNAs in B16 melanoma 4A5 cells. As presented in Table 3, both $\mathbf{6}$ and $\mathbf{2 0}$ significantly downregulated the mRNA expression of tyrosinase and TRP-1 at $100 \mu \mathrm{M} ; \mathbf{1 4}$ and 28 significantly downregulated the mRNA expression of tyrosinase and TRP-2 at $10 \mu \mathrm{M}$.

Table 3. Effects of $\mathbf{6}, \mathbf{1 4}, \mathbf{2 0}$, and 28 on expression of tyrosinase, TRP-1, and TRP-2 mRNA in B16 4 A5 cells.

\begin{tabular}{|c|c|c|c|}
\hline \multirow{2}{*}{ Treatment } & \multicolumn{3}{|c|}{ Tyrosinase mRNA/ $\beta$-actin mRNA } \\
\hline & $\mathbf{0} \mu \mathrm{M}$ & $30 \mu \mathrm{M}$ & $100 \mu \mathrm{M}$ \\
\hline 3-O-(2,3-Dihydroxypropyl)-2-O-hexyl-AsA (6) & $1.00 \pm 0.05$ & $0.60 \pm 0.07^{* *}$ & $0.42 \pm 0.03^{* *}$ \\
\hline 2-O-(2,3-Dihydroxypropyl)-3-O-hexyl-AsA (20) & $1.00 \pm 0.22$ & $0.72 \pm 0.10$ & $0.59 \pm 0.07^{*}$ \\
\hline \multirow{2}{*}{ Treatment } & \multicolumn{3}{|c|}{ TRP-1 mRNA/ $\beta$-actin mRNA } \\
\hline & $0 \mu \mathbf{M}$ & $30 \mu \mathrm{M}$ & $100 \mu \mathrm{M}$ \\
\hline 3-O-(2,3-Dihydroxypropyl)-2-O-hexyl-AsA (6) & $1.00 \pm 0.21$ & $0.48 \pm 0.15^{*}$ & $0.37 \pm 0.05^{* *}$ \\
\hline 2-O-(2,3-Dihydroxypropyl)-3-O-hexyl-AsA (20) & $1.00 \pm 0.21$ & $0.67 \pm 0.12$ & $0.50 \pm 0.15^{*}$ \\
\hline \multirow{2}{*}{ Treatment } & \multicolumn{3}{|c|}{ TRP-2 mRNA/ $\beta$-actin mRNA } \\
\hline & $0 \mu \mathrm{M}$ & $30 \mu \mathrm{M}$ & $100 \mu \mathrm{M}$ \\
\hline 3-O-(2,3-Dihydroxypropyl)-2-O-hexyl-AsA (6) & $1.00 \pm 0.32$ & $0.53 \pm 0.18$ & $0.70 \pm 0.06$ \\
\hline 2-O-(2,3-Dihydroxypropyl)-3-O-hexyl-AsA (20) & $1.00 \pm 0.10$ & $1.07 \pm 0.30$ & $0.88 \pm 0.25$ \\
\hline \multirow{2}{*}{ Treatment } & \multicolumn{3}{|c|}{ Tyrosinase mRNA $/ \beta$-actin mRNA } \\
\hline & $0 \mu \mathrm{M}$ & $3 \mu \mathrm{M}$ & $10 \mu \mathrm{M}$ \\
\hline 3-O-(2,3-Dihydroxypropyl)-2-O-tetradecyl-L-ascorbic acid (14) & $1.00 \pm 0.12$ & $0.78 \pm 0.10$ & $0.58 \pm 0.09 * *$ \\
\hline 2-O-(2,3-Dihydroxypropyl)-3-O-tetradecyl-L-ascorbic acid (28) & $1.00 \pm 0.12$ & $0.54 \pm 0.03^{* *}$ & $0.29 \pm 0.08^{* *}$ \\
\hline \multirow{2}{*}{ Treatment } & \multicolumn{3}{|c|}{ TRP-1 mRNA/ $\beta$-actin mRNA } \\
\hline & $\mathbf{0 \mu M}$ & $3 \mu \mathrm{M}$ & $10 \mu \mathrm{M}$ \\
\hline 3-O-(2,3-Dihydroxypropyl)-2-O-tetradecyl-L-ascorbic acid (14) & $1.00 \pm 0.24$ & $1.02 \pm 0.27$ & $0.92 \pm 0.22$ \\
\hline 2-O-(2,3-Dihydroxypropyl)-3-O-tetradecyl-L-ascorbic acid (28) & $1.00 \pm 0.24$ & $0.88 \pm 0.20$ & $0.83 \pm 0.27$ \\
\hline \multirow{2}{*}{ Treatment } & \multicolumn{3}{|c|}{ TRP-2 mRNA/ $\beta$-actin mRNA } \\
\hline & $0 \mu \mathrm{M}$ & $3 \mu \mathrm{M}$ & $10 \mu \mathrm{M}$ \\
\hline 3-O-(2,3-Dihydroxypropyl)-2-O-tetradecyl-L-ascorbic acid (14) & $1.00 \pm 0.11$ & $0.58 \pm 0.06^{* *}$ & $0.50 \pm 0.08 * *$ \\
\hline 2-O-(2,3-Dihydroxypropyl)-3-O-tetradecyl-L-ascorbic acid (28) & $1.00 \pm 0.11$ & $0.43 \pm 0.11^{* *}$ & $0.35 \pm 0.05^{* *}$ \\
\hline
\end{tabular}

\subsection{Effects on Expression of Tyrosinase Protein}

We next examined the effects of $\mathbf{6}$ and $\mathbf{2 0}$ on the expression of tyrosinase protein since it is the rate-limiting enzyme in melanin synthesis [51]. As presented in Figure 7, both $\mathbf{6}$ and 20 suppressed tyrosinase protein expression in a concentration-dependent manner. Compound $\mathbf{6}$ decreased tyrosinase activity in cultured cells when using L-DOPA as substrates (Figure 8). This suggests that tyrosinase activity in cultured cells is decreased via suppression of the expression of tyrosinase. 


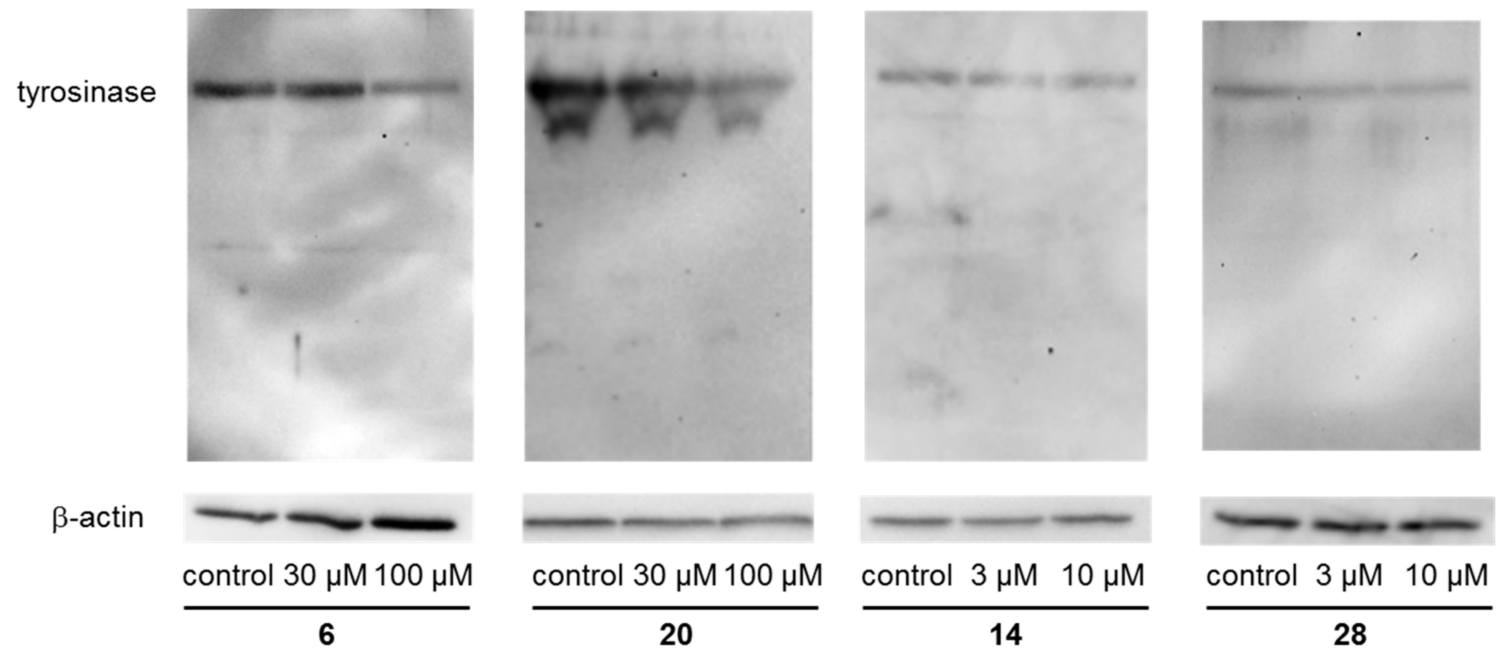

Figure 7. Effects of 6, 14, 20 and $\mathbf{2 8}$ on the expression of tyrosinase protein in B16 4A5 cells. The images are representative of several experiments.

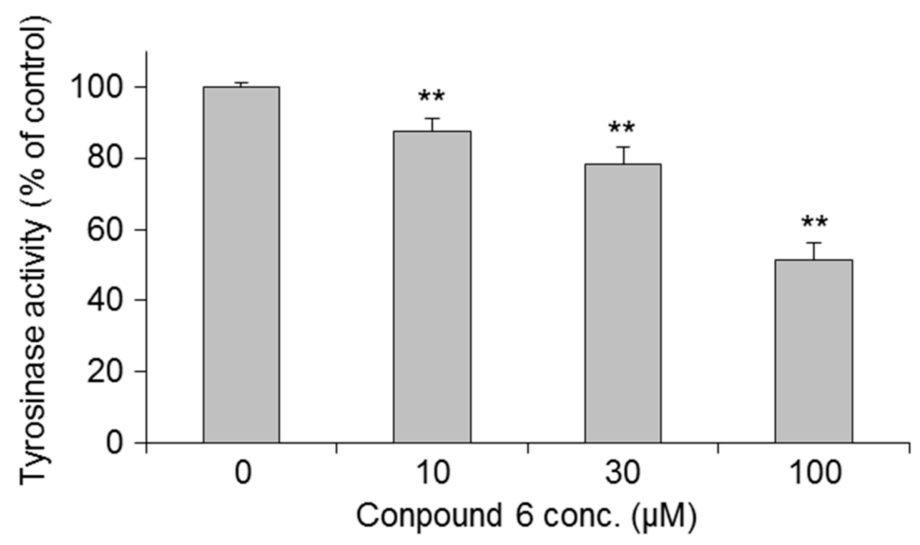

Figure 8. Effects of 3-O-(2,3-dihydroxypropyl)-2-O-hexyl-AsA (6) on tyrosinase activity in cultured cells. Each value represents the mean \pm S.D $(n=3)$; asterisks denote significant differences from the control group, ${ }^{* *} p<0.01$.

\section{Materials and Methods}

\subsection{General Experimental Procedures}

The following instruments were used to obtain physical data: melting points, Yanagimoto micromelting point apparatus (Yanaco New Science Inc., Kyoto, Japan); specific rotations, JASCO P-2200 digital polarimeter (JASCO Corporation, Tokyo, Japan, $l=5 \mathrm{~cm}$ ); UV spectra, UV-1600 spectrometer (Shimadzu Co., Kyoto, Japan); IR spectra, IRPrestige-21 spectrometer (Shimadzu Co.); high-resolution electrospray ionization mass spectrometry (HRESIMS), Exactive Plus mass spectrometer (Thermo Fisher Scientific Inc., Waltham, MA, USA); ${ }^{1} \mathrm{H}-\mathrm{NMR}$ spectra, JNM-ECA600 (600 MHz), JNM-ECA500 (500 MHz), and JNM-ECS400 (400 MHz) spectrometers (JEOL Ltd., Tokyo, Japan); ${ }^{13}$ C-NMR spectra, JNM-ECA600 (150 MHz), JNM-ECA500 (125 MHz), and JNM-ECS400 (100 MHz) spectrometers (JEOL Ltd.) with tetramethylsilane as an internal standard; and HPLC detector, SPD-M20A PDA detector (Shimadzu Co.); HPLC column, Cadenza CD-C18 (Imtakt Co., Kyoto, Japan). The following experimental conditions were used for chromatography: ordinary-phase silica gel column chromatography, silica gel 60N (Kanto Chemical Co., Tokyo, Japan; 63-210 mesh, spherical, neutral); and normal-phase TLC, pre-coated TLC plates with silica 
gel $60 \mathrm{~F}_{254}$ (Merck, Darmstadt, Germany; $0.25 \mathrm{~mm}$ ), detection was carried out by spraying $2 \%$ $\mathrm{H}_{3}\left[\mathrm{PMo}_{12} \mathrm{O}_{40}\right] \cdot \mathrm{nH}_{2} \mathrm{O}-5 \%$ aqueous $\mathrm{H}_{2} \mathrm{SO}_{4}$ on the plates, followed by heating. All chemicals were reagent grade, and were purchased from Wako Pure Chemical Industries, Ltd., Tokyo, Japan or Nacalai Tesque Inc., Kyoto, Japan.

\subsection{Syntheses of Alkylglyceryl Ascorbic Acid Derivatives}

The alkylglyceryl AsA derivatives (1-28) were synthesized by following general procedure: a solution of 1:15 DMSO to alkyl bromide was stirred at $100^{\circ} \mathrm{C}$ for $3 \mathrm{~h}$. The reaction mixture was diluted with water, and extracted with EtOAc. The organic layer was washed with brine (saturated sodium chloride in water), dried, and evaporated. The residue was purified by silica gel chromatography with $\mathrm{CHCl}_{3} / \mathrm{MeOH} / \mathrm{H}_{2} \mathrm{O}$ as the mobile phase. The detailed experimental procedures were described previously [37].

3-O-(2,3-dihydroxypropyl)-AsA (1): An amorphous powder; $[\alpha]_{\mathrm{D}}^{26}+15.4$. ( c 3.70, $\left.\mathrm{MeOH}\right)$; UV [MeOH, $\mathrm{nm}(\log \varepsilon)]: 244$ (3.32); IR (TlBr) $v_{\max } \mathrm{cm}^{-1}: 3275,1759,1693,1335,1045 ;{ }^{1} \mathrm{H}-\mathrm{NMR}\left(600 \mathrm{MHz}, \mathrm{CD}_{3} \mathrm{OD}\right)$ : $\delta 3.59\left(2 \mathrm{H}, \mathrm{m}, \mathrm{H}_{2}-3^{\prime}\right), 3.66\left(2 \mathrm{H}, \mathrm{m}, \mathrm{H}_{2}-6\right), 3.89(1 \mathrm{H}, \mathrm{m}, \mathrm{H}-5), 3.92\left(1 \mathrm{H}, \mathrm{m}, \mathrm{H}-2^{\prime}\right),[4.45(\mathrm{dd}, J=6.5$, $\left.11.0 \mathrm{~Hz}) / 4.49(\mathrm{dd}, J=6.5,11.0 \mathrm{~Hz}), 4.59(\mathrm{dd}, J=3.8,11.0 \mathrm{~Hz}) / 4.62(\mathrm{dd}, J=3.8,11.0 \mathrm{~Hz}), \mathrm{H}_{2}-1^{\prime}\right], 4.82(1 \mathrm{H}$, $\mathrm{d}, J=1.7 \mathrm{~Hz}, \mathrm{H}-4) ;{ }^{13} \mathrm{C}-\mathrm{NMR}\left(150 \mathrm{MHz}, \mathrm{CD}_{3} \mathrm{OD}\right): \delta_{\mathrm{C}} 63.4(\mathrm{t}, \mathrm{C}-6), 63.7\left(\mathrm{t}, \mathrm{C}-3^{\prime}\right), 70.56 / 70.61(\mathrm{~d}, \mathrm{C}-5)$, 71.79/71.89 (d, C-2'), 73.4/73.6 (t, C-1'), 76.9 (d, C-4), 121.17/121.24 (s, C-2), 151.84/151.88 (s, C-3), 173.04/173.07 (s, C-1); HRESIMS m/z: 273.0577 [M + Na] $]^{+}$(calcd for $\mathrm{C}_{9} \mathrm{H}_{14} \mathrm{O}_{8} \mathrm{Na}, 273.0581$ ).

3-O-(2,3-dihydroxypropyl)-2-O-ethyl-AsA (2): An amorphous powder; $[\alpha]_{\mathrm{D}}^{26}+37.0(c 0.32, \mathrm{MeOH})$; UV [MeOH, nm $(\log \varepsilon)]: 236$ (3.91); IR (ATR) $v_{\max } \mathrm{cm}^{-1}: 3316,2934,2889,1748,1667,1321,1169,1111$, 1026; ${ }^{1} \mathrm{H}-\mathrm{NMR}\left(400 \mathrm{MHz}, \mathrm{CD}_{3} \mathrm{OD}\right): \delta 1.31\left(3 \mathrm{H}, \mathrm{t}, J=7.4 \mathrm{~Hz}, \mathrm{H}_{3}-2^{\prime \prime}\right), 3.60\left(2 \mathrm{H}, \mathrm{brd}, J=5.5 \mathrm{~Hz}, \mathrm{H}_{2}-3^{\prime}\right)$, $3.65\left(2 \mathrm{H}\right.$, dd-like, $\left.J=1.8,5.5 \mathrm{~Hz}, \mathrm{H}_{2}-6\right), 3.90\left(2 \mathrm{H}, \mathrm{m}, \mathrm{H}-5,2^{\prime}\right), 4.09\left(2 \mathrm{H}, \mathrm{m}, \mathrm{H}_{2}-1^{\prime \prime}\right),[4.47 / 4.48(1 \mathrm{H}, \mathrm{dd}$, $\left.J=6.4,10.5 \mathrm{~Hz}), 4.59 / 4.60(1 \mathrm{H}, \mathrm{dd}, J=3.6,10.5 \mathrm{~Hz}), \mathrm{H}_{2}-1^{\prime}\right], 4.88(1 \mathrm{H}, \mathrm{brs}, \mathrm{H}-4) ;{ }^{13} \mathrm{C}-\mathrm{NMR}(100 \mathrm{MHz}$, $\left.\mathrm{CD}_{3} \mathrm{OD}\right): \delta_{\mathrm{C}} 15.5\left(\mathrm{q}, \mathrm{C}-2^{\prime \prime}\right), 63.2(\mathrm{t}, \mathrm{C}-6), 63.5\left(\mathrm{t}, \mathrm{C}-3^{\prime}\right), 69.1\left(\mathrm{t}, \mathrm{C}-1^{\prime \prime}\right), 70.46 / 70.50(\mathrm{~d}, \mathrm{C}-5), 71.49 / 71.55(\mathrm{~d}$, C-2'), 73.97/74.05 (t, C-1'), 76.7 (d, C-4), 123.87/123.91 (s, C-2), 159.53/159.58 (s, C-3), 172.3 (s, C-1); HRESIMS $m / z: 301.0883[\mathrm{M}+\mathrm{Na}]^{+}$(calcd for $\mathrm{C}_{11} \mathrm{H}_{18} \mathrm{O}_{8} \mathrm{Na}, 301.0894$ ).

3-O-(2,3-dihydroxypropyl)-2-O-propyl-AsA (3): An amorphous powder; $[\alpha]_{\mathrm{D}}^{26}+41.7$ (c $\left.0.33, \mathrm{MeOH}\right)$; UV [MeOH, nm (log $\varepsilon$ )]: 235 (3.94); IR (ATR) $v_{\max } \mathrm{cm}^{-1}: 3325,2940,2880,1748,1669,1323,1165,1113$, 1040; ${ }^{1} \mathrm{H}-\mathrm{NMR}\left(400 \mathrm{MHz}, \mathrm{CD}_{3} \mathrm{OD}\right): \delta 0.99\left(3 \mathrm{H}, \mathrm{t}, J=7.4 \mathrm{~Hz}, \mathrm{H}_{3}-3^{\prime \prime}\right), 1.72\left(2 \mathrm{H}, \mathrm{m}, \mathrm{H}_{2}-2^{\prime \prime}\right), 3.60(2 \mathrm{H}$, brd, $\left.J=6.0 \mathrm{~Hz}, \mathrm{H}_{2}-3^{\prime}\right), 3.65\left(2 \mathrm{H}\right.$, dd-like, $\left.J=1.4,6.4 \mathrm{~Hz}, \mathrm{H}_{2}-6\right), 3.91\left(2 \mathrm{H}, \mathrm{m}, \mathrm{H}-5,2^{\prime}\right), 3.99(2 \mathrm{H}, \mathrm{m}$, $\left.\mathrm{H}-1^{\prime \prime}\right),\left[4.47 / 4.48(1 \mathrm{H}, \mathrm{dd}, J=6.4,10.5 \mathrm{~Hz}), 4.58 / 4.59(1 \mathrm{H}, \mathrm{dd}, J=4.1,11.0 \mathrm{~Hz}), \mathrm{H}_{2}-1^{\prime}\right], 4.87(1 \mathrm{H}, \mathrm{brs}$, $\mathrm{H}-4) ;{ }^{13} \mathrm{C}-\mathrm{NMR}\left(100 \mathrm{MHz}, \mathrm{CD}_{3} \mathrm{OD}\right): \delta_{\mathrm{C}} 10.7\left(\mathrm{q}, \mathrm{C}-3^{\prime \prime}\right), 24.0\left(\mathrm{t}, \mathrm{C}-2^{\prime \prime}\right), 63.2(\mathrm{t}, \mathrm{C}-6), 63.5\left(\mathrm{t}, \mathrm{C}-3^{\prime}\right), 69.1(\mathrm{t}$, C-1" $\left.{ }^{\prime \prime}\right), 70.49 / 70.53(\mathrm{~d}, \mathrm{C}-5), 71.5 / 71.6\left(\mathrm{~d}, \mathrm{C}-2^{\prime}\right), 74.0 / 74.1\left(\mathrm{t}, \mathrm{C}-1^{\prime}\right), 75.55 / 75.58\left(\mathrm{t}, \mathrm{C}-1^{\prime}\right), 76.7(\mathrm{~d}, \mathrm{C}-4)$, 123.24/123.26 (s, C-2), 159.27/159.30 (s, C-3), 172.3 (s, C-1); HRESIMS m/z: $315.1046[\mathrm{M}+\mathrm{Na}]^{+}$(calcd for $\mathrm{C}_{12} \mathrm{H}_{20} \mathrm{O}_{8} \mathrm{Na}, 315.1050$ ).

2-O-butyl-3-O-(2,3-dihydroxypropyl)-AsA (4): An amorphous powder; $[\alpha]_{\mathrm{D}}^{26}+47.4$ (c 0.34, MeOH); UV [MeOH, nm $(\log \varepsilon)]: 236$ (3.93); IR (TlBr) $v_{\max } \mathrm{cm}^{-1}: 3393,1749,1674,1331,1167,1117,1049 ;{ }^{1} \mathrm{H}-\mathrm{NMR}$ $\left(500 \mathrm{MHz}, \mathrm{CD}_{3} \mathrm{OD}\right): \delta 0.96\left(3 \mathrm{H}, \mathrm{t}, J=7.5 \mathrm{~Hz}, \mathrm{H}_{3}-4^{\prime \prime}\right), 1.45\left(2 \mathrm{H}, \mathrm{m}, \mathrm{H}_{2}-3^{\prime \prime}\right), 1.68\left(2 \mathrm{H}, \mathrm{m}, \mathrm{H}_{2}-2^{\prime \prime}\right), 3.60(2 \mathrm{H}$, brd, $\left.J=5.8 \mathrm{~Hz}, \mathrm{H}_{2}-3^{\prime}\right), 3.65\left(2 \mathrm{H}, \mathrm{m}, \mathrm{H}_{2}-6\right), 3.90(1 \mathrm{H}, \mathrm{m}, \mathrm{H}-5), 3.91(1 \mathrm{H}, \mathrm{m}, \mathrm{H}-8), 4.03\left(1 \mathrm{H}, \mathrm{m}, \mathrm{H}-1^{\prime \prime}\right),[4.47$ $(\mathrm{dd}, J=6.0,10.6 \mathrm{~Hz}) / 4.48(\mathrm{dd}, J=6.3,10.7 \mathrm{~Hz}), 4.57(\mathrm{dd}, J=3.8,10.7 \mathrm{~Hz}) / 4.59(\mathrm{dd}, J=4.0,10.6 \mathrm{~Hz})$, $\left.\mathrm{H}_{2}-1^{\prime}\right],[4.858(\mathrm{~d}, J=1.5 \mathrm{~Hz}) / 4.859(\mathrm{~d}, J=1.5 \mathrm{~Hz}), \mathrm{H}-4] ;{ }^{13} \mathrm{C}-\mathrm{NMR}\left(125 \mathrm{MHz}, \mathrm{CD}_{3} \mathrm{OD}\right): \delta_{\mathrm{C}} 14.1\left(\mathrm{q}, \mathrm{C}-4^{\prime \prime}\right)$, $20.1\left(\mathrm{t}, \mathrm{C}-3^{\prime \prime}\right), 32.9\left(\mathrm{t}, \mathrm{C}-2^{\prime \prime}\right), 63.2(\mathrm{t}, \mathrm{C}-6), 63.56 / 63.59\left(\mathrm{t}, \mathrm{C}-3^{\prime}\right), 70.5 / 70.6(\mathrm{~d}, \mathrm{C}-5), 71.5 / 71.6\left(\mathrm{~d}, \mathrm{C}-2^{\prime}\right)$, $73.69 / 73.72\left(\mathrm{~d}, \mathrm{C}-1^{\prime}\right), 74.0 / 74.1\left(\mathrm{t}, \mathrm{C}-1^{\prime \prime}\right), 76.7(\mathrm{~d}, \mathrm{C}-4), 123.28 / 123.30$ (s, C-2), 159.23/159.25 (s, C-3), 172.2 (s, C-1); HRESIMS $m / z: 329.1203[\mathrm{M}+\mathrm{Na}]^{+}$(calcd for $\mathrm{C}_{13} \mathrm{H}_{22} \mathrm{O}_{8} \mathrm{Na}, 329.1207$ ).

3-O-(2,3-dihydroxypropyl)-2-O-pentyl-AsA (5): An amorphous powder; $[\alpha]_{\mathrm{D}}^{26}+40.9(c 0.32, \mathrm{MeOH})$; $\mathrm{UV}$ [MeOH, nm $(\log \varepsilon)]: 235$ (3.98); IR (ATR) $v_{\max } \mathrm{cm}^{-1}: 3304,2934,2874,1750,1670,1321,1165,1115$, 1032; ${ }^{1} \mathrm{H}-\mathrm{NMR}\left(400 \mathrm{MHz}, \mathrm{CD}_{3} \mathrm{OD}\right): \delta 0.93\left(3 \mathrm{H}, \mathrm{t}, J=6.8 \mathrm{~Hz}, \mathrm{H}_{3}-5^{\prime \prime}\right), 1.39\left(4 \mathrm{H}, \mathrm{m}, \mathrm{H}_{2}-3^{\prime \prime}, 4^{\prime \prime}\right), 1.70(2 \mathrm{H}$, 
$\left.\mathrm{m}, \mathrm{H}_{2}-2^{\prime \prime}\right), 3.60\left(2 \mathrm{H}\right.$, brd, $\left.J=5.5 \mathrm{~Hz}, \mathrm{H}_{2}-3^{\prime}\right), 3.65\left(2 \mathrm{H}\right.$, dd-like, $\left.J=1.4,6.4 \mathrm{~Hz}, \mathrm{H}_{2}-6\right), 3.91(2 \mathrm{H}, \mathrm{m}, \mathrm{H}-5$, $\left.2^{\prime}\right), 4.02\left(1 \mathrm{H}, \mathrm{m}, \mathrm{H}-1^{\prime \prime}\right),[4.47 / 4.48(1 \mathrm{H}, \mathrm{dd}, J=6.4,10.6 \mathrm{~Hz}, J=6.0,10.6 \mathrm{~Hz}), 4.58 / 4.59(1 \mathrm{H}, \mathrm{dd}, J=4.1$, $10.6 \mathrm{~Hz}), \mathrm{H}_{2}-1^{\prime}$ ], $4.86\left(1 \mathrm{H}\right.$, brs, H-4); ${ }^{13} \mathrm{C}-\mathrm{NMR}\left(100 \mathrm{MHz}, \mathrm{CD}_{3} \mathrm{OD}\right): \delta_{\mathrm{C}} 14.4$ (q, C-5 $\left.{ }^{\prime \prime}\right), 23.5\left(\mathrm{t}, \mathrm{C}-4^{\prime \prime}\right)$, $29.1\left(\mathrm{t}, \mathrm{C}-3^{\prime \prime}\right), 30.5\left(\mathrm{t}, \mathrm{C}-2^{\prime \prime}\right), 63.2(\mathrm{t}, \mathrm{C}-6), 63.5 / 63.6\left(\mathrm{t}, \mathrm{C}-3^{\prime}\right), 70.48 / 70.52(\mathrm{~d}, \mathrm{C}-5), 71.5 / 71.6\left(\mathrm{~d}, \mathrm{C}-2^{\prime}\right)$, 74.0/74.1 (t, C-1' $\left.{ }^{\prime} 1^{\prime \prime}\right), 76.7$ (d, C-4), 123.2/123.3 (s, C-2), 159.2/159.3 (s, C-3), 172.3 (s, C-1); HRESIMS $m / z: 343.1357[\mathrm{M}+\mathrm{Na}]^{+}$(calcd for $\mathrm{C}_{14} \mathrm{H}_{24} \mathrm{O}_{8} \mathrm{Na}, 343.1363$ ).

3-O-(2,3-dihydroxypropyl)-2-O-hexyl-AsA (6): An amorphous powder; $[\alpha]_{\mathrm{D}}^{26}+42.2(c 0.32, \mathrm{MeOH})$; UV [MeOH, nm (log $\varepsilon)$ ]: 236 (3.90); IR (TlBr) $v_{\max } \mathrm{cm}^{-1}: 3379,2934,1751,1674,1330,1167,1117,1051$; ${ }^{1} \mathrm{H}-\mathrm{NMR}\left(400 \mathrm{MHz}, \mathrm{CD}_{3} \mathrm{OD}\right): \delta 0.91\left(3 \mathrm{H}, \mathrm{t}, J=6.9 \mathrm{~Hz}, \mathrm{H}_{3}-6^{\prime \prime}\right), 1.33\left(4 \mathrm{H}, \mathrm{m}, \mathrm{H}_{2}-4^{\prime \prime}, 5^{\prime \prime}\right), 1.41(2 \mathrm{H}, \mathrm{m}$, $\left.\mathrm{H}_{2}-3^{\prime \prime}\right), 1.70\left(2 \mathrm{H}, \mathrm{m}, \mathrm{H}_{2}-2^{\prime \prime}\right), 3.60\left(2 \mathrm{H}\right.$, brd, $\left.J=5.5 \mathrm{~Hz}, \mathrm{H}_{2}-3^{\prime}\right), 3.65\left(2 \mathrm{H}\right.$, dd-like, $\left.\mathrm{H}_{2}-6\right), 3.90(2 \mathrm{H}, \mathrm{m}, \mathrm{H}-5$, $\left.2^{\prime}\right), 4.03\left(2 \mathrm{H}, \mathrm{m}, \mathrm{H}-1^{\prime \prime}\right),[4.47 / 4.48(1 \mathrm{H}, \mathrm{dd}, J=6.4,10.6 \mathrm{~Hz} / J=6.0,10.6 \mathrm{~Hz}), 4.57 / 4.59(1 \mathrm{H}, \mathrm{dd}, J=4.1$, $10.7 \mathrm{~Hz}), \mathrm{H}_{2}-1^{\prime}$ ], $4.86\left(1 \mathrm{H}\right.$, brs, H-4); ${ }^{13} \mathrm{C}-\mathrm{NMR}\left(100 \mathrm{MHz}, \mathrm{CD}_{3} \mathrm{OD}\right): \delta_{\mathrm{C}} 14.4$ (q, C-6 $\left.6^{\prime \prime}\right), 23.7$ (t, C-5 $5^{\prime \prime}$ ), $26.6\left(\mathrm{t}, \mathrm{C}-3^{\prime \prime}\right), 30.7\left(\mathrm{t}, \mathrm{C}-2^{\prime \prime}\right), 32.7\left(\mathrm{t}, \mathrm{C}-4^{\prime \prime}\right), 63.2(\mathrm{t}, \mathrm{C}-6), 63.6\left(\mathrm{t}, \mathrm{C}-3^{\prime}\right), 70.5(\mathrm{~d}, \mathrm{C}-5), 71.5 / 71.6\left(\mathrm{~d}, \mathrm{C}-2^{\prime}\right)$, 74.01/74.04/74.09 (t, C-1', 1" ) 76.7 (d, C-4), 123.2/123.3 (s, C-2), 159.2/159.3 (s, C-3), 172.3 (s, C-1); HRESIMS $m / z: 357.1519[\mathrm{M}+\mathrm{Na}]^{+}$(calcd for $\mathrm{C}_{15} \mathrm{H}_{26} \mathrm{O}_{8} \mathrm{Na}$, 357.1520).

3-O-(2,3-dihydroxypropyl)-2-O-heptyl-AsA (7): An amorphous powder; $[\alpha]_{\mathrm{D}}^{26}+29.8(c 0.35, \mathrm{MeOH})$; UV [MeOH, nm (log $\varepsilon$ )]: 236 (3.87); IR (TlBr) $v_{\max } \mathrm{cm}^{-1}: 3389,2932,2507,1751,1674,1331,1169,1119$, $1051 ;{ }^{1} \mathrm{H}-\mathrm{NMR}\left(400 \mathrm{MHz}, \mathrm{CD}_{3} \mathrm{OD}\right): \delta 0.90\left(3 \mathrm{H}, \mathrm{t}, J=6.4 \mathrm{~Hz}, \mathrm{H}_{3}-7^{\prime \prime}\right), 1.34\left(6 \mathrm{H}, \mathrm{m}, \mathrm{H}_{2}-4^{\prime \prime}, 5^{\prime \prime}, 6^{\prime \prime}\right), 1.42(2 \mathrm{H}$, $\left.\mathrm{m}, \mathrm{H}_{2}-3^{\prime \prime}\right), 1.70\left(2 \mathrm{H}, \mathrm{m}, \mathrm{H}_{2}-2^{\prime \prime}\right), 3.60\left(2 \mathrm{H}, \mathrm{brd}, J=5.5 \mathrm{~Hz}, \mathrm{H}_{2}-3^{\prime}\right), 3.65\left(2 \mathrm{H}\right.$, dd-like, $\left.J=1.8,6.4 \mathrm{~Hz}, \mathrm{H}_{2}-6\right)$, $3.90\left(1 \mathrm{H}, \mathrm{m}, \mathrm{H}-5,2^{\prime}\right), 4.04\left(1 \mathrm{H}, \mathrm{m}, \mathrm{H}_{2}-1^{\prime \prime}\right),[4.47(1 \mathrm{H}, \mathrm{dd}, J=6.4,10.6 \mathrm{~Hz}), 4.57 / 4.59(\mathrm{dd}, J=4.1,10.6 \mathrm{~Hz})$, $\mathrm{H}_{2}-1^{\prime}$ ], $4.86(1 \mathrm{H}$, brd, $\left.J=2.3 \mathrm{~Hz}), \mathrm{H}-4\right]$; ${ }^{13} \mathrm{C}-\mathrm{NMR}\left(100 \mathrm{MHz}, \mathrm{CD}_{3} \mathrm{OD}\right): \delta_{\mathrm{C}} 14.4\left(\mathrm{q}, \mathrm{C}-7^{\prime}\right), 23.7\left(\mathrm{t}, \mathrm{C}-6^{\prime}\right)$, 26.9/30.2/30.8/33.0 (t, C-2' $\left.{ }^{\prime}, 3^{\prime}, 4^{\prime}, 5^{\prime}\right), 63.2(\mathrm{t}, \mathrm{C}-6), 63.5 / 63.6\left(\mathrm{t}, \mathrm{C}-3^{\prime}\right), 70.49 / 70.52(\mathrm{~d}, \mathrm{C}-5), 71.52 / 71.59$ (d, C-2'), 74.0/74.1 (t, C-1', $\left.1^{\prime \prime}\right), 76.7$ (d, C-4), 123.2/123.3 (s, C-2), 159.2/159.3 (s, C-3), 172.3 (s, C-1); HRESIMS $m / z: 371.1673[\mathrm{M}+\mathrm{Na}]^{+}$(calcd for $\mathrm{C}_{16} \mathrm{H}_{28} \mathrm{O}_{8} \mathrm{Na}$, 371.1676).

3-O-(2,3-dihydroxypropyl)-2-O-octyl-AsA (8): An amorphous powder; $[\alpha]_{\mathrm{D}}^{26}+32.6(c 0.32, \mathrm{MeOH})$; UV [MeOH, nm (log $\varepsilon)]: 236$ (3.91); IR (KBr) $v_{\max } \mathrm{cm}^{-1}: 3368,2855,1751,1676,1339,1169,1115,1071$; ${ }^{1} \mathrm{H}-\mathrm{NMR}\left(400 \mathrm{MHz}, \mathrm{CD}_{3} \mathrm{OD}\right): \delta 0.90\left(3 \mathrm{H}, \mathrm{t}, J=6.9 \mathrm{~Hz}, \mathrm{H}_{3}-8^{\prime \prime}\right), 1.31\left(10 \mathrm{H}, \mathrm{m}, \mathrm{H}_{2}-4^{\prime \prime}, 5^{\prime \prime}, 6^{\prime \prime}, 7^{\prime \prime}\right), 1.42(2 \mathrm{H}$, $\left.\mathrm{m}, \mathrm{H}_{2}-3^{\prime \prime}\right), 1.70\left(2 \mathrm{H}, \mathrm{m}, \mathrm{H}_{2}-2^{\prime \prime}\right), 3.59\left(2 \mathrm{H}\right.$, brd, $\left.J=6.0 \mathrm{~Hz}, \mathrm{H}_{2}-3^{\prime}\right), 3.65(2 \mathrm{H}$, dd-like, $J=1.8,6.4 \mathrm{~Hz}$, $\left.\mathrm{H}_{2}-6\right), 3.90\left(2 \mathrm{H}, \mathrm{m}, \mathrm{H}-5,2^{\prime}\right), 4.03\left(1 \mathrm{H}, \mathrm{m}, \mathrm{H}_{2}-1^{\prime \prime}\right)$, [4.47/4.48 (1H, dd, J = 6.4, 10.6 Hz), 4.58/4.59 (1H, $\left.\mathrm{dd}, J=4.6,10.6 \mathrm{~Hz} / J=4.1,10.6 \mathrm{~Hz}), \mathrm{H}_{2}-1^{\prime}\right], 4.86(\mathrm{~d}, J=1.8 \mathrm{~Hz}, \mathrm{H}-4) ;{ }^{13} \mathrm{C}-\mathrm{NMR}\left(100 \mathrm{MHz}, \mathrm{CD}_{3} \mathrm{OD}\right)$ : $\delta_{\mathrm{C}} 14.5\left(\mathrm{q}, \mathrm{C}-8^{\prime \prime}\right), 23.7\left(\mathrm{t}, \mathrm{C}-7^{\prime \prime}\right), 27.0 / 30.4 / 30.5 / 30.8 / 33.0\left(\mathrm{t}, \mathrm{C}-2^{\prime}, 3^{\prime}, 4^{\prime}, 5^{\prime}, 6^{\prime}\right), 63.2(\mathrm{t}, \mathrm{C}-6), 63.51 / 63.55$ $\left(\mathrm{t}, \mathrm{C}-3^{\prime}\right), 70.49 / 70.52(\mathrm{~d}, \mathrm{C}-5), 71.52 / 71.59\left(\mathrm{~d}, \mathrm{C}-2^{\prime}\right), 74.02 / 74.09\left(\mathrm{t}, \mathrm{C}-1^{\prime}, 1^{\prime \prime}\right), 76.7(\mathrm{~d}, \mathrm{C}-4), 123.2 / 123.3(\mathrm{~s}$, C-2), 159.26/159.29 (s, C-3), 172.3 (s, C-1); HRESIMS m/z: $385.1829\left[\mathrm{M}+\mathrm{Na}^{+}\right.$(calcd for $\mathrm{C}_{17} \mathrm{H}_{30} \mathrm{O}_{8} \mathrm{Na}$, 385.1833).

3-O-(2,3-dihydroxypropyl)-2-O-nonyl-AsA (9): An amorphous powder; $[\alpha]_{\mathrm{D}}^{26}+33.3(c 0.31, \mathrm{MeOH})$; UV [MeOH, nm (log $\varepsilon$ )]: 236 (3.93); IR (KBr) $v_{\max } \mathrm{cm}^{-1}: 3327,2924,2853,1761,1684,1333,1169,1117$, 1046; ${ }^{1} \mathrm{H}-\mathrm{NMR}\left(400 \mathrm{MHz}, \mathrm{CD}_{3} \mathrm{OD}\right): \delta 0.89\left(3 \mathrm{H}, \mathrm{t}, J=6.8 \mathrm{~Hz}, \mathrm{H}-9^{\prime \prime}\right), 1.30\left(10 \mathrm{H}, \mathrm{m}, \mathrm{H}_{2}-4^{\prime \prime}, 5^{\prime \prime}, 6^{\prime \prime}, 7^{\prime \prime}, 8^{\prime \prime}\right)$, $1.42\left(2 \mathrm{H}, \mathrm{m}, \mathrm{H}_{2}-3^{\prime \prime}\right), 1.70\left(2 \mathrm{H}, \mathrm{m}, \mathrm{H}_{2}-2^{\prime \prime}\right), 3.60\left(2 \mathrm{H}, \mathrm{brd}, J=5.5 \mathrm{~Hz}, \mathrm{H}_{2}-3^{\prime}\right), 3.65(2 \mathrm{H}$, dd-like, $J=1.4$, $\left.6.4 \mathrm{~Hz}, \mathrm{H}_{2}-6\right), 3.91\left(2 \mathrm{H}, \mathrm{m}, \mathrm{H}-5,2^{\prime}\right), 4.03\left(1 \mathrm{H}, \mathrm{m}, \mathrm{H}_{2}-1^{\prime}\right),[4.47 / 4.48(1 \mathrm{H}, \mathrm{dd}, J=6.4,10.6 \mathrm{~Hz}), 4.58 / 4.59$ $\left.(1 \mathrm{H}, \mathrm{dd}, J=4.6,10.6 \mathrm{~Hz}, J=4.1,10.6 \mathrm{~Hz}), \mathrm{H}_{2}-1^{\prime}\right], 4.86(\mathrm{~d}, J=0.9 \mathrm{~Hz}, \mathrm{H}-4) ;{ }^{13} \mathrm{C}-\mathrm{NMR}\left(100 \mathrm{MHz}, \mathrm{CD}_{3} \mathrm{OD}\right)$ ; $\delta_{\mathrm{C}} 14.5\left(\mathrm{q}, \mathrm{C}-9^{\prime \prime}\right), 23.7\left(\mathrm{t}, \mathrm{C}-8^{\prime \prime}\right), 27.0 / 30.4 / 30.5 / 30.7 / 30.8 / 33.1\left(\mathrm{t}, \mathrm{C}-2^{\prime \prime}, 3^{\prime \prime}, 4^{\prime \prime}, 5^{\prime \prime}, 6^{\prime \prime}, 7^{\prime \prime}\right), 63.2(\mathrm{t}, \mathrm{C}-6)$, 63.5/63.6 (t, C-3'), 70.48/70.52 (d, C-5), 71.5/71.6 (d, C-2'), 74.01/74.05/74.09 (t, C-1', $\left.1^{\prime \prime}\right), 76.7$ (d, C-4), 123.2/123.3 (s, C-2), 159.2/159.3 (s, C-3), 172.3 (s, C-1); HRESIMS m/z: 399.1988 [M + Na] ${ }^{+}$(calcd for $\mathrm{C}_{18} \mathrm{H}_{32} \mathrm{O}_{8} \mathrm{Na}$, 399.1989).

2-O-decyl-3-O-(2,3-dihydroxypropyl)-AsA (10): An amorphous powder; $[\alpha]_{\mathrm{D}}^{26}+31.4($ c $0.30, \mathrm{MeOH})$; UV [MeOH, nm (log $\varepsilon)]: 236$ (3.88); IR (KBr) $v_{\max } \mathrm{cm}^{-1}: 3317,2959,2922,2924,2849,1759,1682,1331$, 1165, 1113, 1043; ${ }^{1} \mathrm{H}-\mathrm{NMR}\left(600 \mathrm{MHz}, \mathrm{CD}_{3} \mathrm{OD}\right): \delta 0.89$ (3H, t, $\left.J=7.2 \mathrm{~Hz}, \mathrm{H}_{3}-10^{\prime \prime}\right), 1.30\left(12 \mathrm{H}, \mathrm{brs}, \mathrm{H}_{2}-4^{\prime \prime}\right.$, $\left.5^{\prime \prime}, 6^{\prime \prime}, 7^{\prime \prime}, 8^{\prime \prime}, 9^{\prime \prime}\right), 1.41\left(2 \mathrm{H}, \mathrm{m}, \mathrm{H}_{2}-3^{\prime \prime}\right), 1.69\left(2 \mathrm{H}, \mathrm{m}, \mathrm{H}_{2}-2^{\prime \prime}\right), 3.60\left(2 \mathrm{H}, \mathrm{brd}, \mathrm{J}=5.6 \mathrm{~Hz}, \mathrm{H}_{2}-3^{\prime}\right), 3.65(2 \mathrm{H}, \mathrm{m}$, 
$\left.\mathrm{H}_{2}-6\right), 3.90(1 \mathrm{H}, \mathrm{m}, \mathrm{H}-5), 3.91\left(1 \mathrm{H}, \mathrm{m}, \mathrm{H}-2^{\prime}\right), 4.02\left(1 \mathrm{H}, \mathrm{m}, \mathrm{H}_{2}-1^{\prime \prime}\right),[4.47(\mathrm{dd}, J=6.1,10.7 \mathrm{~Hz}) / 4.48(\mathrm{dd}$, $\left.J=6.2,10.7 \mathrm{~Hz}), 4.57(\mathrm{dd}, J=3.8,10.7 \mathrm{~Hz}) / 4.59(\mathrm{dd}, J=3.9,10.7 \mathrm{~Hz}), \mathrm{H}_{2}-1^{\prime}\right],[4.860(\mathrm{~d}, J=1.1 \mathrm{~Hz}) / 4.862$ $(\mathrm{d}, J=1.5 \mathrm{~Hz}), \mathrm{H}-4):{ }^{13} \mathrm{C}-\mathrm{NMR}\left(150 \mathrm{MHz}, \mathrm{CD}_{3} \mathrm{OD}\right) ; \delta_{\mathrm{C}} 14.4\left(\mathrm{q}, \mathrm{C}-10^{\prime \prime}\right), 23.7\left(\mathrm{t}, \mathrm{C}-9^{\prime \prime}\right), 26.9\left(\mathrm{t}, \mathrm{C}-3^{\prime \prime}\right)$, $30.48\left(\mathrm{t}, \mathrm{C}-2^{\prime \prime}\right), 30.44 / 30.48 / 30.7 / 30.8\left(\mathrm{t}, \mathrm{C}-4^{\prime \prime}, 5^{\prime \prime}, 6^{\prime \prime}, 7^{\prime \prime}\right), 33.1\left(\mathrm{t}, \mathrm{C}-8^{\prime \prime}\right), 63.2(\mathrm{t}, \mathrm{C}-6), 63.5 / 63.6\left(\mathrm{t}, \mathrm{C}-3^{\prime}\right)$, 70.5/70.6 (d, C-5), 71.5/71.6 (d, C-2'), 74.02/74.05 (t, C-1'), 74.11 (t, C-1") $) 76.7(\mathrm{~d}, \mathrm{C}-4), 123.26 / 123.29$ (s, C-2), 159.24/159.27 (s, C-3), 172.2 (s, C-1); HRESIMS m/z: $413.2145[\mathrm{M}+\mathrm{Na}]^{+}$(calcd for $\mathrm{C}_{9}{ }_{9} \mathrm{H}_{34} \mathrm{O}_{8} \mathrm{Na}$, 413.2146).

3-O-(2,3-dihydroxypropyl)-2-O-undecyl-AsA (11): An amorphous powder; $[\alpha]_{\mathrm{D}}^{26}+34.7(c 0.34, \mathrm{MeOH})$; $\mathrm{UV}[\mathrm{MeOH}, \mathrm{nm}(\log \varepsilon)]: 236$ (3.88); IR (KBr) $v_{\max } \mathrm{cm}^{-1}: 3300,2916,2851,1761,1684,1329,1171,1119$, 1063, 1030; ${ }^{1} \mathrm{H}-\mathrm{NMR}\left(600 \mathrm{MHz}, \mathrm{CD}_{3} \mathrm{OD}\right): \delta 0.89\left(3 \mathrm{H}, \mathrm{t}, J=6.9 \mathrm{~Hz}, \mathrm{H}_{3}-11^{\prime \prime}\right), 1.29\left(14 \mathrm{H}, \mathrm{brs}, \mathrm{H}_{2}-4^{\prime \prime}, 5^{\prime \prime}, 6^{\prime \prime}\right.$, $\left.7^{\prime \prime}, 8^{\prime \prime}, 9^{\prime \prime}, 10^{\prime \prime}\right), 1.41\left(2 \mathrm{H}, \mathrm{m}, \mathrm{H}_{2}-3^{\prime \prime}\right), 1.70\left(2 \mathrm{H}, \mathrm{m}, \mathrm{H}_{2}-2^{\prime \prime}\right), 3.60\left(2 \mathrm{H}, \mathrm{brd}, J=5.8 \mathrm{~Hz}, \mathrm{H}_{2}-3^{\prime \prime}\right), 3.65(2 \mathrm{H}, \mathrm{m}$, $\left.\mathrm{H}_{2}-6\right), 3.90(1 \mathrm{H}, \mathrm{m}, \mathrm{H}-5), 3.91\left(1 \mathrm{H}, \mathrm{m}, \mathrm{H}-2^{\prime}\right), 4.02\left(1 \mathrm{H}, \mathrm{m}, \mathrm{H}_{2}-1^{\prime \prime}\right),[4.47(\mathrm{dd}, J=6.3,10.6 \mathrm{~Hz}) / 4.48$ (dd, $\left.J=6.3,10.6 \mathrm{~Hz}), 4.57(\mathrm{dd}, J=4.0,10.6 \mathrm{~Hz}) / 4.59(\mathrm{dd}, J=4.0,10.6 \mathrm{~Hz}), \mathrm{H}_{2}-1^{\prime}\right],[4.860(\mathrm{~d}, J=1.8 \mathrm{~Hz}) / 4.861$ $(\mathrm{d}, J=1.8 \mathrm{~Hz}), \mathrm{H}-4):{ }^{13} \mathrm{C}-\mathrm{NMR}\left(150 \mathrm{MHz}, \mathrm{CD}_{3} \mathrm{OD}\right) ; \delta_{\mathrm{C}} 14.4\left(\mathrm{q}, \mathrm{C}-11^{\prime \prime}\right), 23.7\left(\mathrm{t}, \mathrm{C}-10^{\prime \prime}\right), 26.9\left(\mathrm{t}, \mathrm{C}-3^{\prime \prime}\right), 30.70$ $\left(\mathrm{t}, \mathrm{C}-2^{\prime \prime}\right), 30.47 / 30.49 / 30.70 / 30.74 / 30.8\left(\mathrm{t}, \mathrm{C}-4^{\prime \prime}, 5^{\prime \prime}, 6^{\prime \prime}, 7^{\prime \prime}, 8^{\prime \prime}\right), 33.1\left(\mathrm{t}, \mathrm{C}-9^{\prime \prime}\right), 63.2(\mathrm{t}, \mathrm{C}-6), 63.5 / 63.6$ $\left(\mathrm{t}, \mathrm{C}-3^{\prime}\right), 70.5 / 70.6(\mathrm{~d}, \mathrm{C}-5), 71.5 / 71.6\left(\mathrm{~d}, \mathrm{C}-2^{\prime}\right), 74.02 / 74.05\left(\mathrm{t}, \mathrm{C}-1^{\prime}\right), 74.11\left(\mathrm{t}, \mathrm{C}-1^{\prime \prime}\right), 76.7(\mathrm{~d}, \mathrm{C}-4)$, 123.27/123.29 (s, C-2), 159.2/159.3 (s, C-3), 172.4 (s, C-1); HRESIMS m/z: 427.2299 [M + Na] ${ }^{+}$(calcd for $\mathrm{C}_{20} \mathrm{H}_{36} \mathrm{O}_{8} \mathrm{Na}$, 427.2302).

3-O-(2,3-dihydroxypropyl)-2-O-dodecyl-AsA (12): An amorphous powder; $[\alpha]_{\mathrm{D}}^{26}+38.4(c 0.31, \mathrm{MeOH})$; UV [MeOH, nm $(\log \varepsilon)]: 236$ (3.86); IR (KBr) $v_{\max } \mathrm{cm}^{-1}: 3422,2918,2851,1749,1676,1319,1115,1070$; ${ }^{1} \mathrm{H}-\mathrm{NMR}\left(500 \mathrm{MHz}, \mathrm{CD}_{3} \mathrm{OD}\right): \delta 0.89\left(3 \mathrm{H}, \mathrm{t}, J=6.6 \mathrm{~Hz}, \mathrm{H}_{3}-12^{\prime \prime}\right), 1.29\left(16 \mathrm{H}, \mathrm{brs}, \mathrm{H}_{2}-4^{\prime \prime}, 5^{\prime \prime}, 6^{\prime \prime}, 7^{\prime \prime}, 8^{\prime \prime}, 9^{\prime \prime}\right.$, $\left.10^{\prime \prime}, 11^{\prime \prime}\right), 1.41\left(2 \mathrm{H}, \mathrm{m}, \mathrm{H}_{2}-3^{\prime \prime}\right), 1.70\left(2 \mathrm{H}, \mathrm{m}, \mathrm{H}_{2}-2^{\prime \prime}\right), 3.60\left(2 \mathrm{H}\right.$, brd, $\left.J=5.7 \mathrm{~Hz}, \mathrm{H}_{2}-3^{\prime}\right), 3.65\left(2 \mathrm{H}, \mathrm{m}, \mathrm{H}_{2}-6\right)$, $3.90(1 \mathrm{H}, \mathrm{m}, \mathrm{H}-5), 3.91\left(1 \mathrm{H}, \mathrm{m}, \mathrm{H}-2^{\prime}\right), 4.02\left(1 \mathrm{H}, \mathrm{m}, \mathrm{H}_{2}-1^{\prime \prime}\right),[4.47(\mathrm{dd}, J=6.4,10.7 \mathrm{~Hz}) / 4.48(\mathrm{dd}, J=6.4$, $\left.10.7 \mathrm{~Hz}), 4.57(\mathrm{dd}, J=4.0,10.7 \mathrm{~Hz}) / 4.59(\mathrm{dd}, J=4.0,10.7 \mathrm{~Hz}), \mathrm{H}_{2}-7\right], 4.86\left(1 \mathrm{H}, \mathrm{m}, J=6.6 \mathrm{~Hz}, \mathrm{H}-2^{\prime}\right)$ : ${ }^{13} \mathrm{C}-\mathrm{NMR}\left(125 \mathrm{MHz}, \mathrm{CD}_{3} \mathrm{OD}\right) ; \delta_{\mathrm{C}} 14.4\left(\mathrm{q}, \mathrm{C}-12^{\prime \prime}\right), 23.7\left(\mathrm{t}, \mathrm{C}-11^{\prime \prime}\right), 27.0\left(\mathrm{t}, \mathrm{C}-3^{\prime \prime}\right), 30.5\left(\mathrm{t}, \mathrm{C}-4^{\prime \prime}\right), 30.76(\mathrm{t}$, $\left.\mathrm{C}-2^{\prime \prime}\right), 30.72 / 30.76 / 30.79 / 30.81\left(\mathrm{t}, \mathrm{C}-5^{\prime \prime}, 6^{\prime \prime}, 7^{\prime \prime}, 8^{\prime \prime}, 9^{\prime \prime}, 10^{\prime \prime}\right), 33.1\left(\mathrm{t}, \mathrm{C}-10^{\prime \prime}\right), 63.2(\mathrm{t}, \mathrm{C}-6), 63.56 / 63.58(\mathrm{t}$, C-3'), 70.5/70.6 (d, C-5), 71.5/71.6 (d, C-2'), $74.0(\mathrm{t}, \mathrm{C}-7), 74.1$ (t, C-1"'), 76.7 (d, C-4), 123.27/123.29 (s, C-2), 159.2/159.3 (s, C-3), 172.2 (s, C-1); HRESIMS $m / z: 441.2457[\mathrm{M}+\mathrm{Na}]^{+}$(calcd for $\mathrm{C}_{21} \mathrm{H}_{38} \mathrm{O}_{8} \mathrm{Na}$, 441.2459).

3-O-(2,3-dihydroxypropyl)-2-O-tridecyl-AsA (13): An amorphous powder; $[\alpha]_{\mathrm{D}}^{26}+35.8(c 0.30, \mathrm{MeOH})$; $\mathrm{UV}$ [MeOH, nm $(\log \varepsilon)]: 231$ (4.02); IR (KBr) $v_{\max } \mathrm{cm}^{-1}: 3289,2916,2849,1761,1684,1329,1119,1171$, 1119, 1063, 1030; ${ }^{1} \mathrm{H}-\mathrm{NMR}\left(500 \mathrm{MHz}, \mathrm{CD}_{3} \mathrm{OD}\right): \delta 0.89\left(3 \mathrm{H}, \mathrm{t}, J=6.9 \mathrm{~Hz}, \mathrm{H}_{3}-13^{\prime \prime}\right), 1.28\left(18 \mathrm{H}, \mathrm{brs}, \mathrm{H}_{2}-4^{\prime \prime}\right.$, $\left.5^{\prime \prime}, 6^{\prime \prime}, 7^{\prime \prime}, 8^{\prime \prime}, 9^{\prime \prime}, 10^{\prime \prime}, 11^{\prime \prime}, 12^{\prime \prime}\right), 1.41\left(2 \mathrm{H}, \mathrm{m}, \mathrm{H}_{2}-3^{\prime \prime}\right), 1.70\left(2 \mathrm{H}, \mathrm{m}, \mathrm{H}_{2}-2^{\prime \prime}\right), 3.60(2 \mathrm{H}, \mathrm{brd}, J=5.8 \mathrm{~Hz}$, $\left.\mathrm{H}_{2}-3^{\prime}\right), 3.65\left(2 \mathrm{H}, \mathrm{m}, \mathrm{H}_{2}-6\right), 3.90(1 \mathrm{H}, \mathrm{m}, \mathrm{H}-5), 3.91\left(1 \mathrm{H}, \mathrm{m}, \mathrm{H}-2^{\prime}\right), 4.02\left(1 \mathrm{H}, \mathrm{m}, \mathrm{H}_{2}-1^{\prime \prime}\right),[4.47(\mathrm{dd}, J=6.3$, $\left.10.7 \mathrm{~Hz}) / 4.48(\mathrm{dd}, J=6.3,10.7 \mathrm{~Hz}), 4.57(\mathrm{dd}, J=4.0,10.7 \mathrm{~Hz}) / 4.59(\mathrm{dd}, J=4.0,10.7 \mathrm{~Hz}), \mathrm{H}_{2}-1^{\prime}\right],[4.859$ $(\mathrm{d}, J=1.8 \mathrm{~Hz}) / 4.861(\mathrm{~d}, J=1.8 \mathrm{~Hz}), \mathrm{H}-4]:{ }^{13} \mathrm{C}-\mathrm{NMR}\left(125 \mathrm{MHz}, \mathrm{CD}_{3} \mathrm{OD}\right) ; \delta_{\mathrm{C}} 14.4\left(\mathrm{q}, \mathrm{C}-13^{\prime \prime}\right), 23.7(\mathrm{t}$, $\left.\mathrm{C}-12^{\prime \prime}\right), 27.0\left(\mathrm{t}, \mathrm{C}-3^{\prime \prime}\right), 30.81\left(\mathrm{t}, \mathrm{C}-2^{\prime \prime}\right), 30.48 / 30.50 / 30.71 / 30.78 / 30.81\left(\mathrm{t}, \mathrm{C}-4^{\prime \prime}, 5^{\prime \prime}, 6^{\prime \prime}, 7^{\prime \prime}, 8^{\prime \prime}, 9^{\prime \prime}, 10^{\prime \prime}, 11^{\prime \prime}\right)$, $33.1\left(\mathrm{t}, \mathrm{C}-12^{\prime \prime}\right), 63.2(\mathrm{t}, \mathrm{C}-6), 63.56 / 63.58\left(\mathrm{t}, \mathrm{C}-3^{\prime}\right), 70.5 / 70.6(\mathrm{~d}, \mathrm{C}-5), 71.5 / 71.6\left(\mathrm{~d}, \mathrm{C}-2^{\prime}\right), 74.0\left(\mathrm{t}, \mathrm{C}-1^{\prime}\right)$, $74.1\left(\mathrm{t}, \mathrm{C}-1^{\prime \prime}\right), 76.7$ (d, C-4), 123.27/123.29 (s, C-2), 159.2/159.3 (s, C-3), 172.2 (s, C-1); HRESIMS $m / z$ : $455.2612[\mathrm{M}+\mathrm{Na}]^{+}$(calcd for $\left.\mathrm{C}_{22} \mathrm{H}_{40} \mathrm{O}_{8} \mathrm{Na}, 455.2615\right)$.

3-O-(2,3-dihydroxypropyl)-2-O-tetradecyl-AsA (14): An amorphous powder; $[\alpha]_{\mathrm{D}}^{26}+24.4$ (c 0.31 , $\mathrm{MeOH}) ; \mathrm{UV}$ [MeOH, nm (log $\varepsilon)$ ]: 230 (3.99); IR (KBr) $v_{\max } \mathrm{cm}^{-1}: 3326,2920,2849,1759,1680,1466,1329$, 1165, 1115, 1034; ${ }^{1} \mathrm{H}-\mathrm{NMR}\left(500 \mathrm{MHz}, \mathrm{CD}_{3} \mathrm{OD}\right): \delta 0.89\left(3 \mathrm{H}, \mathrm{t}, J=7.2 \mathrm{~Hz}, \mathrm{H}_{3}-14^{\prime \prime}\right), 1.28\left(20 \mathrm{H}, \mathrm{brs}, \mathrm{H}_{2}-4^{\prime \prime}\right.$, $\left.5^{\prime \prime}, 6^{\prime \prime}, 7^{\prime \prime}, 8^{\prime \prime}, 9^{\prime \prime}, 10^{\prime \prime}, 11^{\prime \prime}, 12^{\prime \prime}, 13^{\prime \prime}\right), 1.41\left(2 \mathrm{H}, \mathrm{m}, \mathrm{H}_{2}-3^{\prime \prime}\right), 1.70\left(2 \mathrm{H}, \mathrm{m}, \mathrm{H}_{2}-2^{\prime \prime}\right), 3.60(2 \mathrm{H}$, brd, $J=5.8 \mathrm{~Hz}$, $\left.\mathrm{H}_{2}-3^{\prime}\right), 3.65\left(2 \mathrm{H}, \mathrm{m}, \mathrm{H}_{2}-6\right), 3.90(1 \mathrm{H}, \mathrm{m}, \mathrm{H}-5), 3.91\left(1 \mathrm{H}, \mathrm{m}, \mathrm{H}-2^{\prime}\right), 4.02\left(1 \mathrm{H}, \mathrm{m}, \mathrm{H}_{2}-1^{\prime \prime}\right),[4.47(\mathrm{dd}, J=6.4$, $\left.10.7 \mathrm{~Hz}) / 4.48(\mathrm{dd}, J=6.4,10.7 \mathrm{~Hz}), 4.57(\mathrm{dd}, J=3.8,10.7 \mathrm{~Hz}) / 4.59(\mathrm{dd}, J=3.8,10.7 \mathrm{~Hz}), \mathrm{H}_{2}-1^{\prime}\right],[4.858$ $(\mathrm{d}, J=1.5 \mathrm{~Hz}) / 4.860(\mathrm{~d}, J=1.5 \mathrm{~Hz}), \mathrm{H}-4]:{ }^{13} \mathrm{C}-\mathrm{NMR}\left(125 \mathrm{MHz}, \mathrm{CD}_{3} \mathrm{OD}\right) ; \delta_{\mathrm{C}} 14.4\left(\mathrm{q}, \mathrm{C}-14^{\prime \prime}\right), 23.7$ (t, $\left.\mathrm{C}-13^{\prime \prime}\right), 27.0\left(\mathrm{t}, \mathrm{C}-3^{\prime \prime}\right), 30.80\left(\mathrm{t}, \mathrm{C}-2^{\prime \prime}\right), 30.48 / 30.51 / 30.72 / 30.76 / 30.80\left(\mathrm{t}, \mathrm{C}-4^{\prime \prime}, 5^{\prime \prime}, 6^{\prime \prime}, 7^{\prime \prime}, 8^{\prime \prime}, 9^{\prime \prime}, 10^{\prime \prime}, 11^{\prime \prime}\right)$, 
$33.1\left(\mathrm{t}, \mathrm{C}-12^{\prime \prime}\right), 63.2(\mathrm{t}, \mathrm{C}-6), 63.56 / 63.59\left(\mathrm{t}, \mathrm{C}-3^{\prime}\right), 70.5 / 70.6(\mathrm{~d}, \mathrm{C}-5), 71.5 / 71.6\left(\mathrm{~d}, \mathrm{C}-2^{\prime}\right), 74.0\left(\mathrm{t}, \mathrm{C}-1^{\prime}\right)$, $74.1\left(\mathrm{t}, \mathrm{C}-\mathrm{1}^{\prime \prime}\right), 76.7$ (d, C-4), 123.27/123.30 (s, C-2), 159.23/159.25 (s, C-3), 172.2 (s, C-1); HRESIMS m/z: $469.2769[\mathrm{M}+\mathrm{Na}]^{+}$(calcd for $\mathrm{C}_{23} \mathrm{H}_{42} \mathrm{O}_{8} \mathrm{Na}, 469.2772$ ).

2-O-(2,3-dihydroxypropyl)-AsA (15): Colorless needles, mp.153.0-153.2; $[\alpha]_{\mathrm{D}}^{26}+55.7(c 0.31, \mathrm{MeOH})$; $\mathrm{UV}$ [MeOH, nm (log $\varepsilon$ )]: 238 (3.89); IR (KBr) $v_{\max } \mathrm{cm}^{-1}: 3326,2920,2849,1759,1680,1466,1329,1165$, 1115, 1034; ${ }^{1} \mathrm{H}-\mathrm{NMR}\left(400 \mathrm{MHz}, \mathrm{CD}_{3} \mathrm{OD}\right): \delta 3.61\left(2 \mathrm{H}, \mathrm{m}, \mathrm{H}_{2}-3^{\prime}\right), 3.67(2 \mathrm{H}, \mathrm{m})\left(2 \mathrm{H}, \mathrm{m}, \mathrm{H}_{2}-6\right), 3.90(1 \mathrm{H}$, m, H-2'), $3.92\left(1 \mathrm{H}, \mathrm{dt}-\mathrm{like}, J=1.8,6.4 \mathrm{~Hz}, \mathrm{H}_{3}-5\right),[4.07(1 \mathrm{H}, \mathrm{dd}, J=4.1,10.4 \mathrm{~Hz}) / 4.09(1 \mathrm{H}, \mathrm{d}, J=3.6$, $\left.10.4 \mathrm{~Hz}), \mathrm{H}-1^{\prime}\right], 4.86(1 \mathrm{H}, \mathrm{d}, J=1.8 \mathrm{~Hz}, \mathrm{H}-4):{ }^{13} \mathrm{C}-\mathrm{NMR}\left(100 \mathrm{MHz}, \mathrm{CD}_{3} \mathrm{OD}\right) ; \delta_{\mathrm{C}} 63.3(\mathrm{t}, \mathrm{C}-6), 63.7(\mathrm{t}$, C-3'), $70.4(\mathrm{~d}, \mathrm{C}-5), 72.0\left(\mathrm{~d}, \mathrm{C}-2^{\prime}\right), 74.6\left(\mathrm{t}, \mathrm{C}-\mathrm{1}^{\prime}\right), 76.8\left(\mathrm{t}, \mathrm{C}-4^{\prime}\right), 122.2(\mathrm{~s}, \mathrm{C}-2), 161.6(\mathrm{~s}, \mathrm{C}-3), 172.9(\mathrm{~s}, \mathrm{C}-1)$; HRESIMS $m / z: 273.0576[\mathrm{M}+\mathrm{Na}]^{+}$(calcd for $\mathrm{C}_{9} \mathrm{H}_{14} \mathrm{O}_{8} \mathrm{Na}, 273.0581$ ).

2-O-(2,3-dihydroxypropyl)-3-O-ethyl-AsA (16): Pale yellow oil; $[\alpha]_{\mathrm{D}}^{26}+34.3$ ( c 0.33, MeOH); UV [MeOH, $\mathrm{nm}(\log \varepsilon)]: 236$ (3.86); IR (ATR) $v_{\max } \mathrm{cm}^{-1}: 3337,2938,2881,1744,1665,1325,1173,1109,1038 ;{ }^{1} \mathrm{H}-\mathrm{NMR}$ $\left(400 \mathrm{MHz}, \mathrm{CD}_{3} \mathrm{OD}\right): \delta 1.38\left(3 \mathrm{H}, \mathrm{t}, J=6.8 \mathrm{~Hz}, \mathrm{H}_{3}-2^{\prime \prime}\right), 3.58\left(2 \mathrm{H}, \mathrm{m}, \mathrm{H}_{2}-3^{\prime}\right) 3.64(2 \mathrm{H}$, dd-like, $J=1.4,6.4 \mathrm{~Hz}$, $\left.\mathrm{H}_{2}-6\right), 3.87\left(2 \mathrm{H}, \mathrm{m}, \mathrm{H}-5,2^{\prime}\right)$, [3.97 (1H, m), $4.13(1 \mathrm{H}, \mathrm{m}), 4.68\left(2 \mathrm{H}, \mathrm{m}, \mathrm{H}_{2}-1^{\prime \prime}\right), 4.83(\mathrm{~d}, J=0.9 \mathrm{~Hz}, \mathrm{H}-4)$ : 13C-NMR (100 MHz, CD3OD) ; $\delta_{\mathrm{C}} 15.5\left(\mathrm{q}, \mathrm{C}-2^{\prime \prime}\right), 63.3(\mathrm{t}, \mathrm{C}-6), 63.98 / 63.48\left(\mathrm{t}, \mathrm{C}-3^{\prime}\right), 69.6\left(\mathrm{t}, \mathrm{C}-1^{\prime \prime}\right), 70.6$ (d, C-5), 72.0 (d, C-2') , 75.19/75.23 (t, C-1'), 76.7 (d, C-4), 122.60/122.62 (s, C-2), 159.7 (s, C-3), 175.6 (s, C-1); HRESIMS $m / z: 301.0887$ [M + Na] ${ }^{+}$(calcd for $\mathrm{C}_{11} \mathrm{H}_{18} \mathrm{O}_{8} \mathrm{Na}, 301.0894$ ).

2-O-(2,3-dihydroxypropyl)-3-O-propyl-AsA (17): Pale yellow oil; $[\alpha]_{\mathrm{D}}^{26}+49.8$ (c 0.31, MeOH); UV [MeOH, nm (log $\varepsilon$ )]: 237 (3.94); IR (ATR) $v_{\max } \mathrm{cm}^{-1}: 3339,2938,2882,1744,1665,1327,1173,1040$; ${ }^{1} \mathrm{H}-\mathrm{NMR}\left(400 \mathrm{MHz}, \mathrm{CD}_{3} \mathrm{OD}\right): \delta 1.01\left(3 \mathrm{H}, \mathrm{t}, J=7.3 \mathrm{~Hz}, \mathrm{H}_{3}-3^{\prime \prime}\right), 1.78\left(2 \mathrm{H}, \mathrm{m}, \mathrm{H}_{2}-2^{\prime \prime}\right), 3.58\left(2 \mathrm{H}, \mathrm{m}, \mathrm{H}_{2}-3^{\prime}\right)$, $3.64\left(2 \mathrm{H}\right.$, dd-like, $\left.J=0.9,6.4 \mathrm{~Hz}, \mathrm{H}_{2}-6\right), 3.87\left(2 \mathrm{H}, \mathrm{m}, \mathrm{H}-5,2^{\prime}\right)$, [3.96/3.97 (1H, dd, $\left.J=6.4,10.1 \mathrm{~Hz}\right)$, $\left.4.11 / 4.13(1 \mathrm{H}, \mathrm{dd}, J=4.1,10.1 \mathrm{~Hz}), \mathrm{H}_{2}-1^{\prime}\right], 4.50\left(2 \mathrm{H}, \mathrm{m}, \mathrm{H}_{2}-1^{\prime \prime}\right), 4.83(1 \mathrm{H}, \mathrm{d}, J=1.4 \mathrm{~Hz}, \mathrm{H}-4):{ }^{13} \mathrm{C}-\mathrm{NMR}$ $\left(100 \mathrm{MHz}, \mathrm{CD}_{3} \mathrm{OD}\right) ; \delta_{\mathrm{C}} 10.3\left(\mathrm{q}, \mathrm{C}-3^{\prime \prime}\right), 23.9\left(\mathrm{t}, \mathrm{C}-2^{\prime \prime}\right), 63.3(\mathrm{t}, \mathrm{C}-6), 64.0\left(\mathrm{t}, \mathrm{C}-3^{\prime}\right), 70.6(\mathrm{~d}, \mathrm{C}-5), 72.0$ (d, C-2'), $75.1\left(\mathrm{t}, \mathrm{C}-1^{\prime \prime}\right), 75.19 / 75.23\left(\mathrm{t}, \mathrm{C}-1^{\prime}\right), 76.7(\mathrm{~d}, \mathrm{C}-4), 122.4$ (s, C-2), 159.9 (s, C-3), 172.6 (s, C-1); HRESIMS $m / z: 315.1042[\mathrm{M}+\mathrm{Na}]^{+}$(calcd for $\mathrm{C}_{12} \mathrm{H}_{20} \mathrm{O}_{8} \mathrm{Na}, 315.1050$ ).

3-O-butyl-2-O-(2,3-dihydroxypropyl)-AsA (18): Pale yellow oil; $[\alpha]_{\mathrm{D}}^{26}+46.6$ (c 0.31, MeOH); UV [MeOH, $\mathrm{nm}(\log \varepsilon)]: 237$ (3.89); IR (ATR) $v_{\max } \mathrm{cm}^{-1}: 3341,2936,2876,1746,1665,1329,1171,1115,1036 ;{ }^{1} \mathrm{H}-\mathrm{NMR}$ $\left(400 \mathrm{MHz}, \mathrm{CD}_{3} \mathrm{OD}\right): \delta 0.97\left(3 \mathrm{H}, \mathrm{t}, J=7.3 \mathrm{~Hz}, \mathrm{H}_{3}-4^{\prime \prime}\right), 1.47\left(2 \mathrm{H}, \mathrm{m}, \mathrm{H}_{2}-3^{\prime \prime}\right), 1.74\left(2 \mathrm{H}, \mathrm{m}, \mathrm{H}_{2}-2^{\prime \prime}\right), 3.58(2 \mathrm{H}$, $\left.\mathrm{m}, \mathrm{H}_{2}-3^{\prime}\right), 3.64\left(2 \mathrm{H}\right.$, dd-like, $\left.J=0.8,6.4 \mathrm{~Hz}, \mathrm{H}_{2}-6\right), 3.86\left(2 \mathrm{H}, \mathrm{m}, \mathrm{H}-5,2^{\prime}\right),[3.96 / 3.97(1 \mathrm{H}, \mathrm{dd}, J=6.4$, $\left.10.1 \mathrm{~Hz}), 4.11 / 4.13(1 \mathrm{H}, \mathrm{dd}, J=4.1,10.1 \mathrm{~Hz}), \mathrm{H}_{2}-1^{\prime}\right], 4.55\left(2 \mathrm{H}, \mathrm{m}, \mathrm{H}_{2}-1^{\prime \prime}\right), 4.83(1 \mathrm{H}, \mathrm{d}, J=1.4 \mathrm{~Hz}, \mathrm{H}-4)$ : ${ }^{13} \mathrm{C}-\mathrm{NMR}\left(100 \mathrm{MHz}, \mathrm{CD}_{3} \mathrm{OD}\right) ; \delta_{\mathrm{C}} 14.1\left(\mathrm{q}, \mathrm{C}-4^{\prime \prime}\right), 19.9\left(\mathrm{t}, \mathrm{C}-3^{\prime \prime}\right), 32.7\left(\mathrm{t}, \mathrm{C}-2^{\prime \prime}\right), 63.3(\mathrm{t}, \mathrm{C}-6), 63.28 / 64.01$ $\left(\mathrm{t}, \mathrm{C}-3^{\prime}\right), 70.6(\mathrm{~d}, \mathrm{C}-5), 71.9\left(\mathrm{~d}, \mathrm{C}-2^{\prime}\right), 73.4\left(\mathrm{t}, \mathrm{C}-1^{\prime \prime}\right), 75.2 / 75.3\left(\mathrm{t}, \mathrm{C}-1^{\prime}\right), 76.7(\mathrm{~d}, \mathrm{C}-4), 122.60 / 122.62(\mathrm{~s}$, C-2), 159.9 (s, C-3), 172.62/172.63 (s, C-1); HRESIMS m/z: $329.1200[\mathrm{M}+\mathrm{Na}]^{+}\left(\right.$calcd for $\mathrm{C}_{13} \mathrm{H}_{22} \mathrm{O}_{8} \mathrm{Na}$, 329.1207).

2-O-(2,3-dihydroxypropyl)-3-O-pentyl-AsA (19): Pale yellow oil; $[\alpha]_{\mathrm{D}}^{26}+44.4$ (c 0.30, $\left.\mathrm{MeOH}\right)$; UV [MeOH, nm $(\log \varepsilon)$ ]: 236 (3.93); IR (ATR) $v_{\max } \mathrm{cm}^{-1}: 3358,2934,2872,1748,1665,1331,1169,1115$, 1040; ${ }^{1} \mathrm{H}-\mathrm{NMR}\left(400 \mathrm{MHz}, \mathrm{CD}_{3} \mathrm{OD}\right): \delta 0.94\left(3 \mathrm{H}, \mathrm{t}, J=6.9 \mathrm{~Hz}, \mathrm{H}_{3}-5^{\prime \prime}\right), 1.40\left(4 \mathrm{H}, \mathrm{m}, \mathrm{H}_{2}-3,4^{\prime \prime}\right), 1.76(2 \mathrm{H}, \mathrm{m}$, $\left.\mathrm{H}_{2}-2^{\prime \prime}\right), 3.58\left(2 \mathrm{H}, \mathrm{m}, \mathrm{H}_{2}-3^{\prime}\right), 3.64\left(2 \mathrm{H}\right.$, dd-like, $\left.J=1.4,6.4 \mathrm{~Hz}, \mathrm{H}_{2}-6\right), 3.86\left(2 \mathrm{H}, \mathrm{m}, \mathrm{H}-5,2^{\prime}\right),[3.96 / 3.98$ $\left.(1 \mathrm{H}, \mathrm{dd}, J=6.4,10.1 \mathrm{~Hz}), 4.11 / 4.13(1 \mathrm{H}, \mathrm{dd}, J=4.1,10.1 \mathrm{~Hz}), \mathrm{H}_{2}-1^{\prime}\right], 4.54\left(2 \mathrm{H}, \mathrm{m}, \mathrm{H}_{2}-1^{\prime \prime}\right), 4.84(1 \mathrm{H}$, brs, $\mathrm{H}-4):{ }^{13} \mathrm{C}-\mathrm{NMR}\left(100 \mathrm{MHz}, \mathrm{CD}_{3} \mathrm{OD}\right) ; \delta_{\mathrm{C}} 14.3\left(\mathrm{q}, \mathrm{C}-5^{\prime \prime}\right), 23.4\left(\mathrm{t}, \mathrm{C}-4^{\prime \prime}\right), 28.9\left(\mathrm{t}, \mathrm{C}-3^{\prime \prime}\right), 30.3\left(\mathrm{t}, \mathrm{C}-2^{\prime \prime}\right), 63.3$ $(\mathrm{t}, \mathrm{C}-6), 63.97 / 64.00\left(\mathrm{t}, \mathrm{C}-3^{\prime}\right), 70.6(\mathrm{~d}, \mathrm{C}-5), 72.0\left(\mathrm{~d}, \mathrm{C}-2^{\prime}\right), 73.7\left(\mathrm{t}, \mathrm{C}-1^{\prime \prime}\right), 75.21 / 75.25\left(\mathrm{t}, \mathrm{C}-1^{\prime}\right), 76.7(\mathrm{~d}$, C-4), 122.57/122.60 (s, C-2), 159.9 (s, C-3), 172.6 (s, C-1); HRESIMS m/z: 343.1357 [M + Na] ${ }^{+}$(calcd for $\left.\mathrm{C}_{14} \mathrm{H}_{24} \mathrm{O}_{8} \mathrm{Na}, 343.1363\right)$.

2-O-(2,3-dihydroxypropyl)-3-O-hexyl-AsA (20): Pale yellow oil; $[\alpha]_{\mathrm{D}}^{26}+42.5($ c $0.35, \mathrm{MeOH})$; UV [MeOH, nm $(\log \varepsilon)]: 237$ (3.96); IR (ATR) $v_{\max } \mathrm{cm}^{-1}: 3367,2930,2859,1748,1667,1331,1167,1117,1041$; ${ }^{1} \mathrm{H}-\mathrm{NMR}\left(400 \mathrm{MHz}, \mathrm{CD}_{3} \mathrm{OD}\right): \delta 0.92\left(3 \mathrm{H}, \mathrm{t}-\mathrm{like}, J=6.9 \mathrm{~Hz}, \mathrm{H}_{3}-6^{\prime \prime}\right), 1.34\left(4 \mathrm{H}, \mathrm{m}, \mathrm{H}_{2}-4^{\prime \prime}, 5^{\prime \prime}\right), 1.44(2 \mathrm{H}$, $\left.\mathrm{m}, \mathrm{H}_{2}-3^{\prime \prime}\right), 1.75\left(2 \mathrm{H}, \mathrm{m}, \mathrm{H}_{2}-2^{\prime \prime}\right), 3.57\left(2 \mathrm{H}, \mathrm{m}, \mathrm{H}_{2}-3^{\prime}\right) 3.63\left(2 \mathrm{H}\right.$, dd-like, $\left.J=1.4,6.4 \mathrm{~Hz}, \mathrm{H}_{2}-6\right), 3.86(2 \mathrm{H}$, m, H-5, 2' $),\left[3.95 / 3.97(1 \mathrm{H}, \mathrm{dd}, J=6.4,10.1 \mathrm{~Hz}), 4.10 / 4.12(1 \mathrm{H}, \mathrm{dd}, J=4.1,10.1 \mathrm{~Hz}), \mathrm{H}_{2}-1^{\prime}\right], 4.53(2 \mathrm{H}$, 
m, $\left.\mathrm{H}_{2}-1^{\prime \prime}\right), 4.84\left(1 \mathrm{H}\right.$, brs, H-4): ${ }^{13} \mathrm{C}-\mathrm{NMR}\left(100 \mathrm{MHz}, \mathrm{CD}_{3} \mathrm{OD}\right) ; \delta_{\mathrm{C}} 14.3\left(\mathrm{q}, \mathrm{C}-6^{\prime \prime}\right), 23.6\left(\mathrm{t}, \mathrm{C}-5^{\prime \prime}\right), 26.3(\mathrm{t}$, $\left.\mathrm{C}^{\prime \prime}{ }^{\prime \prime}\right), 30.6\left(\mathrm{t}, \mathrm{C}-3^{\prime \prime}\right), 32.6\left(\mathrm{t}, \mathrm{C}-2^{\prime \prime}\right) 63.3(\mathrm{t}, \mathrm{C}-6), 64.00 / 64.03\left(\mathrm{t}, \mathrm{C}-3^{\prime}\right), 70.6(\mathrm{~d}, \mathrm{C}-5), 72.0\left(\mathrm{~d}, \mathrm{C}-2^{\prime}\right), 73.7(\mathrm{t}$, C-1" $\left.{ }^{\prime \prime}\right), 75.2 / 75.3\left(\mathrm{t}, \mathrm{C}-1^{\prime}\right), 76.7$ (d, C-4), 122.60/122.63 (s, C-2), 159.9 (s, C-3), 172.6 (s, C-1); HRESIMS $m / z: 357.1515[\mathrm{M}+\mathrm{Na}]^{+}$(calcd for $\mathrm{C}_{15} \mathrm{H}_{26} \mathrm{O}_{8} \mathrm{Na}, 357.1520$ ).

2-O-(2,3-dihydroxypropyl)-3-O-heptyl-AsA (21): Pale yellow oil; $[\alpha]_{\mathrm{D}}^{26}+40.4$ (c 0.34, $\left.\mathrm{MeOH}\right)$; UV [MeOH, nm (log $\varepsilon$ )]: 235 (3.91); IR (ATR) $v_{\max } \mathrm{cm}^{-1}$ : 3341, 2926, 2857, 1748, 1669, 1331, 1167, 1115, 1040; ${ }^{1} \mathrm{H}-\mathrm{NMR}\left(400 \mathrm{MHz}, \mathrm{CD}_{3} \mathrm{OD}\right): \delta 0.90\left(3 \mathrm{H}, \mathrm{t}-\mathrm{like}, J=6.9 \mathrm{~Hz}, \mathrm{H}_{3}-7^{\prime \prime}\right), 1.36\left(6 \mathrm{H}, \mathrm{m}, \mathrm{H}_{2}-4^{\prime \prime}, 5^{\prime \prime}, 6^{\prime \prime}\right), 1.44(2 \mathrm{H}$, $\left.\mathrm{m}, \mathrm{H}_{2}-3^{\prime \prime}\right), 1.75\left(2 \mathrm{H}, \mathrm{m}, \mathrm{H}_{2}-2^{\prime \prime}\right), 3.57\left(2 \mathrm{H}, \mathrm{m}, \mathrm{H}_{2}-3^{\prime}\right) 3.64\left(2 \mathrm{H}\right.$, dd-like, $\left.J=1.8,6.0 \mathrm{~Hz}, \mathrm{H}_{2}-6\right), 3.86(2 \mathrm{H}, \mathrm{m}$, $\left.\mathrm{H}-5,2^{\prime}\right),\left[3.94 / 3.97(1 \mathrm{H}, \mathrm{dd}, J=6.4,10.1 \mathrm{~Hz}), 4.11 / 4.13(1 \mathrm{H}, \mathrm{dd}, J=4.1,10.1 \mathrm{~Hz}), \mathrm{H}_{2}-1^{\prime}\right], 4.54(2 \mathrm{H}, \mathrm{m}$, $\left.\mathrm{H}_{2}-1^{\prime \prime}\right), 4.83(1 \mathrm{H}, \mathrm{d}, J=1.8 \mathrm{~Hz}, \mathrm{H}-4):{ }^{13} \mathrm{C}-\mathrm{NMR}\left(100 \mathrm{MHz}, \mathrm{CD}_{3} \mathrm{OD}\right) ; \delta_{\mathrm{C}} 14.4\left(\mathrm{q}, \mathrm{C}-7^{\prime \prime}\right), 23.7\left(\mathrm{t}, \mathrm{C}-6^{\prime \prime}\right)$, $26.7\left(\mathrm{t}, \mathrm{C}-5^{\prime \prime}\right), 30.1 / 30.7\left(\mathrm{t}, \mathrm{C}-3^{\prime \prime}, 4^{\prime \prime}\right), 32.9\left(\mathrm{t}, \mathrm{C}-2^{\prime \prime}\right), 63.3(\mathrm{t}, \mathrm{C}-6), 63.97 / 64.01\left(\mathrm{t}, \mathrm{C}-3^{\prime}\right), 70.6(\mathrm{~d}, \mathrm{C}-5), 71.9$ $\left(\mathrm{d}, \mathrm{C}-2^{\prime}\right), 73.7\left(\mathrm{t}, \mathrm{C}-1^{\prime \prime}\right), 75.21 / 75.25\left(\mathrm{t}, \mathrm{C}-1^{\prime}\right), 76.7(\mathrm{~d}, \mathrm{C}-4), 122.58 / 122.60(\mathrm{~s}, \mathrm{C}-2), 159.9$ (s, C-3), 172.6 (s, C-1); HRESIMS m/z: $371.1674\left[\mathrm{M}+\mathrm{Na}^{+}\right.$(calcd for $\mathrm{C}_{16} \mathrm{H}_{28} \mathrm{O}_{8} \mathrm{Na}, 371.1676$ ).

2-O-(2,3-dihydroxypropyl)-3-O-octyl-AsA (22): Pale yellow oil; $[\alpha]_{\mathrm{D}}^{26}+42.3$ ( c 0.34, MeOH); UV [MeOH, $\mathrm{nm}(\log \varepsilon)]: 236$ (3.92); IR (ATR) $v_{\max } \mathrm{cm}^{-1}: 3364,2924,2857,1748,1667,1331,1165,1115,1036 ;{ }^{1} \mathrm{H}-\mathrm{NMR}$ $\left(400 \mathrm{MHz}, \mathrm{CD}_{3} \mathrm{OD}\right): \delta 0.90\left(3 \mathrm{H}, \mathrm{t}, J=6.8 \mathrm{~Hz}, \mathrm{H}_{3}-8^{\prime \prime}\right), 1.32\left(8 \mathrm{H}, \mathrm{m}, \mathrm{H}_{2}-4^{\prime \prime}, 5^{\prime \prime}, 6^{\prime \prime}, 7^{\prime \prime}\right), 1.42\left(2 \mathrm{H}, \mathrm{m}, \mathrm{H}_{2}-3^{\prime \prime}\right)$, $1.75\left(2 \mathrm{H}, \mathrm{m}, \mathrm{H}_{2}-2^{\prime \prime}\right), 3.58\left(2 \mathrm{H}, \mathrm{m}, \mathrm{H}_{2}-3^{\prime}\right) 3.63\left(2 \mathrm{H}\right.$, dd-like, J = 1.4, 6.4 Hz, $\left.\mathrm{H}_{2}-6\right), 3.87\left(2 \mathrm{H}, \mathrm{m}, \mathrm{H}-5,2^{\prime}\right)$, [3.96/3.97 (1H, dd, $\left.J=6.4,10.1 \mathrm{~Hz}), 4.11 / 4.12(1 \mathrm{H}, \mathrm{dd}, J=3.9,10.1 \mathrm{~Hz}), \mathrm{H}_{2}-1^{\prime}\right], 4.53\left(2 \mathrm{H}, \mathrm{m}, \mathrm{H}_{2}-1^{\prime \prime}\right)$, $4.83(1 \mathrm{H}, \mathrm{d}, J=1.4, \mathrm{H}-4):{ }^{13} \mathrm{C}-\mathrm{NMR}\left(100 \mathrm{MHz}, \mathrm{CD}_{3} \mathrm{OD}\right) ; \delta_{\mathrm{C}} 14.4\left(\mathrm{q}, \mathrm{C}-8^{\prime \prime}\right), 23.7\left(\mathrm{t}, \mathrm{C}-7^{\prime \prime}\right), 26.7\left(\mathrm{t}, \mathrm{C}-6^{\prime \prime}\right)$, 30.33/30.39 (t, C-4" $\left.4^{\prime \prime} 5^{\prime \prime}\right), 30.6\left(\mathrm{t}, \mathrm{C}-3^{\prime \prime}\right), 32.9\left(\mathrm{t}, \mathrm{C}-2^{\prime \prime}\right), 63.3(\mathrm{t}, \mathrm{C}-6), 63.99 / 64.02\left(\mathrm{t}, \mathrm{C}-3^{\prime}\right), 70.6(\mathrm{~d}, \mathrm{C}-5)$, $72.0\left(\mathrm{~d}, \mathrm{C}-2^{\prime}\right), 73.7\left(\mathrm{t}, \mathrm{C}-1^{\prime \prime}\right), 75.2 / 75.3\left(\mathrm{t}, \mathrm{C}-1^{\prime}\right), 76.68 / 76.70(\mathrm{~d}, \mathrm{C}-4), 122.60 / 122.64(\mathrm{~s}, \mathrm{C}-2), 159.9(\mathrm{~s}, \mathrm{C}-3)$, 172.63/172.64 (s, C-1); HRESIMS m/z: $385.1827[\mathrm{M}+\mathrm{Na}]^{+}$(calcd for $\mathrm{C}_{17} \mathrm{H}_{30} \mathrm{O}_{8} \mathrm{Na}$, 385.1833).

2-O-(2,3-dihydroxypropyl)-3-O-nonyl-AsA (23): Pale yellow oil; $[\alpha]_{\mathrm{D}}^{26}+39.1$ (c 0.30, MeOH); UV [MeOH, nm (log $\varepsilon$ )]: 237 (3.92); IR (ATR) $v_{\max } \mathrm{cm}^{-1}: 3358,2924,2855,1750,1669,1333,1163,1115,1040$; ${ }^{1} \mathrm{H}-\mathrm{NMR}\left(400 \mathrm{MHz}, \mathrm{CD}_{3} \mathrm{OD}\right): \delta 0.90\left(3 \mathrm{H}, \mathrm{t}, J=7.3 \mathrm{~Hz}, \mathrm{H}_{3}-9^{\prime \prime}\right), 1.30\left(10 \mathrm{H}, \mathrm{brs}, \mathrm{H}_{2}-4^{\prime \prime}, 5^{\prime \prime}, 6^{\prime \prime}, 7^{\prime \prime}, 8^{\prime \prime}\right), 1.42$ $\left(2 \mathrm{H}, \mathrm{m}, \mathrm{H}_{2}-3^{\prime \prime}\right), 1.75\left(2 \mathrm{H}, \mathrm{m}, \mathrm{H}_{2}-2^{\prime \prime}\right), 3.58\left(2 \mathrm{H}, \mathrm{m}, \mathrm{H}_{2}-3^{\prime}\right) 3.64\left(2 \mathrm{H}\right.$, dd-like, $\left.J=1.4,6.4 \mathrm{~Hz}, \mathrm{H}_{2}-6\right), 3.86$ $\left(2 \mathrm{H}, \mathrm{m}, \mathrm{H}-5,2^{\prime}\right),\left[3.96 / 3.97(1 \mathrm{H}, \mathrm{dd}, J=6.4,10.1 \mathrm{~Hz}), 4.11 / 4.13(1 \mathrm{H}, \mathrm{dd}, J=4.1,10.1 \mathrm{~Hz}), \mathrm{H}_{2}-1^{\prime}\right], 4.53$ $\left(2 \mathrm{H}, \mathrm{m}, \mathrm{H}_{2}-1^{\prime \prime}\right), 4.83(1 \mathrm{H}, \mathrm{d}, J=1.4, \mathrm{H}-4):{ }^{13} \mathrm{C}-\mathrm{NMR}\left(100 \mathrm{MHz}, \mathrm{CD}_{3} \mathrm{OD}\right) ; \delta_{\mathrm{C}} 14.5\left(\mathrm{q}, \mathrm{C}-9^{\prime \prime}\right), 23.7\left(\mathrm{t}, \mathrm{C}-8^{\prime \prime}\right)$, $26.7\left(\mathrm{t}, \mathrm{C}-7^{\prime \prime}\right), 30.4 / 30.5 / 30.6\left(\mathrm{t}, \mathrm{C}-3^{\prime \prime}, 4^{\prime \prime}, 5^{\prime \prime}, 6^{\prime \prime}\right), 30.6\left(\mathrm{t}, \mathrm{C}-3^{\prime \prime}\right), 33.1\left(\mathrm{t}, \mathrm{C}-2^{\prime \prime}\right), 63.2(\mathrm{t}, \mathrm{C}-6), 63.97 / 64.00(\mathrm{t}$, C-3'), $70.6(\mathrm{~d}, \mathrm{C}-5), 71.9\left(\mathrm{~d}, \mathrm{C}-2^{\prime}\right), 73.7\left(\mathrm{t}, \mathrm{C}-\mathrm{1}^{\prime \prime}\right), 75.2 / 75.3\left(\mathrm{t}, \mathrm{C}-1^{\prime}\right), 76.7$ (d, C-4), 122.57/122.60 (s, C-2), 159.9 (s, C-3), 172.6 (s, C-1); HRESIMS m/z: 399.1984 [M + Na] ${ }^{+}$(calcd for $\mathrm{C}_{18} \mathrm{H}_{32} \mathrm{O}_{8} \mathrm{Na}$, 399.1989).

3-O-decyl-2-O-(2,3-dihydroxypropyl)-AsA (24): Pale yellow oil; $[\alpha]_{\mathrm{D}}^{26}+36.7$ ( c 0.33, MeOH); UV [MeOH, $\mathrm{nm}(\log \varepsilon)]: 237$ (4.02); IR (ATR) $v_{\max } \mathrm{cm}^{-1}: 3364,2924,2855,1749,1666,1333,1165,1119,1030 ;{ }^{1} \mathrm{H}-\mathrm{NMR}$ (400 MHz, CD $\left.\mathrm{CD}_{3} \mathrm{OD}\right): \delta 0.89\left(3 \mathrm{H}, \mathrm{t}, J=6.9 \mathrm{~Hz}, \mathrm{H}_{3}-10^{\prime \prime}\right), 1.30\left(12 \mathrm{H}, \mathrm{brs}, \mathrm{H}_{2}-4^{\prime \prime}, 5^{\prime \prime}, 6^{\prime \prime}, 7^{\prime \prime}, 8^{\prime \prime}, 9^{\prime \prime}\right), 1.43(2 \mathrm{H}$, $\left.\mathrm{m}, \mathrm{H}_{2}-3^{\prime \prime}\right), 1.75\left(2 \mathrm{H}, \mathrm{m}, \mathrm{H}_{2}-2^{\prime \prime}\right), 3.59\left(2 \mathrm{H}, \mathrm{m}, \mathrm{H}_{2}-3^{\prime}\right) 3.66\left(2 \mathrm{H}\right.$, dd-like, J = 1.4, 6.4 Hz, $\left.\mathrm{H}_{2}-6\right), 3.86(2 \mathrm{H}$, m, H-5, 2' $),\left[3.96 / 3.97(1 \mathrm{H}, \mathrm{dd}, J=6.4,10.1 \mathrm{~Hz}), 4.10 / 4.12(1 \mathrm{H}, \mathrm{dd}, J=4.1,10.1 \mathrm{~Hz}), \mathrm{H}_{2}-1^{\prime}\right], 4.53(2 \mathrm{H}$, $\left.\mathrm{m}, \mathrm{H}_{2}-1^{\prime \prime}\right), 4.83(1 \mathrm{H}, \mathrm{brs}, \mathrm{H}-4):{ }^{13} \mathrm{C}-\mathrm{NMR}\left(100 \mathrm{MHz}, \mathrm{CD}_{3} \mathrm{OD}\right) ; \delta_{\mathrm{C}} 14.4\left(\mathrm{q}, \mathrm{C}-10^{\prime \prime}\right), 23.7\left(\mathrm{t}, \mathrm{C}-9^{\prime \prime}\right), 26.7(\mathrm{t}$, $\left.\mathrm{C}-8^{\prime \prime}\right), 30.4 / 30.7\left(\mathrm{t}, \mathrm{C}-3^{\prime \prime}, 4^{\prime \prime}, 5^{\prime \prime}, 6^{\prime \prime}, 7^{\prime \prime}\right), 33.0\left(\mathrm{t}, \mathrm{C}-2^{\prime \prime}\right), 63.3(\mathrm{t}, \mathrm{C}-6), 64.0\left(\mathrm{t}, \mathrm{C}-3^{\prime}\right), 70.6(\mathrm{~d}, \mathrm{C}-5), 72.0(\mathrm{~d}$, C-2'), $73.7\left(\mathrm{t}, \mathrm{C}-1^{\prime \prime}\right), 75.2 / 75.3\left(\mathrm{t}, \mathrm{C}-1^{\prime}\right), 76.7(\mathrm{~d}, \mathrm{C}-4), 122.61 / 122.64$ (s, C-2), 159.9 (s, C-3), 172.6 (s, C-1); HRESIMS $m / z: 413.2146[\mathrm{M}+\mathrm{Na}]^{+}$(calcd for $\mathrm{C}_{19} \mathrm{H}_{34} \mathrm{O}_{8} \mathrm{Na}, 413.2146$ ).

2-O-(2,3-dihydroxypropyl)-3-O-undecyl-AsA (25): Pale yellow oil; $[\alpha]_{\mathrm{D}}^{26}+35.9$ (c 0.31, $\left.\mathrm{MeOH}\right)$; UV [MeOH, nm (log $\varepsilon$ )]: 237 (3.95); IR (ATR) $v_{\max } \mathrm{cm}^{-1}:$ 3358, 2922, 2853, 1750, 1669, 1333, 1163, 1115, 1040; ${ }^{1} \mathrm{H}-\mathrm{NMR}\left(400 \mathrm{MHz}, \mathrm{CD}_{3} \mathrm{OD}\right): \delta 0.89\left(3 \mathrm{H}, \mathrm{t}, J=6.9 \mathrm{~Hz}, \mathrm{H}_{3}-11^{\prime \prime}\right), 1.29\left(14 \mathrm{H}, \mathrm{brs}, \mathrm{H}_{2}-4^{\prime \prime}, 5^{\prime \prime}, 6^{\prime \prime}, 7^{\prime \prime}, 8^{\prime \prime}\right.$, $\left.9^{\prime \prime}, 10^{\prime \prime}\right), 1.44\left(2 \mathrm{H}, \mathrm{m}, \mathrm{H}_{2}-3^{\prime \prime}\right), 1.75\left(2 \mathrm{H}, \mathrm{m}, \mathrm{H}_{2}-2^{\prime \prime}\right), 3.58\left(2 \mathrm{H}, \mathrm{m}, \mathrm{H}_{2}-3^{\prime}\right) 3.64(2 \mathrm{H}$, dd-like, $J=1.4,6.4 \mathrm{~Hz}$, $\left.\mathrm{H}_{2}-6\right), 3.86\left(2 \mathrm{H}, \mathrm{m}, \mathrm{H}-5,2^{\prime}\right)$, [3.96/3.97 (1H, dd, $\left.J=6.4,10.1 \mathrm{~Hz}\right), 4.10 / 4.13(1 \mathrm{H}, \mathrm{dd}, J=4.1,10.1 \mathrm{~Hz})$, $\left.\mathrm{H}_{2}-1^{\prime}\right], 4.53\left(2 \mathrm{H}, \mathrm{m}, \mathrm{H}_{2}-1^{\prime \prime}\right), 4.83(1 \mathrm{H}, \mathrm{d}, J=1.4 \mathrm{~Hz}, \mathrm{H}-4):{ }^{13} \mathrm{C}-\mathrm{NMR}\left(100 \mathrm{MHz}, \mathrm{CD}_{3} \mathrm{OD}\right) ; \delta_{\mathrm{C}} 14.4(\mathrm{q}$, $\left.\mathrm{C}-11^{\prime \prime}\right), 23.8\left(\mathrm{t}, \mathrm{C}-10^{\prime \prime}\right), 26.7\left(\mathrm{t}, \mathrm{C}-9^{\prime \prime}\right), 30.46 / 30.48 / 30.69 / 30.73 / 30.77\left(\mathrm{t}, \mathrm{C}-3^{\prime \prime}, 4^{\prime \prime}, 5^{\prime \prime}, 6^{\prime \prime}, 7^{\prime \prime}, 8^{\prime \prime}\right), 33.1(\mathrm{t}$, C-2" $\left.{ }^{\prime \prime}\right), 63.2(\mathrm{t}, \mathrm{C}-6), 64.0\left(\mathrm{t}, \mathrm{C}-3^{\prime}\right), 70.6(\mathrm{~d}, \mathrm{C}-5), 71.9\left(\mathrm{~d}, \mathrm{C}-2^{\prime}\right), 73.7\left(\mathrm{t}, \mathrm{C}-1^{\prime \prime}\right), 75.2 / 75.3\left(\mathrm{t}, \mathrm{C}-1^{\prime}\right), 76.7(\mathrm{~d}$, 
C-4), 122.58/122.60 (s, C-2), 159.9 (s, C-3), 172.6 (s, C-1); HRESIMS m/z: $427.2301[\mathrm{M}+\mathrm{Na}]^{+}$(calcd for $\left.\mathrm{C}_{20} \mathrm{H}_{36} \mathrm{O}_{8} \mathrm{Na}, 427.2302\right)$.

2-O-(2,3-dihydroxypropyl)-3-O-dodecyl-AsA (26): An amorphous powder; $[\alpha]_{\mathrm{D}}^{26}+41.7(c 0.33, \mathrm{MeOH})$; UV [MeOH, nm $(\log \varepsilon)]: 237$ (3.96); IR (ATR) $v_{\max } \mathrm{cm}^{-1}: 3341,2922,2853,1748,1668,1335,1165,1115$, 1028; ${ }^{1} \mathrm{H}-\mathrm{NMR}\left(400 \mathrm{MHz}, \mathrm{CD}_{3} \mathrm{OD}\right): \delta 0.89\left(3 \mathrm{H}, \mathrm{t}, J=6.8 \mathrm{~Hz}, \mathrm{H}_{3}-12^{\prime \prime}\right), 1.29\left(16 \mathrm{H}, \mathrm{brs}, \mathrm{H}_{2}-4^{\prime \prime}, 5^{\prime \prime}, 6^{\prime \prime}, 7^{\prime \prime}\right.$, $\left.8^{\prime \prime}, 9^{\prime \prime}, 10^{\prime \prime}, 11^{\prime \prime}\right), 1.44\left(2 \mathrm{H}, \mathrm{m}, \mathrm{H}_{2}-3^{\prime \prime}\right), 1.75\left(2 \mathrm{H}, \mathrm{m}, \mathrm{H}_{2}-2^{\prime \prime}\right), 3.57\left(2 \mathrm{H}, \mathrm{m}, \mathrm{H}_{2}-3^{\prime}\right) 3.64(2 \mathrm{H}$, dd-like, J = 1.8, $\left.6.4 \mathrm{~Hz}, \mathrm{H}_{2}-6\right), 3.86\left(2 \mathrm{H}, \mathrm{m}, \mathrm{H}-5,2^{\prime}\right),[3.96 / 3.97(1 \mathrm{H}, \mathrm{dd}, J=6.4,10.1 \mathrm{~Hz}), 4.11 / 4.13(1 \mathrm{H}, \mathrm{dd}, J=4.1$, $\left.10.1 \mathrm{~Hz}), \mathrm{H}_{2}-1^{\prime}\right], 4.53\left(2 \mathrm{H}, \mathrm{m}, \mathrm{H}_{2}-1^{\prime \prime}\right), 4.83(1 \mathrm{H}, \mathrm{d}, J=1.4 \mathrm{~Hz}, \mathrm{H}-4):{ }^{13} \mathrm{C}-\mathrm{NMR}\left(100 \mathrm{MHz}, \mathrm{CD}_{3} \mathrm{OD}\right)$; $\delta_{\mathrm{C}} 14.4\left(\mathrm{q}, \mathrm{C}-12^{\prime \prime}\right), 23.7\left(\mathrm{t}, \mathrm{C}-11^{\prime \prime}\right), 26.7\left(\mathrm{t}, \mathrm{C}-10^{\prime \prime}\right), 30.47 / 30.67 / 30.70 / 30.74 / 30.78\left(\mathrm{t}, \mathrm{C}-3^{\prime \prime}, 4^{\prime \prime}, 5^{\prime \prime}, 6^{\prime \prime}\right.$, $\left.7^{\prime \prime}, 8^{\prime \prime}, 9^{\prime \prime}\right), 33.1\left(\mathrm{t}, \mathrm{C}-2^{\prime \prime}\right), 63.3(\mathrm{t}, \mathrm{C}-6), 64.00 / 64.03\left(\mathrm{t}, \mathrm{C}-3^{\prime}\right), 70.6(\mathrm{~d}, \mathrm{C}-5), 71.9\left(\mathrm{~d}, \mathrm{C}-2^{\prime}\right), 73.7\left(\mathrm{t}, \mathrm{C}-1^{\prime \prime}\right)$, 75.22/75.27 (t, C-1'), 76.7 (d, C-4), 122.61/122.64 (s, C-2), 159.9 (s, C-3), 172.6 (s, C-1); HRESIMS m/z: $441.2458[\mathrm{M}+\mathrm{Na}]^{+}$(calcd for $\left.\mathrm{C}_{21} \mathrm{H}_{38} \mathrm{O}_{8} \mathrm{Na}, 441.2459\right)$.

2-O-(2,3-dihydroxypropyl)-3-O-tridecyl-AsA (27): An amorphous powder; $[\alpha]_{\mathrm{D}}^{26}+37.8(c 0.30, \mathrm{MeOH})$; UV [MeOH, nm $(\log \varepsilon)]: 233$ (4.02); IR (ATR) $v_{\max } \mathrm{cm}^{-1}: 3358,2922,2853,1750,1670,1333,1167,1115$, 1042; ${ }^{1} \mathrm{H}-\mathrm{NMR}\left(400 \mathrm{MHz}, \mathrm{CD}_{3} \mathrm{OD}\right): \delta 0.89\left(3 \mathrm{H}, \mathrm{t}, J=6.4 \mathrm{~Hz}, \mathrm{H}_{3}-13^{\prime \prime}\right), 1.29\left(18 \mathrm{H}, \mathrm{brs}, \mathrm{H}_{2}-4^{\prime \prime}, 5^{\prime \prime}, 6^{\prime \prime}, 7^{\prime \prime}\right.$, $\left.8^{\prime \prime}, 9^{\prime \prime}, 10^{\prime \prime}, 11^{\prime \prime}, 12^{\prime \prime}\right), 1.44\left(2 \mathrm{H}, \mathrm{m}, \mathrm{H}_{2}-3^{\prime \prime}\right), 1.75\left(2 \mathrm{H}, \mathrm{m}, \mathrm{H}_{2}-2^{\prime \prime}\right), 3.58\left(2 \mathrm{H}, \mathrm{m}, \mathrm{H}_{2}-3^{\prime}\right) 3.64$ (2H, dd-like, $\left.J=1.8,6.0 \mathrm{~Hz}, \mathrm{H}_{2}-6\right), 3.86\left(2 \mathrm{H}, \mathrm{m}, \mathrm{H}-5,2^{\prime}\right),[3.96 / 3.97(1 \mathrm{H}, \mathrm{dd}, J=6.9,10.1 \mathrm{~Hz} / 6.4,10.1 \mathrm{~Hz}), 4.11 / 4.13$ $\left.(1 \mathrm{H}, \mathrm{dd}, J=3.7,10.1 \mathrm{~Hz}), \mathrm{H}_{2}-1^{\prime}\right], 4.54\left(2 \mathrm{H}, \mathrm{m}, \mathrm{H}_{2}-1^{\prime \prime}\right), 4.83(1 \mathrm{H}, \mathrm{d}, J=1.4 \mathrm{~Hz}, \mathrm{H}-4):{ }^{13} \mathrm{C}-\mathrm{NMR}(100 \mathrm{MHz}$, $\left.\mathrm{CD}_{3} \mathrm{OD}\right) ; \delta_{\mathrm{C}} 14.5\left(\mathrm{q}, \mathrm{C}-13^{\prime \prime}\right), 23.7\left(\mathrm{t}, \mathrm{C}-12^{\prime \prime}\right), 26.7\left(\mathrm{t}, \mathrm{C}-11^{\prime \prime}\right), 30.48 / 30.69 / 30.73 / 30.78 / 30.81\left(\mathrm{t}, \mathrm{C}-3^{\prime \prime}, 4^{\prime \prime}\right.$, $\left.5^{\prime \prime}, 6^{\prime \prime}, 7^{\prime \prime}, 8^{\prime \prime}, 9^{\prime \prime}, 10^{\prime \prime}\right), 33.1\left(\mathrm{t}, \mathrm{C}-2^{\prime \prime}\right), 63.2(\mathrm{t}, \mathrm{C}-6), 63.96 / 63.99\left(\mathrm{t}, \mathrm{C}-3^{\prime}\right), 70.6(\mathrm{~d}, \mathrm{C}-5), 71.9\left(\mathrm{~d}, \mathrm{C}-2^{\prime}\right), 73.7$ $\left(\mathrm{t}, \mathrm{C}-1^{\prime \prime}\right), 75.19 / 75.25$ (t, C-1') 76.7 (d, C-4), 122.6 (s, C-2), 159.9 (s, C-3), 172.6 (s, C-1); HRESIMS m/z: $455.2616[\mathrm{M}+\mathrm{Na}]^{+}$(calcd for $\left.\mathrm{C}_{22} \mathrm{H}_{40} \mathrm{O}_{8} \mathrm{Na}, 455.2615\right)$.

2-O-(2,3-dihydroxypropyl)-3-O-tetradecyl-AsA (28): An amorphous powder; $[\alpha]_{\mathrm{D}}^{26}+31.1$ (c 0.30, $\mathrm{MeOH}) ; \mathrm{UV}$ [MeOH, $\mathrm{nm}(\log \varepsilon)]: 237$ (3.93); IR (ATR) $v_{\max } \mathrm{cm}^{-1}: 3379,2922,2853,1750,1669,1333$, $1167,1117,1040 ;{ }^{1} \mathrm{H}-\mathrm{NMR}\left(400 \mathrm{MHz}, \mathrm{CD}_{3} \mathrm{OD}\right): \delta 0.89\left(3 \mathrm{H}, \mathrm{t}, J=6.4 \mathrm{~Hz}, \mathrm{H}_{3}-14^{\prime \prime}\right), 1.28\left(20 \mathrm{H}, \mathrm{brs}, \mathrm{H}_{2}-4^{\prime \prime}\right.$, $\left.5^{\prime \prime}, 6^{\prime \prime}, 7^{\prime \prime}, 8^{\prime \prime}, 9^{\prime \prime}, 10^{\prime \prime}, 11^{\prime \prime}, 12^{\prime \prime}, 13^{\prime \prime}\right), 1.44\left(2 \mathrm{H}, \mathrm{m}, \mathrm{H}_{2}-3^{\prime \prime}\right), 1.75\left(2 \mathrm{H}, \mathrm{m}, \mathrm{H}_{2}-2^{\prime \prime}\right), 3.58\left(2 \mathrm{H}, \mathrm{m}, \mathrm{H}_{2}-3^{\prime}\right) 3.64$ ( $2 \mathrm{H}$, dd-like, $\left.J=1.4,6.4 \mathrm{~Hz}, \mathrm{H}_{2}-6\right), 3.86\left(2 \mathrm{H}, \mathrm{m}, \mathrm{H}-5,2^{\prime}\right)$, [3.96/3.97 (1H, dd, $\left.J=6.9,10.1 \mathrm{~Hz} / 6.4,10.1 \mathrm{~Hz}\right)$, 4.11/4.13 (1H, dd, $\left.J=4.1,10.1 \mathrm{~Hz}), \mathrm{H}_{2}-1^{\prime}\right], 4.54\left(2 \mathrm{H}, \mathrm{m}, \mathrm{H}_{2}-1^{\prime \prime}\right), 4.83(1 \mathrm{H}, \mathrm{d}, J=0.9 \mathrm{~Hz}, \mathrm{H}-4):{ }^{13} \mathrm{C}-\mathrm{NMR}$ $\left(100 \mathrm{MHz}, \mathrm{CD}_{3} \mathrm{OD}\right) ; \delta_{\mathrm{C}} 14.5\left(\mathrm{q}, \mathrm{C}-14^{\prime \prime}\right), 23.7\left(\mathrm{t}, \mathrm{C}-13^{\prime \prime}\right), 26.7\left(\mathrm{t}, \mathrm{C}-12^{\prime \prime}\right), 30.48 / 30.69 / 30.73 / 30.78 / 30.81$ $\left(\mathrm{t}, \mathrm{C}-3^{\prime \prime}, 4^{\prime \prime}, 5^{\prime \prime}, 6^{\prime \prime}, 7^{\prime \prime}, 8^{\prime \prime}, 9^{\prime \prime}, 10^{\prime \prime}, 11^{\prime \prime}\right), 33.1\left(\mathrm{t}, \mathrm{C}-2^{\prime \prime}\right), 63.2(\mathrm{t}, \mathrm{C}-6), 63.97 / 64.00\left(\mathrm{t}, \mathrm{C}-3^{\prime}\right), 70.6(\mathrm{~d}, \mathrm{C}-5)$, $71.9\left(\mathrm{~d}, \mathrm{C}-2^{\prime}\right), 73.7\left(\mathrm{t}, \mathrm{C}-1^{\prime \prime}\right), 75.20 / 75.25\left(\mathrm{t}, \mathrm{C}-1^{\prime}\right), 76.7$ (d, C-4), 122.6 (s, C-2), 159.9 (s, C-3), 172.6 (s, C-1); HRESIMS $m / z: 469.2773[\mathrm{M}+\mathrm{Na}]^{+}$(calcd for $\mathrm{C}_{23} \mathrm{H}_{42} \mathrm{O}_{8} \mathrm{Na}, 469.2772$ ).

\subsection{Reagents for Bioassays}

Dulbecco's modified Eagle's medium (DMEM, $4.5 \mathrm{~g} / \mathrm{L}$ glucose) was purchased from Sigma-Aldrich (St. Louis, MO, USA). Fetal bovine serum (FBS), penicillin, and streptomycin were purchased from Gibco (Invitrogen, Carlsbad, CA, USA). All other chemicals used in this study were purchased from Wako Pure Chemical Co., Ltd. (Osaka, Japan). The 48- and 96-well microplates (Sumilon) were purchased from Sumitomo Bakelite Co., Ltd. (Tokyo, Japan).

\subsection{Cell Culture}

Murine B16 melanoma 4A5 cells (RCB0557) were obtained from Riken Cell Bank (Tsukuba, Japan). The cells were grown in DMEM supplemented with $10 \%$ FBS, penicillin (100 units $/ \mathrm{mL}$ ), and streptomycin $(100 \mu \mathrm{g} / \mathrm{mL})$ at $37{ }^{\circ} \mathrm{C}$ in $5 \% \mathrm{CO}_{2} /$ air. The cells were harvested by incubation in phosphate-buffered saline (PBS) containing $0.05 \%$ ethylenediaminetetraacetic acid (EDTA) and $0.02 \%$ trypsin for $\sim 5 \mathrm{~min}$ at $37^{\circ} \mathrm{C}$ and used for the subsequent bioassays.

Normal human epidermal melanocytes (NHEMs; Black donor) were obtained from Kurabo (Osaka, Japan), and were cultured in DermaLife Basal Medium (Kurabo, Osaka) supplemented with DermaLife M LifeFactors (Kurabo, Osaka) at $37^{\circ} \mathrm{C}$ in $5 \% \mathrm{CO}_{2} /$ air. 


\subsection{Melanogenesis and Cell Viability}

The effects on theophylline-stimulated melanogenesis and viability of B16 melanoma 4A5 cells were examined according to previously described protocols [21-27]. Briefly, murine B16 melanoma $4 \mathrm{~A} 5$ cells were seeded into 48-well plates in DMEM. After $24 \mathrm{~h}$ of culture, a test compound and theophylline $(1 \mathrm{mM})$ were added and incubated for $72 \mathrm{~h}$. The melanin content and cell viability were then measured. $\mathrm{IC}_{50}$ values were determined graphically.

Inhibition (\%) was calculated using the following formula, where A and B indicate the optical density of the vehicle- and test compound-treated groups, respectively, and $\mathrm{C}$ indicates cell viability $(\%)($ see below): Inhibition $(\%)=[(\mathrm{A}-\mathrm{B}) / \mathrm{A}] /(\mathrm{C} / 100) \times 100$.

\subsection{Melanogenesis in Normal Melanocytes}

Effects on melanogenesis in NHEMs were examined according to a protocol described previously [21-27,34] with modifications. The cells $\left(3.0 \times 10^{5}\right.$ cells $/ 2 \mathrm{~mL} /$ well $)$ were seeded into 6-well multiplates. After $24 \mathrm{~h}$ of culture, a test compound was added and incubated for 6 days. The cells were harvested using DermaLife Basal Medium supplemented with DermaLife M LifeFactors, and then treated with $1 \mathrm{M} \mathrm{NaOH}\left(50 \mu \mathrm{L} /\right.$ tube, $\left.80{ }^{\circ} \mathrm{C}, 30 \mathrm{~min}\right)$ to yield a lysate. An aliquot $(100 \mu \mathrm{L})$ of the lysate was transferred to a 96-well microplate, and the optical density of each well was measured with a microplate reader at $405 \mathrm{~nm}$ (reference $655 \mathrm{~nm}$ ). The test compound was dissolved in DMSO, and the final concentration in the medium was $0.1 \%$. The production rates of melanin were corrected based on the viability of melanoma cells.

\subsection{AsA Derivative Stability}

To determine stability, the samples were stored at $125^{\circ} \mathrm{C}$, and the residual ratio was calculated by measuring the remaining compound by HPLC. HPLC mobile phase conditions were as follows: AsA was described previously, 6 and 20 were $40 \%$ methanol containing $0.1 \%$ formic acid at flow rate of $0.2 \mathrm{~mL} / \mathrm{min}[52,53]$.

\subsection{Mushroom Tyrosinase}

Tyrosinase activities using L-tyrosine or L-DOPA as a substrate were determined according to the protocols described previously [20,22-27]. Briefly, samples, L-tyrosine (2.5 mM, or L-DOPA, $3.0 \mathrm{mM})$, mushroom tyrosinase ( 46 units $/ \mathrm{mL}$ ), and phosphate buffer were mixed in a 96-well plate and incubated at $25^{\circ} \mathrm{C}$. (L-tyrosine; $30 \mathrm{~min}, \mathrm{~L}-\mathrm{DOPA} ; 5 \mathrm{~min}$ ). The absorbance was then measured at $492 \mathrm{~nm}$.

\subsection{Mammalian Tyrosinase}

Tyrosinase activity using L-DOPA as a substrate was determined according to protocols described previously [50]. Briefly, B16 cells were seeded into 6-well plates in DMEM. After preculture with theophylline $(1 \mathrm{mM})$ for $72 \mathrm{~h}$, the cells were solubilized using $0.1 \%$ Triton X-100. Fifty microliters of each lysate and sample was then mixed with $100 \mu \mathrm{L} 2 \mathrm{mM}$ L-DOPA. After the mixtures were incubated for $30 \mathrm{~min}$ at $37^{\circ} \mathrm{C}$, the absorbance of each solution at $492 \mathrm{~nm}$ was measured.

\subsection{Expression of Tyrosinase, TRP-1, and TRP-2 $m R N A$}

The expression of tyrosinase, TRP-1, and TRP-2 mRNA was assessed according to previously reported methods [20,23-26]. Briefly, murine B16 melanoma 4A5 cells were seeded into 96-well plates in DMEM. After $24 \mathrm{~h}$ of culture, a test compound and theophylline $(1 \mathrm{mM})$ were added and incubated for $72 \mathrm{~h}$. Then, the amount of each mRNA was quantified by quantitative reverse transcription PCR.

\subsection{Expression of Tyrosinase Protein}

The expression of tyrosinase protein was assessed according to a previously reported method [54]. Briefly, murine B16 melanoma 4A5 cells were seeded into 6-well plates in DMEM. After $24 \mathrm{~h}$ of culture, 
a test compound and theophylline $(1 \mathrm{mM})$ were added and incubated for $72 \mathrm{~h}$. The expression of tyrosinase protein then was measured by western blotting.

\subsection{Tyrosinase Activity in B16 Cells}

Tyrosinase activity in cultured cells was determined according to protocols described previously [34] with modifications. Briefly, B16 melanoma 4 A5 cells $\left(4 \times 10^{3}\right.$ cells $/ 100 \mu \mathrm{L} /$ well $)$ were seeded into 96-well plates in DMEM. After pre-culture with sample and theophylline $(1 \mathrm{mM})$ for $72 \mathrm{~h}$, the cells were solubilized using $0.1 \%$ Triton X-100, and then each lysate was mixed with $50 \mu \mathrm{L}$ $2 \mathrm{mM}$ L-DOPA. After the mixtures were incubated for $1 \mathrm{~h}$ at $37^{\circ} \mathrm{C}$, the absorbance of the solution at $492 \mathrm{~nm}$ was measured using the microplate reader.

\subsection{Statistics}

Values are expressed as means \pm S.D. One-way analysis of variance (ANOVA) followed by Dunnett's test was used for statistical analysis. Probability $(p)$ values less than 0.05 were considered significant.

\section{Conclusions}

We examine the inhibitory effects of 28 alkylglyceryl-AsA derivatives (1-28) on theophylline-stimulated murine B16 melanoma 4A5 cells. We find the following structural requirements to be important for the inhibitory activity of alkylglyceryl-AsA derivatives toward melanogenesis: (i) alkylation of glyceryl-AsA is essential for the activity; (ii) the 3-O-alkyl-2-O(2,3-dihydroxypropyl)-AsA compounds (16-28) exhibit stronger activities than those of the corresponding 2-O-alkyl-3-O-(2,3-dihydroxypropyl)-AsA compounds (2-14); and (iii) derivatives with longer alkyl chains have significantly stronger inhibitory activity. Using these guidelines along with our cytotoxicity data, 3-O-(2,3-dihydroxypropyl)-2-O-hexyl-AsA (6, $\left.\mathrm{IC}_{50}=81.4 \mu \mathrm{M}\right)$ and 2-O-(2,3-dihydroxypropyl)-3-O-hexyl-AsA $\left(20, \mathrm{IC}_{50}=117 \mu \mathrm{M}\right)$ are deemed the best candidate derivatives for use in cosmetics. However, although it has a limited effective concentration range, 2-O-(2,3-dihydroxypropyl)-3-O-tetradecyl-AsA (28, $\left.\mathrm{IC}_{50}=5.0 \mu \mathrm{M}\right)$ demonstrates high melanogenesis inhibitory activity. These derivatives are also found to be more stable than AsA and to have favorable characteristics for skin penetration. Mechanistic studies reveal that the mechanisms of action of $\mathbf{6}$ and 20, with respect to their melanogenesis inhibitory activities, are the inhibition of tyrosinase and TRP-1 mRNA expression, as well as tyrosinase protein expression, but not the direct inhibition of tyrosinase enzymatic activity (Figure 9). Further skin brightening effects of these candidates, such as those involving intracellular melanosome transport, require further study.

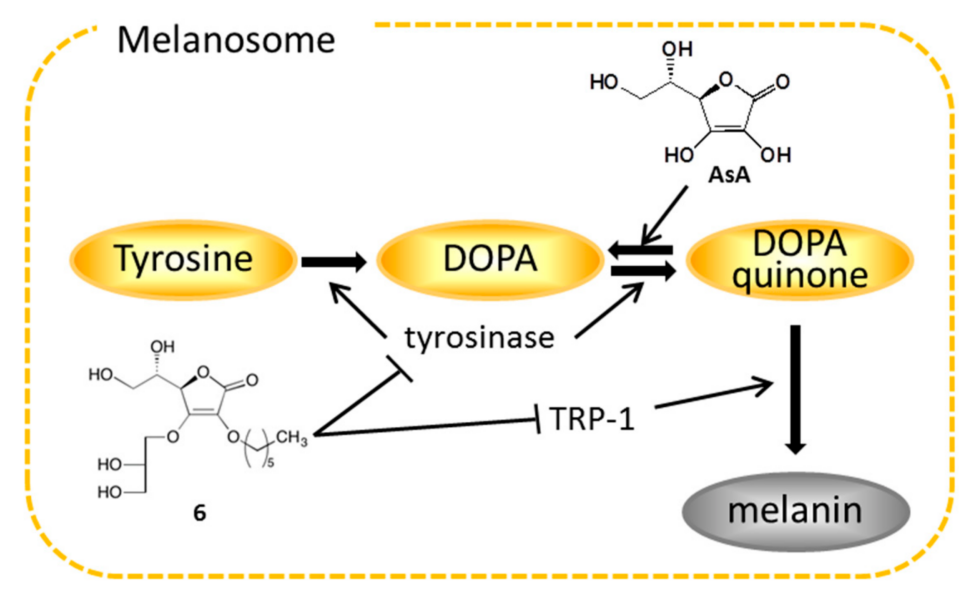

Figure 9. Plausible mechanisms of action of alkylglyceryl-AsA derivatives on melanogenesis inhibitory activity. AsA: L-ascorbic acid. 
Supplementary Materials: Supplementary Materials are available at http:/ / www.mdpi.com/1422-0067/19/4/ $1144 /$ s1.

Acknowledgments: This work was supported by the MEXT-Supported Program for the Strategic Research Foundation at Private Universities, 2014-2018, Japan (S1411037, Toshio Morikawa), as well as JSPS KAKENHI, Japan, a Grant Number 18K06726 (Toshio Morikawa).

Author Contributions: Norihisa Taira, Yushi Katsuyama, Masato Yoshioka, Osamu Muraoka, and Toshio Morikawa conceived and designed the experiments. Norihisa Taira, Yushi Katsuyama, and Toshio Morikawa performed the experiments. Norihisa Taira, Yushi Katsuyama, and Toshio Morikawa analyzed the data. Norihisa Taira and Toshio Morikawa wrote the paper.

Conflicts of Interest: The authors declare no conflicts of interest.

\section{References}

1. Land, E.J.; Ramsden, C.A.; Riley, P.A. Tyrosinase autoactivation and the chemistry of ortho-quinone amines. Acc. Chem. Res. 2003, 36, 300-308. [CrossRef] [PubMed]

2. d'Ischia, M.; Napolitano, A.; Pezzella, A.; Land, E.J.; Ramsden, C.A.; Riley, P.A. 5,6-Dihydroxyindoles and indole-5,6-diones. Adv. Heterocycl. Chem. 2005, 89, 1-63.

3. d'Ischia, M.; Napolitano, A.; Pezzella, A.; Meredith, P.; Sarna, T. Chemical and structural diversity in eumelanins: Unexplored bio-optoelectronic materials. Angew. Chem. Int. Ed. 2009, 48, 3914-3921. [CrossRef] [PubMed]

4. d'Ischia, M.; Napolitano, A.; Ball, V.; Chen, C.-T.; Buehler, M.J. Polydopamine and eumelanin: From structure-property relationships to a unified tailoring strategy. Acc. Chem. Res. 2014, 47, 3541-3550. [CrossRef] [PubMed]

5. Micillo, R.; Panzella, L.; Koike, K.; Monfrecola, G.; Napolitano, A.; d'Ischia, M. "Fifty Shades" of black and red or how carboxyl groups fine tune eumelanin and pheomelanin properties. Int. J. Mol. Sci. 2016, 17, 746. [CrossRef] [PubMed]

6. d'Ischia, M.; Wakamatsu, K.; Napolitano, A.; Briganti, S.; Garcia-Borron, J.-C.; Kovacs, D.; Meredith, P.; Pezzella, A.; Picardo, M.; Sarna, T.; et al. Melanins and melanogenesis: Methods, standards, protocols. Pigm. Cell Res. 2013, 26, 616-633. [CrossRef] [PubMed]

7. Slominski, A.; Tobin, D.J.; Shibahara, S.; Wortsman, J. Melanin pigmentation in mammalian skin and its hormonal regulation. Physiol. Rev. 2004, 84, 1155-1228. [CrossRef] [PubMed]

8. Slominski, A.; Wortsman, J.; Plonka, P.M.; Schallreuter, K.U.; Paus, R.; Tobin, D.J. Hair follicle pigmentation. J. Investig. Dermatol. 2005, 124, 13-21. [CrossRef] [PubMed]

9. Prota, G. Progress in the chemistry of melanins and related metabolites. Med. Res. Rev. 1988, 8, 525-556. [CrossRef] [PubMed]

10. Kim, Y.J.; Uyama, H. Tyrosinase inhibitors from natural and synthetic sources: Structure, inhibition mechanism and perspective for the future. Cell. Mol. Life Sci. 2005, 62, 1707-1723. [CrossRef] [PubMed]

11. Hearing, V.J.; Korner, A.M.; Pawelek, J.M. New regulators of melanogenesis are associated with purified tyrosinase isozymes. J. Investig. Dermatol. 1982, 79, 16-18. [CrossRef] [PubMed]

12. Hearing, V.J.; Jiménez, M. Mammalian tyrosinase-the critical regulatory control point in melanocyte pigmentation. Int. J. Biochem. 1987, 19, 1141-1147. [CrossRef]

13. Kuzumaki, T.; Matsuda, A.; Wakamatsu, K.; Ito, S.; Ishikawa, K. Eumelanin biosynthesis is regulated by coordinate expression of tyrosinase and tyrosinase-related protein-1 genes. Exp. Cell Res. 1993, 207, 33-40. [CrossRef] [PubMed]

14. Friedmann, P.S.; Gilchrest, B.A. Ultraviolet radiation directly induces pigment production by cultured human melanocytes. J. Cell. Physiol. 1987, 133, 88-94. [CrossRef] [PubMed]

15. Slominski, A.; Wortsman, J.; Luger, T.; Paus, R.; Slomon, S. Corticotropin releasing hormone and proopiomelanocortin involvement in the cutaneous response to Stress. Physiol. Rev. 2000, 80, 979-1020. [CrossRef] [PubMed]

16. Slominski, A.; Zmijewski, M.A.; Zbytek, B.; Tobin, D.J.; Theoharides, T.C.; Rivier, J. Key role CRF in the skin stress response system. Endocr. Rev. 2013, 34, 827-884. [CrossRef] [PubMed]

17. Hunt, G.; Todd, C.; Cresswell, J.E.; Thody, A.J. Alpha-melanocyte stimulating hormone and its analogue Nle4DPhe7 alpha-MSH affect morphology, tyrosinase activity and melanogenesis in cultured human melanocytes. J. Cell Sci. 1994, 107, 205-211. [PubMed] 
18. Steinberg, M.L.; Whittaker, J.R. Stimulation of melanotic expression in a melanoma cell line by theophylline. J. Cell. Physiol. 1976, 87, 265-275. [CrossRef] [PubMed]

19. Slominski, A.; Zmijewski, M.A.; Pawelek, J. L-tyrosine and L-dihydroxyphenylalanine as hormone-like regulators of melanocyte functions. Pigment Cell Melanoma Res. 2012, 25, 14-27. [CrossRef] [PubMed]

20. Morikawa, T.; Nakanishi, Y.; Ninomiya, K.; Matsuda, H.; Nakashima, S.; Miki, H.; Miyashita, Y.; Yoshikawa, M.; Hayakawa, T.; Muraoka, O. Dimeric pyrrolidinoindoline-type alkaloids with melanogenesis inhibitory activity in flower buds of Chimonanthus praecox. J. Nat. Med. 2014, 68, 539-549. [CrossRef] [PubMed]

21. Tanabe, G.; Sugano, Y.; Shirato, M.; Sonoda, N.; Tsutsui, N.; Morikawa, T.; Ninomiya, K.; Yoshikawa, M.; Muraoka, O. Total synthesis of 4,5-didehydroguadiscine: A potent melanogenesis inhibitor from the Brazilian medicinal herb, Hornschuchia obliqua. J. Nat. Prod. 2015, 78, 1536-1542. [CrossRef] [PubMed]

22. Morikawa, T.; Kitagawa, N.; Tanabe, G.; Ninomiya, K.; Okugawa, S.; Motai, C.; Yoshikawa, M.; Lee, I.-J.; Muraoka, O. Quantitative determination of alkaloids in lotus flower (flower buds of Nelumbo nucifera) and their melanogenesis inhibitory activity. Molecules 2016, 21, 930. [CrossRef] [PubMed]

23. Morikawa, T.; Ninomiya, K.; Kuramoto, H.; Kamei, I.; Yoshikawa, M.; Muraoka, O. Phenylethanoid and phenylpropanoid glycosides with melanogenesis inhibitory activity from the flowers of Nercissus tazetta var. chinensis. J. Nat. Med. 2016, 70, 89-101. [CrossRef] [PubMed]

24. Ninomiya, K.; Matsumoto, T.; Chaipech, S.; Miyake, S.; Katsuyama, Y.; Tsuboyama, A.; Pongpiriyadacha, Y.; Hayakawa, T.; Muraoka, O.; Morikawa, T. Simultaneous quantitative analysis of 12 methoxyflavones with melanogenesis inhibitory activity from the rhizomes of Kaempferia parviflora. J. Nat. Med. 2016, 70, 179-189. [CrossRef] [PubMed]

25. Manse, Y.; Ninomiya, K.; Nishi, R.; Kamei, I.; Katsuyama, Y.; Imagawa, T.; Chaipech, S.; Muraoka, O.; Morikawa, T. Melanogenesis inhibitory activity of a 7-O-9'-linked neolignan from Alpinia galanga. Bioorg. Med. Chem. 2016, 24, 6215-6224. [CrossRef] [PubMed]

26. Manse, Y.; Ninomiya, K.; Okazaki, A.; Okada-Nishida, E.; Imagawa, T.; Imamura-Mizushima, M.; Yamano, Y.; Kaname, K.; Nakamura, S.; Morikawa, T. Melanogenesis inhibitory activity of diterpenoid and triterpenoid constituents from the aerial part of Isodon trichocarpus. Nat. Prod. Commun. 2017, 12, 1185-1188.

27. Manse, Y.; Ninomiya, K.; Nishi, R.; Hashimoto, Y.; Chaipech, S.; Muraoka, O.; Morikawa, T. Labdane-type diterpenes, galangalditerpenes A-C, with melanogenesis inhibitory activity from the fruit of Alpinia galanga. Molecules 2017, 22, 2279. [CrossRef] [PubMed]

28. Tagawa, M.; Murata, T.; Onuma, T.; Kameyama, K.; Sakai, C.; Kondo, S.; Yonemoto, K.; Quigley, J.; Dorsky, A.; Bucks, D.; et al. Inhibitory effects of magnesium ascorbyl phosphate on melanogenesis. J. Soc. Cosmet. Chem. Jpn. 1993, 27, 409-414. [CrossRef]

29. Kumano, Y.; Sakamoto, T.; Egawa, M.; Iwai, I.; Tanaka, M.; Yamamoto, I. In vitro and in vivo prolonged biological activities of novel vitamin $C$ derivative, 2-O- $\alpha$-D-glucopyranosyl-L-acsorbic acid (AA-2G), in cosmetic fields. J. Nutr. Sci. Vitaminol. 1998, 44, 345-359. [CrossRef] [PubMed]

30. Silva, G.M.; Campos, P.M.M. Histopathological, morphometric and stereological studies of ascorbic acid and magnesium ascorbyl phosphate in a skin formulation. Int. J. Cosmet. Sci. 2000, 22, 169-179. [CrossRef] [PubMed]

31. Panich, U.; Tangsupa-a-nan, V.; Onkoksiing, T.; Kongtaphan, K.; Kasetsinsombat, K.; Akarasereenont, P.; Wongkajornsilp, A. Inhibition of UVA-mediated melanogenesis by ascorbic acid through modulation of antioxidant defence and nitric oxide system. Arch. Pharm. Res. 2011, 34, 811-820. [CrossRef] [PubMed]

32. Lee, S.-A.; Son, Y.-O.; Kook, S.-H.; Choi, K.-C.; Lee, J.-C. Ascorbic acid increases the activity and synthesis of tyrosinase in B16F10 cells through activation of p38 mitogen-activated protein kinase. Arch. Dermatol. Res. 2011, 303, 669-678. [CrossRef] [PubMed]

33. Kameyama, K.; Sakai, C.; Kondoh, S.; Yonemoto, K.; Nishiyama, S.; Tagawa, M.; Murata, T.; Ohnuma, T.; Dorsky, A.; Bucks, D.; et al. Inhibitory effect of magnesium L-ascorbyl-2-phosphate (VC-PMG) on melanogenesis in vitro and in vivo. J. Am. Acad. Dermatol. 1996, 34, 29-33. [CrossRef]

34. Matsuda, S.; Shibayama, H.; Hisama, M.; Ohtsuki, M.; Iwaki, M. Inhibitory effects of a novel ascorbic derivative, disodium isostearyl 2-O-L-ascorbyl phosphate on melanogenesis. Chem. Pharm. Bull. 2008, 56, 292-297. [CrossRef] [PubMed]

35. Kwak, J.Y.; Park, S.; Seok, J.K.; Liu, K.-H.; Boo, Y.C. Ascorbyl coumarates as multifunctional cosmeceutical agents that inhibit melanogenesis and enhance collagen synthesis. Arch. Dermatol. Res. 2015, 307, 635-643. [CrossRef] [PubMed] 
36. Kim, H.M.; An, H.S.; Bae, J.-S.; Kim, J.Y.; Choi, C.H.; Kim, J.Y.; Lim, J.K.; Choi, J.-H.; Song, H.; Moon, S.H.; et al. Effects of palmitoyl-KVK-L-ascorbic acid on skin wrinkles and pigmentation. Arch. Dermatol. Res. 2017, 309, 397-402. [CrossRef] [PubMed]

37. Yoshioka, M.; Taira, N.; Kamiyama, A.; Uehara, K.; Hashimoto, N. Ascorbic Acid Derivative or Salt Thereof, Production Method Thereof, and Cosmetic. U.S. Patent US 8163939B2, 24 April 2012.

38. Bos, J.D.; Meinardi, M.M.H.M. The 500 Dalton role for the skin penetration of chemical compounds and drugs. Exp. Dermatol. 2000, 9, 165-169. [CrossRef] [PubMed]

39. Ong, M.W.S.; Maibach, H.I. Skin whitening agents. In Handbook of Cosmetic Science and Technology, 4th ed.; Barel, A.O., Paye, M., Maibach, H.I., Eds.; CRC Press: Boca Raton, FL, USA, 2014; pp. 423-438, ISBN 978-1-84214-564-7.

40. Couteau, C.; Coiffard, L. Overview of skin whitening agents: Drugs and cosmetic products. Cosmetics 2016, 3, 27. [CrossRef]

41. Chiku, K.; Dohi, H.; Saito, A.; Ebise, H.; Kouzai, Y.; Shinoyama, H.; Nishida, Y.; Ando, A. Enzymatic synthesis of 4-hydroxyphenyl-D-oligoxylosides and their notable tyrosinase inhibitory activity. Biosci. Biotechnol. Biochem. 2009, 73, 1123-1128. [CrossRef] [PubMed]

42. Parvez, S.; Kang, M.; Chung, H.-S.; Bae, H. Naturally occurring tyrosinase inhibitors: Mechanism and applications in skin health, cosmetics and agriculture industries. Phytother. Res. 2007, 21, 805-816. [CrossRef] [PubMed]

43. Bao, K.; Dai, Y.; Zhu, Z.-B.; Tu, F.-J.; Zhang, W.-G.; Yao, X.-S. Design and synthesis of biphenyl derivatives as mushroom tyrosinase inhibitors. Bioorg. Med. Chem. 2010, 18, 6708-6714. [CrossRef] [PubMed]

44. Parvez, S.; Kang, M.; Chung, H.-S.; Cho, C.; Hong, M.-C.; Shin, M.-K.; Bae, H. Survey and mechanism of skin depigmenting and lightening agents. Phytother. Res. 2006, 20, 921-934. [CrossRef] [PubMed]

45. Chang, T.-S. An updated review of tyrosinase inhibitors. Int. J. Mol. Sci. 2009, 10, 2440-2475. [CrossRef] [PubMed]

46. Isaacs, N.; Eldik, R. A mechanistic study of the reduction of quinones by ascorbic acid. J. Chem. Soc. Perkin Trans. 2 1997, 1465-1468. [CrossRef]

47. Ros, J.R.; Rodríguez-López, J.N.; García-Cánovas, F. Effect of L-ascorbic acid on the monophenolase activity of tyrosinase. Biochem. J. 1993, 295, 309-312. [CrossRef] [PubMed]

48. Jiménez-Cervantes, C.; Solano, F.; Kobayashi, T.; Urabe, K.; Hearing, V.J.; Lozano, J.A.; García-Borrón, J.C. A new enzymatic function in the melanogenic pathway. The 5,6-dihydroxyindole-2-carboxylic acid oxidase activity of tyrosinase-related protein-1 (TRP1). J. Biol. Chem. 1994, 269, 17993-18001. [PubMed]

49. Taira, N.; Katsuyama, Y.; Yoshioka, M.; Okano, Y.; Masaki, H. 3-O-Glycery-2-O-hexyl ascorbate suppresses melanogenesis by interfering with intracellular melanosome transport and suppressing tyrosinase protein synthesis. J. Cosmet. Dermatol. 2017, in press. [CrossRef] [PubMed]

50. Bertolotto, C.; Buscà, R.; Abbe, P.; Bille, K.; Aberdam, E.; Ortonne, J.-P.; Ballotti, R. Different cis-acting elements are lnvolved in the regulation of TRP1 and TRP2 promoter activities by cyclic AMP: Pivotal role of M boxes (GTCATGTGCT) and of microphthalmia. Mol. Cell. Biol. 1998, 18, 694-702. [CrossRef] [PubMed]

51. Iozumi, K.; Hoganson, G.E.; Pennella, R.; Everett, M.A.; Fuller, B.B. Role of tyrosinase as the determinant of pigmentation in cultured human melanocytes. J. Investig. Dermatol. 1993, 100, 806-811. [CrossRef] [PubMed]

52. Mitsuzumi, H. Properties of a novel vitamin C supplement, L-ascorbic acid 2-glucoside, and its uses in the field of foods. Foods Food Ingred. J. Jpn. 2006, 211, 435-444.

53. Shibayama, H.; Ueda, K.; Yoshio, K.; Matsuda, S.; Hisama, M.; Miyazawa, M. Synthesis and characterization of new ascorbic derivative:sodium isostearyl 2-O-L-ascorbyl phosphate. J. Oleo Sci. 2005, 54, 601-608. [CrossRef]

54. Katsuyama, Y.; Taira, N.; Yoshioka, M.; Okano, Y.; Masaki, H. Disruption of melanosome transport in melanocytes treated with theophylline causes their degradation by autophagy. Biochem. Biophys. Res. Commun. 2017, 485, 126-130. [CrossRef] [PubMed]

(C) 2018 by the authors. Licensee MDPI, Basel, Switzerland. This article is an open access article distributed under the terms and conditions of the Creative Commons Attribution (CC BY) license (http:/ / creativecommons.org/licenses/by/4.0/). 